\title{
Hydroxo-bridged active site of a flavodiiron NO reductase revealed by spectroscopy and computations
}

\author{
Filipe Folgosa, ${ }^{\mathrm{a}, \S}$ Vladimir Pelmenschikov, ${ }^{\mathrm{b},{ }^{*}, \S}$ Matthias Keck, ${ }^{\mathrm{c}}$ Christian Lorent, ${ }^{\mathrm{b}}$ Yoshitaka Yoda, ${ }^{\mathrm{d}}$ \\ James A. Birrell, ${ }^{\mathrm{e}}$ Martin Kaupp, ${ }^{\mathrm{b}}$ Miguel Teixeira, ${ }^{\mathrm{a}}$ Kenji Tamasaku, ${ }^{\mathrm{f}}$ Christian Limberg, ${ }^{\mathrm{c}}$ Lars \\ Lauterbach $^{\mathrm{b}, *}$ \\ a Instituto de Tecnologia Química e Biológica António Xavier, ITQB NOVA, Av. da República, 2780-157 \\ Oeiras, Portugal \\ ${ }^{b}$ Institut für Chemie, Technische Universität Berlin, 10623 Berlin, Germany. E-mail: \\ lars.lauterbach@tu-berlin.de; pelmentschikov@tu-berlin.de \\ ${ }^{c}$ Department of Chemistry, Humboldt-Universität zu Berlin, Brook-Taylor-Strasse 2, 12489 Berlin, \\ Germany \\ a JASRI, SPring-8, Sayo-gun, Hyogo 679-5198, Japan \\ ${ }^{e}$ Max Planck Institute for Chemical Energy Conversion, Stiftstrasse 34-36, 45470 Mülheim an der \\ Ruhr, Germany \\ ${ }^{f}$ RIKEN SPring-8 Center, Sayo-gun, Hyogo 679-5148, Japan \\ * Corresponding authors. ${ }^{\S}$ These authors contributed equally.
}

\section{(1)}

Abstract: $\mathrm{NO}$ and $\mathrm{O}_{2}$ are detoxified in many organisms using flavodiiron proteins (FDPs). The exact coordination of the iron centre in the active site of these enzymes remains unclear in spite of numerous structural studies. Here, we used ${ }^{57} \mathrm{Fe}$ nuclear resonance vibrational spectroscopy (NRVS) to probe the iron-ligand interactions in Escherichia coli FDP. This data combined with density functional theory (DFT) and ${ }^{57} \mathrm{Fe}$ Mössbauer spectroscopy indicate that the oxidised form of FDP contains a dihydroxo-diferric $\mathrm{Fe}(\mathrm{III})-\left(\mu \mathrm{OH}^{-}\right)_{2}-\mathrm{Fe}(\mathrm{III})$ active site, while its reduction gives rise to a monohydroxo-diferrous $\mathrm{Fe}(\mathrm{II})-$ $\left(\mu \mathrm{OH}^{-}\right)-\mathrm{Fe}(\mathrm{II})$ site upon elimination of one bridging $\mathrm{OH}^{-}$ligand, thereby providing an open coordination site for NO binding. Prolonged NRVS data collection of the oxidised FDP sample resulted in photoreduction and formation of a partially reduced diiron centre with two bridging hydroxo ligands. These results have crucial implications for studying and understanding the mechanism of FDP as well as other non-haem diiron enzymes. 
Nitric oxide (NO) inhibits multiple cellular processes including aerobic respiration and energy metabolism. ${ }^{1}$ Therefore, NO is produced in response to pathogens by the human innate immune system. In order to survive this threat, microbes utilise several enzymes to detoxify NO. Among these are the flavodiiron proteins (FDPs), which reduce it to the innocuous $\mathrm{N}_{2} \mathrm{O} .^{2,3}$ FDPs have a minimal core constituted by a metallo- $\beta$-lactamase-like domain, containing the catalytic diiron centre, and a flavodoxin-like domain with a flavin mononucleotide (FMN). The FDP from Escherichia coli (ECFDP) has an extra rubredoxin-like domain at its C-terminus, which is important for electron transfer as the electron entry point. ${ }^{3,4}$ Although some FDPs are able to reduce $\mathrm{O}_{2}$ to $\mathrm{H}_{2} \mathrm{O}$ or $\mathrm{NO}$ to $\mathrm{N}_{2} \mathrm{O}$, most of them cannot accomplish these reactions at the same rate, showing preference to one of the substrates. ${ }^{5}$ The EcFDP is the only known FDP with a clear preference for NO over $\mathrm{O}_{2}$, exhibiting a rate of ca. 10 times higher for the NO reduction. Electrons for this reaction are transferred from NADH via an NADH:flavorubredoxin oxidoreductase..$^{5,7}$

Several three-dimensional structures of FDPs have been determined by X-ray crystallography, which disclosed that the diiron active site is coordinated by four histidines, two aspartates, one glutamate and one $\mu$-hydroxo bridge (Figs. 1 and S8). ${ }^{6,8,9}$ With two histidines at each Fe and one bridging bidentate carboxylate of Asp166, the FDP metal-ligand core bears an approximate reflection symmetry. Similar non-haem diiron centres are found in a variety of other proteins, such as soluble methane monooxygenase, $\Delta 9$-desaturase, ribonucleotide reductase, (bacterio)ferritin, toluene monooxygenase, haemerythrin, and rubrerythrin. ${ }^{10}$
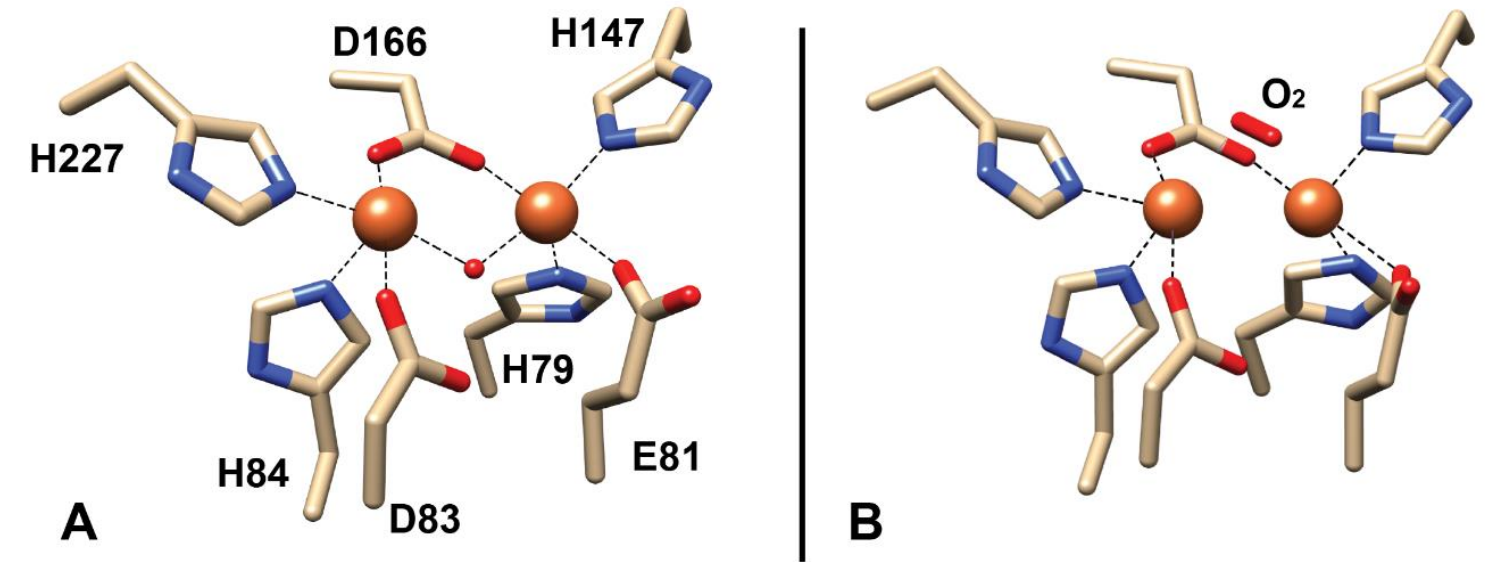

Fig. 1 Representation of the active site of the E. coli flavodiiron protein obtained by X-ray crystallography. A: structure in the as-isolated (oxidised) form (PDB 4D02). B: structure of the dithionite-reduced crystal (PDB 5LLD). Orange spheres represent iron. The structure represented in $\mathbf{A}$ shows a $\mu$-hydroxo $\left(\mu \mathrm{OH}^{-}\right)$ligand bridging the two iron ions, while the structure represented in $\mathbf{B}$ shows a dioxygen molecule in the vicinity of the diiron centre. ${ }^{6}$ The phosphate ion present in the as-isolated protein structure was omitted for clarity. 
The structural studies also showed that, in general, non-haem diiron active sites can harbour at least one mononuclear oxygen metal ligand in the Fe(III)Fe(III) oxidised state. Many structures of the $\mathrm{Fe}(\mathrm{II}) \mathrm{Fe}(\mathrm{II})$ reduced states reveal a bridging mononuclear oxygen species, which is missing in the EcFDP structure (Table S1). ${ }^{6,8,11-13}$ However, the discrimination between oxo and hydroxo bridging ligands has been precluded by insufficient resolution of the crystal structures available. Spectroscopic studies on an $\mathrm{O}_{2}$-selective FDP from Thermotoga maritima (TmFDP) suggest that $\mathrm{NO}$ reduction to $\mathrm{N}_{2} \mathrm{O}$ follows a sequential binding of two NO molecules to the reduced diiron centre, forming mono- and dinitrosyl intermediates. ${ }^{14}$ The detection of an intermediate species, assigned to an antiferromagnetically coupled diferrous-dinitrosyl species with an exchange energy $J=60 \mathrm{~cm}^{-1}$ point to a hydroxo bridge between the two $\mathrm{Fe}(\mathrm{II})-$ NO centres that could be important for the N-N bond formation. ${ }^{14}$ It was also proposed that, contrary to what was found in the TmFDP (PDB 1VME) and EcFDP (PDB 4D02) ${ }^{6}$ crystal structures, the TmFDP harbours two bridging hydroxo ligands coordinated in the oxidised state, one of which is lost in the diferrous state. ${ }^{15}$ This implies that the mono- $\mu$-hydroxo diferrous FDP species is probably the catalytically functional state that reacts with the substrates.

The enzymatic NO conversion mechanism of EcFDP, which is the only known NO-specific FDP, is key to understanding one of the most important microbial NO detoxification pathways. Here, we investigate the diiron coordination of EcFDP in its oxidised and reduced states using ${ }^{57} \mathrm{Fe}$ nuclear resonance vibrational (NRVS) and Mössbauer, spectroscopies combined with density functional theory (DFT) calculations.

\section{Results and Discussion}

A truncated derivative of ECFDP (residues 1-400) was used as our model system, hereafter referred to as FDP-D, in order to avoid the ${ }^{57} \mathrm{Fe}$ signal interference from the rubredoxin domain, otherwise naturally present in the native protein. FDP-D showed comparable spectroscopic and biochemical properties to native ECFDP. ${ }^{7}$ FDP-D was enriched with ${ }^{57} \mathrm{Fe}$ and prepared as described in the ESI.

Zero-field Mössbauer spectra of the as-isolated (oxidised, FDP-Dox) and dithionite reduced (FDP-D $D_{\text {RED }}$ ) protein samples at $13 \mathrm{~K}$ are shown in Fig. 2 . The spectrum of FDP-Dox is similar to that of TmFDP. ${ }^{15,16}$ The fits of the zero-field spectra deconvoluted the signals of two unequal Fe ions with the parameters listed in Table 1 (Fig. S1). The isomer shifts ( $\delta=0.50$ and $0.49 \mathrm{~mm} / \mathrm{s})$ and quadrupole splitting parameters $\left(\Delta \mathrm{E}_{\mathrm{Q}}=0.70\right.$ and $\left.1.00 \mathrm{~mm} / \mathrm{s}\right)$ indicate that both iron species are high-spin $\mathrm{Fe}^{3+}$. A previous study with TmFDP showed that at $4.2 \mathrm{~K}$, the two high-spin $(S=5 / 2) \mathrm{Fe}^{3+}$ ions are exchange-coupled antiferromagnetically to produce a diamagnetic $(S=0)$ ground state. ${ }^{15}$ In agreement with this observation, FDP-Dox is EPR-silent. ${ }^{7}$ 


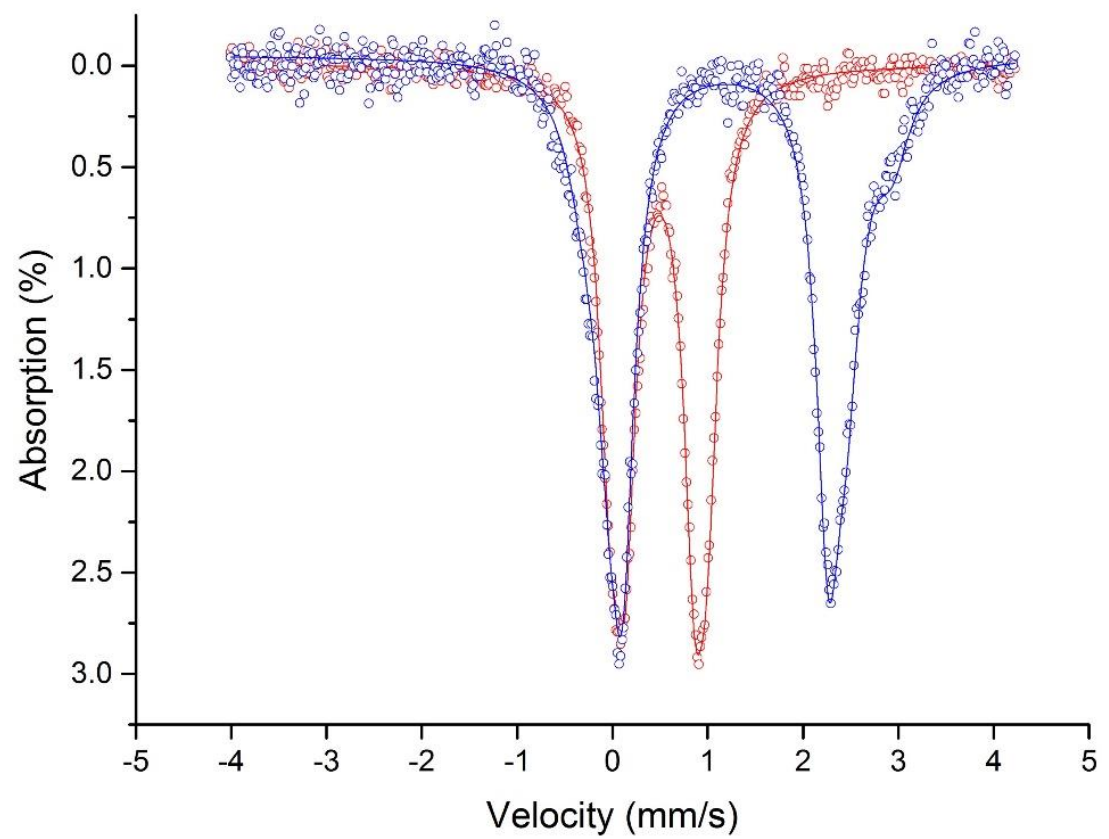

Fig. 2 Zero-field Mössbauer spectra (dots) and fittings (lines) of as-isolated FDP-Dox (red) and reduced

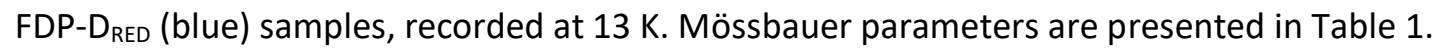

The Mössbauer parameters were also compared to other non-haem diiron enzymes (Table S1). The most similar to FDP-Dox were those of soluble methane monooxygenase (sMMO), which contains two hexacoordinated iron ions connected by two bridging hydroxo ligands in its oxidised state. ${ }^{17,12}$

Reduction with dithionite leads to a significant change in the spectrum (Figs. 2 and S3). The zero-field Mössbauer spectrum of FDP- $D_{\text {RED }}$ showed quadrupole doublets with parameters indicative of high-spin $(S=2) \mathrm{Fe}^{2+}$ (Table 1 ) as observed for reduced TmFDP. ${ }^{15}$ Besides the contribution of the two main species consistent with pentacoordinated iron centres, the spectrum also presents a third minor feature (13\%) that shows a higher $E_{Q}$ value, possibly due to a hexacoordinated centre indicating a modified amino acid coordination or free iron in solution. ${ }^{18}$ The spectra at $120 \mathrm{~K}$ and at $13 \mathrm{~K}$ in the presence of an external magnetic field of 37 $\mathrm{mT}$, applied parallel to the $\mathrm{y}$-ray direction, were nearly identical to the zero-field Mössbauer spectrum of FDP-D $D_{\text {RED }}$ at $13 \mathrm{~K}$ (Fig. S2). A comparison of the Mössbauer parameters of iron species \#1 and \#2 with other non-haem diiron enzymes (Table S1) suggests a pentacoordinated structure with one $\mu$-hydroxo ligand such as in reduced ribonucleotide reductase or SMMO. ${ }^{12}$, $13,17,19$ 
Table 1: Mössbauer parameters of as-isolated and reduced FDP-D. Symbols: $\delta$ $=$ isomer shift, $\Delta \mathrm{E}_{\mathrm{Q}}=$ quadrupole splitting, $\Gamma=$ line width at half maximum, $\mathrm{I}=$ intensity contribution.

\begin{tabular}{|c|c|c|c|c|c|c|}
\hline Sample & $\begin{array}{l}\text { Species } \\
\text { Number }\end{array}$ & $\begin{array}{l}\delta \\
(\mathrm{mm} / \mathrm{s})\end{array}$ & $\begin{array}{l}\Delta \mathrm{E}_{\mathrm{Q}} \\
(\mathrm{mm} / \mathrm{s})\end{array}$ & $\begin{array}{l}\Gamma \\
(\mathrm{mm} / \mathrm{s})\end{array}$ & $\begin{array}{l}\text { I } \\
\text { (\%) }\end{array}$ & $\begin{array}{l}118 \\
119 \\
120\end{array}$ \\
\hline \multirow[t]{2}{*}{ FDP-Dox } & $\# 1$ & 0.50 & 0.71 & 0.28 & 50 & 121 \\
\hline & $\# 2$ & 0.49 & 1.00 & 0.29 & 50 & 122 \\
\hline \multirow[t]{3}{*}{ FDP-D ${ }_{\text {RED }}$} & $\# 1$ & 1.18 & 2.14 & 0.29 & 43.5 & 124 \\
\hline & $\# 2$ & 1.20 & 2.46 & 0.38 & 43.5 & 125 \\
\hline & $\# 3$ & 1.32 & 3.23 & 0.44 & 13 & 126 \\
\hline
\end{tabular}

In order to unequivocally determine the structure of the FDP active site, vibrational spectroscopy was employed. Initial resonance Raman (RR) spectroscopic experiments on FDPD lacked resonance enhanced metal ligand vibrations ${ }^{20}$ and gave only signals arising from intrinsic FMN (Fig. S6). In contrast to the traditional infrared (IR) and RR techniques prone to their selection rules, a distinct advantage of NRVS is that it detects all vibrational modes with ${ }^{57}$ Fe nuclei motion, thus having high specificity and sensitivity to the iron centres. ${ }^{21,22}$

Our first NRVS data of FDP-Dox showed changes to the spectra during the $20 \mathrm{~h}$ of data collection (Fig. S7). Mössbauer spectra recorded after the $20 \mathrm{~h}$ NRVS measurements (Fig. S5) revealed two new additional iron species with a total of $12 \%$ contribution (Table S2). The fitted isomer shifts $(\delta=1.28$ and $1.24 \mathrm{~mm} / \mathrm{s})$ and quadrupole splittings $\left(\Delta \mathrm{E}_{\mathrm{Q}}=2.03\right.$ and $\left.2.70 \mathrm{~mm} / \mathrm{s}\right)$ correspond to high-spin $\mathrm{Fe}^{2+}$, which indicates partial photoreduction of the active site by the $14.4 \mathrm{keV} \mathrm{X}$-rays. Here, the two $\mathrm{Fe}^{2+}$ Mössbauer species are tentatively associated with either iron site photoreduced.

Three other oxidised FDP-D samples from the same preparation were investigated by NRVS for 4, 6, and $10 \mathrm{~h}$ data collection times, respectively, and their Mössbauer spectra were subsequently recorded (Fig. S4). No changes were identified after $4 \mathrm{~h}$, while after $6 \mathrm{~h}$ the Mössbauer spectrum changed slightly and after $10 \mathrm{~h}$ a total intensity of approximately $8 \%$ of two high-spin $\mathrm{Fe}^{2+}$ species was detected (Table S2). Thus, only the first NVRS spectra measured up to $4 \mathrm{~h}$ were considered for calculating the ${ }^{57} \mathrm{Fe}$ partial vibrational density of states (PVDOS) of FDP-Dox (Fig. 3).

The NRVS of FDP-Dox displays three major bands in the $200-300 \mathrm{~cm}^{-1}$ vibrational energy region, broader features in the $300-400 \mathrm{~cm}^{-1}$ region, and smaller intensity peaks at $471 \mathrm{~cm}^{-1}$ and $527 \mathrm{~cm}^{-1}$ with additional shoulders. Previous NRVS and DFT studies of a series of high-spin 


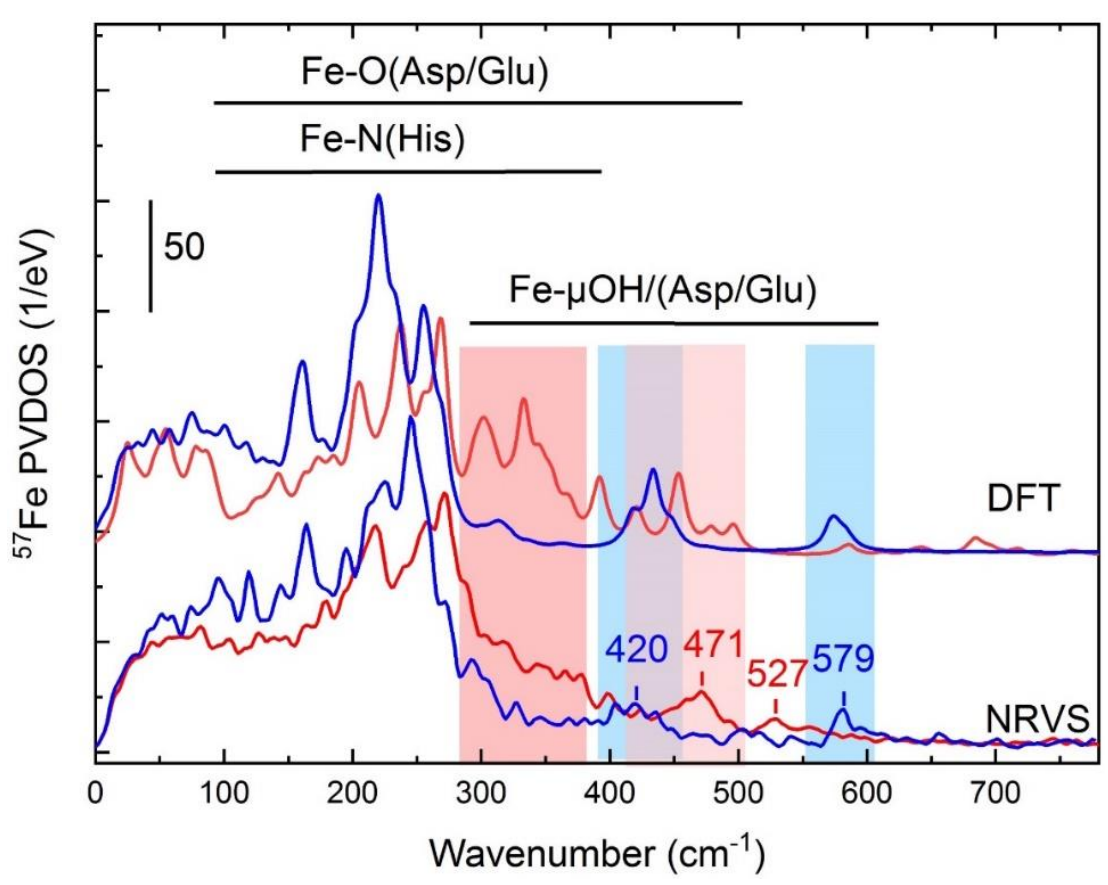

151

152

153

154

155

156

157

158

159

160

161

162

163

164

165

166

167

168

169

170

171

172

173

Fig. $3^{57}$ Fe-PVDOS spectra of FDP-D in the as-isolated FDP-Dox (red) and reduced FDP-D RED (blue) states from NRVS experiments (bottom) and DFT calculations (top). The vibrational signatures for the diiron active site with histidine, glutamate, aspartate and bridging $\mu \mathrm{OH}^{-}$ligands are shown. Redox-dependent changes are indicated by red and blue bars. An alternative comparison of these spectra is available in Fig. S18.

$\mathrm{Fe}(\mathrm{III}) \mathrm{Fe}(\mathrm{III})$ model compounds showed that mainly Fe/O/N core vibrational modes contributed to the bands between 200 and $300 \mathrm{~cm}^{-1} \cdot{ }^{23}$ The corresponding Fe-O stretches of mono-oxo, peroxo and di-oxo/hydroxo bridging ligands were identified between 350 and $600 \mathrm{~cm}^{-1}$. Remarkably, our NRVS data of FDP-Dox correspond better with the di-oxo/hydroxo than with the mono-oxo compounds. ${ }^{23}$

The reduction of FDP-D resulted in a red shift of the bands below $350 \mathrm{~cm}^{-1}$ (Fig. 3). The Mössbauer spectra for the pre-NRVS and post-NRVS FDP-DRED samples were nearly identical (not shown), which indicates that no radiation damage occurred. The red shift is consistent with the $\mathrm{Fe}(\mathrm{III}) \mathrm{Fe}(\mathrm{III})$ to $\mathrm{Fe}(\mathrm{II}) \mathrm{Fe}(\mathrm{II})$ reduction, resulting in longer metal-ligand bond lengths. ${ }^{21}$ The reduced FDP-D shows more intense features mostly in the lower-energy region at $163 \mathrm{~cm}^{-}$ ${ }^{1}$ and between $185 \mathrm{~cm}^{-1}$ and $275 \mathrm{~cm}^{-1}$. At higher energies, a feature with two shoulders appears at $420 \mathrm{~cm}^{-1}$ and a distinct peak at $579 \mathrm{~cm}^{-1}$. The two high-energy features are analogous to $\mathrm{Fe}(\mathrm{III})-\mu \mathrm{O}-\mathrm{Fe}(\mathrm{III})$ compounds showing symmetric Fe-O stretches in the $\sim 530-550 \mathrm{~cm}^{-1} \mathrm{region}$ and anti-symmetric Fe-O stretches in the $\sim 710-750 \mathrm{~cm}^{-1}$ region. ${ }^{23-26}$ A recent NRVS study of a series of trigonal bipyramidal $\mathrm{Fe}(\mathrm{III})$-hydroxo and -oxo complexes with varying $\mathrm{H}$-bonding networks showed that even subtle changes in the H-network resulted in significant shifts of the $\mathrm{Fe}-\mathrm{O}(\mathrm{H})$ vibrational frequencies. ${ }^{27}$ 
Protonation of an oxo ligand caused a large $\sim 180 \mathrm{~cm}^{-1}$ red shift in the energy of the stretching $175 \mathrm{Fe}-\mathrm{O}$ band to $\sim 480 \mathrm{~cm}^{-1}$ and elongation of the Fe-O(H) bond. The lower energy bands of FDP$176 D_{\text {RED }}$ can therefore be explained by the reduction of the diiron centre resulting in longer bonds, a bridging hydroxo instead of an oxo species, or a change in the hydrogen bond network.

A broad set of in total 28 alternative DFT models of the FDP active site has been computationally explored, invariantly containing seven side chains binding the two Fe ions as described in the ESI methods section, targeting the reproduction of the NRVS-observed FDP$D_{\text {OX/RED }}$ spectra. The structural alternatives involved modifications of the bridging oxygenous ligands, their number, and protonation level. These included primarily hydroxo $\mathrm{OH}^{-}$species as well as water $\mathrm{H}_{2} \mathrm{O}$, peroxo $\mathrm{O}_{2}{ }^{2-}$, superoxo $\mathrm{O}_{2}{ }^{{ }^{-}-}$, and oxo $\mathrm{O}^{2-}$ Fe ligands, or a vacant bridging site. Following X-ray structural data (Fig. S8), ${ }^{6,8} \mathrm{O}_{2}$ and $\mathrm{H}_{2} \mathrm{O}$ molecules weakly bound in the FDP active site pocket have been further considered, as well as a bidentate phosphate anion $\mathrm{PO}_{4}{ }^{3-}$ coordination observed in the crystal structure of the oxidised state of EcFDP (Fig. S8). The calculations generally relied on broken-symmetry ${ }^{28}$ (BS) solutions implying antiferromagnetic coupling between the two high-spin homovalent iron sites and approximating the diamagnetic (total $S=0$ ) state. Furthermore, alternative electronic states as well as mixed-valence (total $S$ $=1 / 2) \mathrm{Fe}(\mathrm{III}) \mathrm{Fe}(\mathrm{II})$ diiron cores were explored. All these models are described in the Supplementary Results section of ESI, with their structures and ${ }^{57} \mathrm{Fe}-\mathrm{PVDOS}$ spectra displayed correspondingly in Figs. S9-S17 and Figs. S18-S26.

Considered as candidates representing a pure sample, many DFT models are in apparent conflict with the collected NRVS data. The best fit between the NRVS-observed and DFT-calculated ${ }^{57} \mathrm{Fe}-\mathrm{PVDOS}$ signatures (Figs. 3 and S18) for the FDP-D $\mathrm{DED}_{\text {RED }}$ and FDP-Dox states were produced by configurations described as $\mathrm{Fe}(\mathrm{III})-\left(\mu \mathrm{OH}^{-}\right)_{2}-\mathrm{Fe}(\mathrm{III})$ and $\mathrm{Fe}(\mathrm{II})-\left(\mu \mathrm{OH}^{-}\right)-\mathrm{Fe}(\mathrm{II})$, respectively. Both the oxidised and reduced state models (Fig. 4 and Figs. S9, S10) retain pseudo reflection symmetries of their metal-ligand cores, where the mirror plane passes between the two Fe sites and encompasses the $\mu \mathrm{OH}^{-}$ligand(s).

DFT optimisations further suggest approximate arrangements of the FDP active site, where the four iron-imidazole Fe(III)-N(His) coordinations are coplanar with the oxidised ironhydroxo Fe(III)- $\left(\mathrm{HOH}^{-}\right)_{2}-\mathrm{Fe}(\mathrm{III})$ core, and four iron-carboxylate Fe(II)-O(Asp,Glu) coordinations are coplanar with the reduced Fe(II)- $\left(\mu \mathrm{OH}^{-}\right)-\mathrm{Fe}(\mathrm{II})$ core (Fig. 4). While the FDP-D ox state shows two hexacoordinate $\mathrm{Fe}(\mathrm{III})$ sites, reductive elimination of one $\mathrm{\mu OH}^{-}$ligand produces the FDP$D_{\text {RED }}$ state with two pentacoordinate $\mathrm{Fe}(\mathrm{II})$ sites and the remaining $\mathrm{\mu OH}^{-}$position in qualitative agreement with the X-ray structural reference (Fig. S8). ${ }^{6,8}$ This redox-dependent active site transformation largely follows a recent rationalisation by Weitz et al. for an $\mathrm{O}_{2}$-selective FDP, ${ }^{15}$ and agrees with our Mössbauer results outlined above. 

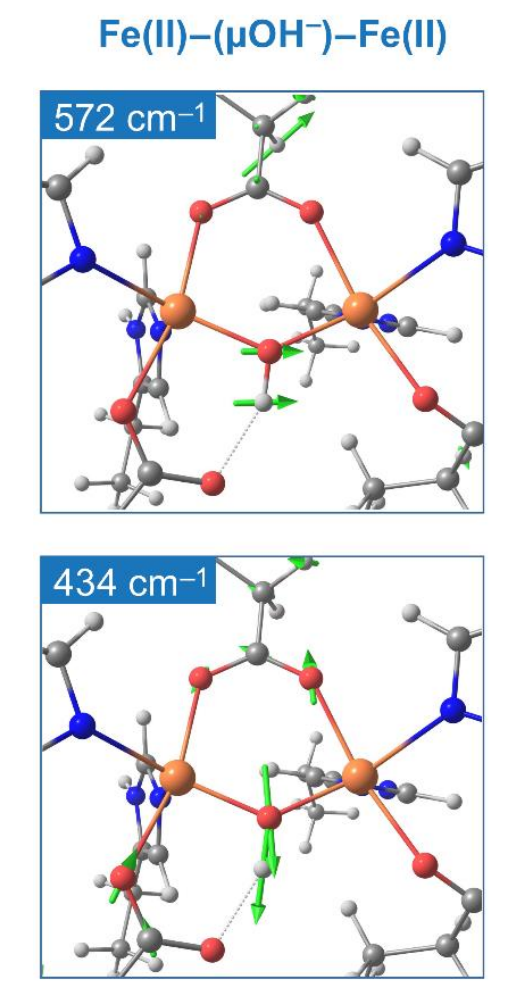

$$
\mathrm{Fe}(\mathrm{III})-\left(\mathrm{HOH}^{-}\right)_{2}-\mathrm{Fe}(\mathrm{III})
$$
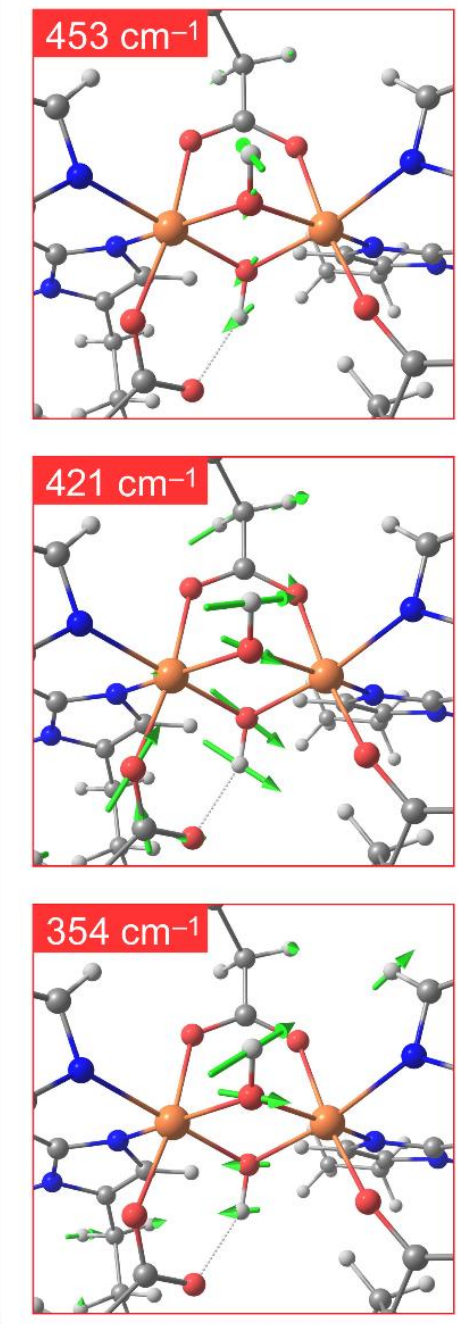

Fig. 4 Important Fe- $\mu \mathrm{OH}^{-}$normal modes shown as green arrows for the reduced (left) and oxidised (right) DFT models of the FDP-D active site, with their vibrational energies $\left(\mathrm{cm}^{-1}\right)$ provided. The individual mode intensities in context of the ${ }^{57} \mathrm{Fe}-\mathrm{PVDOS}$ (NRVS) spectra are indicated in Fig. S18. These and other normal mode animations are available as part of the ESI.

An important redox-invariant determinant, presently deduced for both the FDP-DRED/OX structures, is the hydrogen bonding between the bridging hydroxo ligand and the Asp83 carboxylate oxygen (Figs. 4 and 5). The characteristic $\mu \mathrm{O}(\mathrm{H}) \cdots \mathrm{O}(\mathrm{Asp})$ interaction at $\sim 2.5-2.8 \AA$, as commonly found for a homologous aspartate in the FDP crystal structures, compares well with the DFT-optimized distance of $\sim 2.7-2.8 \AA$. A local minimum avoiding the $\mu \mathrm{OH} \cdots \mathrm{O}$ (Asp83) hydrogen bond was found more unfavourable by $10 \mathrm{kcal} / \mathrm{mol}$ and produced an inferior match to the FDP-D RED NRVS data (Figs. S12 and S21a).

Figs. 3 and S18 display a significant overlap between the NRVS-observed and DFTcalculated ${ }^{57} \mathrm{Fe}-\mathrm{PVDOS}$ signatures, including their redox-dependent changes. Recalling the NRVS analysis from the previous section, both experiment and theory indicate a consistent redistribution of the Fe nuclear motion during the redox event: while the FDP-Dox state spectral 
intensity gradually declines up to $\sim 500-600 \mathrm{~cm}^{-1}$, the FDP-D $D_{\text {RED }}$ state instead displays a welldefined cutoff of the high-intensity region at $\sim 300 \mathrm{~cm}^{-1}$. This redox-dependent spectral difference results from the compressed and dihydroxo-bridged $\mathrm{Fe}(\mathrm{III})-\left(\mu \mathrm{OH}^{-}\right)_{2}-\mathrm{Fe}(\mathrm{III})$ core with a shortened $\mathrm{Fe} \cdots \mathrm{Fe}=3.06 \AA$ $\mathrm{optimised}$ distance. The monohydroxo-bridged $\mathrm{Fe}(\mathrm{II})-\left(\mu \mathrm{OH}^{-}\right)-\mathrm{Fe}(\mathrm{II})$ core with a longer $\mathrm{Fe} \cdots \mathrm{Fe}=3.53 \AA$ distance instead produces normal modes with a lesser degree of vibrational coupling between the two Fe sites. Among the two types of FDP protein ligands, the four carboxylates are the ones that move $\sim 0.1-0.2 \AA$ further away from the metal sites upon reduction, thereby redistributing the $\mathrm{Fe}-\mathrm{O}(\mathrm{Asp}, \mathrm{Glu})$ vibrations within their $\sim 100-500 \mathrm{~cm}^{-1}$ range to predominantly lower frequencies. The metal-to-imidazole distances, however, remain essentially redox unaffected, together with the corresponding $\mathrm{Fe}-\mathrm{N}$ (His) vibrational pattern within $100-400 \mathrm{~cm}^{-1}$. The oxidised FDP-Dox state DFT model, in contrast to FDP-D RED $_{\text {, showed }}$ a significantly higher number of mixed $\mathrm{Fe}-\mu \mathrm{OH}^{-} / \mathrm{O}$ (Asp,Glu) vibrations in the $\sim 300-400 \mathrm{~cm}^{-1}$ region, all contributing to the ${ }^{57} \mathrm{Fe}$-PVDOS. Another difference here is the prediction of mixed $\mathrm{Fe}-\mu \mathrm{O}-\mathrm{H}$ bending modes in the $\sim 600-800 \mathrm{~cm}^{-1}$ region exclusively in FDP-Dox (vs. $>800 \mathrm{~cm}^{-1}$ in FDP-D RED with their small ${ }^{57} \mathrm{Fe}$-PVDOS intensities at the level of the experimental error. The effects listed above can be traced in the ${ }^{57} \mathrm{Fe}-\mu \mathrm{OH}^{-} / \mathrm{O}(\mathrm{Asp}, \mathrm{Glu}) / \mathrm{N}(\mathrm{His}) \mathrm{KED}$ profiles shown in Fig. S19 as well as in the DFT-based normal mode animations provided as part of the ESI.

In the high-intensity region below $300 \mathrm{~cm}^{-1}$, two prominent and matching bands in the

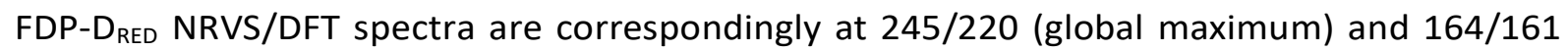
$\mathrm{cm}^{-1}$ (Fig. S18a). In contrast, NRVS/DFT ${ }^{57} \mathrm{Fe}$-PVDOS of FDP-Dox shows a blue-shifted and diminished-intensity global maximum at correspondingly $271 / 268 \mathrm{~cm}^{-1}$, with a $2^{\text {nd }}$-highest intensity band at $218 / 237 \mathrm{~cm}^{-1}$ (Fig. S18b). Regardless of the oxidation states, the aforementioned bands represent Fe-His/Asp/Glu stretches and bends, where the entire imidazole and carboxylate groups participate in vibration.

In the region above $300 \mathrm{~cm}^{-1}$, the matching NRVS/DFT ${ }^{57} \mathrm{Fe}$-PVDOS features of FDP-D $\mathrm{DED}$ are correspondingly at (i) $\sim 400-440 / 420-450 \mathrm{~cm}^{-1}$ (with maxima at $419 / 434 \mathrm{~cm}^{-1}$ ) and (ii) at $581 / 574 \mathrm{~cm}^{-1}$. Employing the FDP active site approximately mirror plane symmetry, DFT rationalises these bands as correspondingly (i) in-plane and (ii) out-of-plane iron-hydroxo Fe$\mu \mathrm{OH}^{-}$vibrations (Fig. 4, left). The two ${ }^{57} \mathrm{Fe}-\mathrm{PVDOS}$ features are produced by several normal modes each, due to the vibrational coupling between $\mathrm{\mu OH}^{-}$and carboxylates from the terminal Asp83 and bridging Asp166 Fe ligands. These couplings have correspondingly (i) Fe-O(Asp) stretching and (ii) Fe-O-C(Asp) bending character. In comparison, FDP-Dox shows a tentatively matching NRVS/DFT band at $471 / 453 \mathrm{~cm}^{-1}$, with the underlying DFT normal mode of mostly in- 


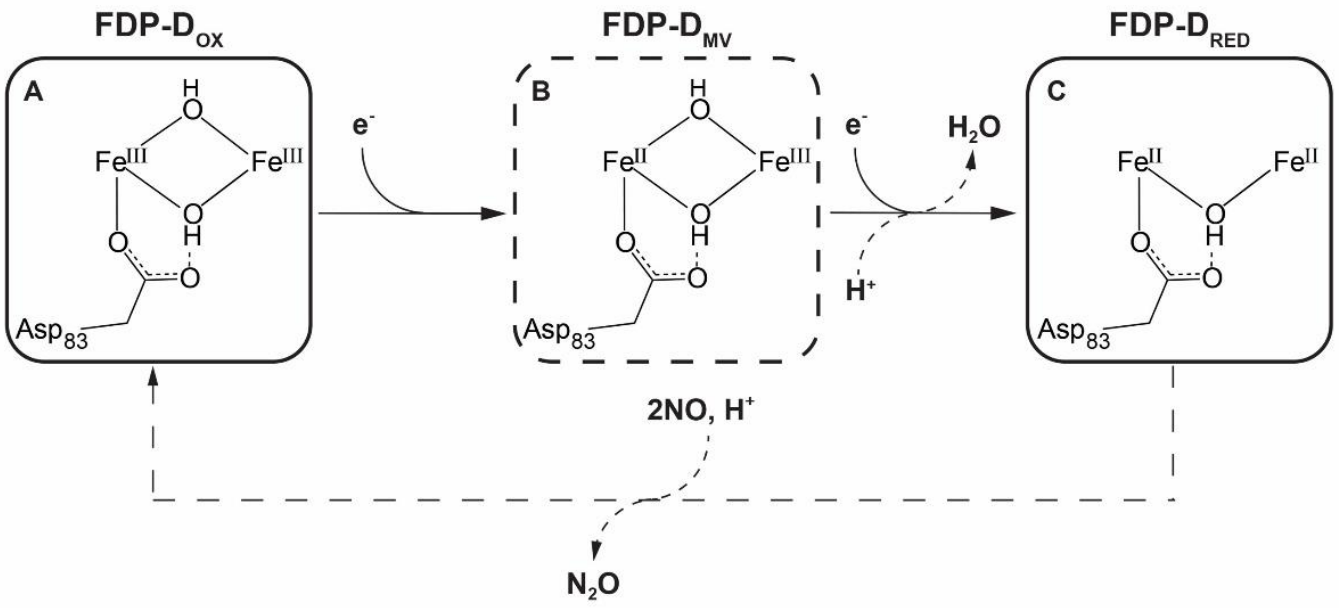

Fig. 5 Diiron core structures of EcFDP in the fully oxidized FDP-D ${ }_{0 x}(\mathbf{A})$, mixed-valence FDP-D $D_{M V}(\mathbf{B})$ and reduced FDP-D $\mathrm{DED}_{\text {(C) }}$ states, proposed in this study. The amino acids other than Asp83 were omitted for clarity. Representation of the FDP-D ox and FDP- $D_{\text {RED }}$ species arise from the NRVS experiment and DFT calculations. The proposal of the FDP- $D_{\mathrm{MV}}$ species is based on the DFT calculation performed to adjust to the contribution of a mixed-valence state detected upon photoreduction promoted by prolonged NRVS data collection. The dashed line in the lower part of the scheme represents the reaction with the substrate, NO, during the catalytic cycle.

plane character ( $i$ above), where the two $\mathrm{\mu OH}^{-}$ligands displace in-phase (Fig. 4, right panel). From the DFT calculations, the out-of-plane $\left(\mu^{-} \mathrm{OH}^{-}\right)_{2}$ modes (ii above) of FDP-Dox appear at lower energies, $421 \mathrm{~cm}^{-1}$ (symmetric) and $354 \mathrm{~cm}^{-1}$ (asymmetric), where they become mixed with the $\mathrm{Fe}-\mathrm{O}(\mathrm{Asp}, \mathrm{Glu}) / \mathrm{N}$ (His) vibrations having higher ${ }^{57} \mathrm{Fe}-\mathrm{PVDOS}$ intensities compared to the isolated $\mathrm{Fe}-\mathrm{\mu OH}^{-}$motions. The vibrational energy order of modes type (i) and (ii) is therefore

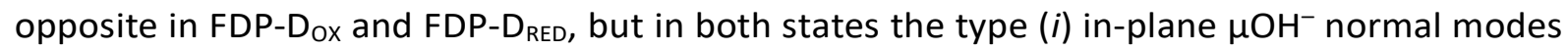
produce higher individual ${ }^{57} \mathrm{Fe}-\mathrm{PVDOS}$ intensities (Fig. S18).

For the photoreduced species upon prolonged NRVS data collection (see above), alternative DFT models of the FDP active site were examined. Indeed, the presence of a $24 \%$ contribution of a mixed-valence $\mathrm{Fe}(\mathrm{III})-(\mu \mathrm{OH})_{2}-\mathrm{Fe}(\mathrm{II})$ state $\left(F D P-\mathrm{D}_{\mathrm{MV}}\right)$ is in a good agreement with the changes of the experimental NRVS data based on the 17-20 $\mathrm{h}$ collection interval (Figs. S7 and S2Ob), as well as the post-NRVS Mössbauer data (Fig. S5). Although red-shifted global spectral maxima at vibrational energies below $220 \mathrm{~cm}^{-1}$ might be explained by a contribution of a diferrous $\mathrm{Fe}(\mathrm{II})-\left(\mathrm{HOH}^{-}\right)_{2}-\mathrm{Fe}(\mathrm{II})$ species (Fig. S2Oa), the better performance of the (partially) reduced models with two rather than one bridging hydroxo ligands (Fig. S20) indicate an active site structure similar to that of the oxidised state (Fig. S11 bottom). This is logical, considering how unlikely it is for ligand dissociation to occur under cryogenic conditions. A mixed-valence species, that has also been observed by EPR spectroscopy upon reduction with 1 equivalent of menadiol, ${ }^{7}$ might represent an intermediate during catalysis (Fig. 5).

\section{Conclusions}

In conclusion, the first combined NRVS, DFT and Mössbauer characterisation of a nonhaem diiron enzyme has addressed the active site composition and redox-dependent changes 
in the NO-converting EcFDP. We demonstrated the presence of two bridging hydroxo ligands in the oxidised state, and one bridging hydroxo ligand in the reduced state (Fig. 5). This finding unravels a discrepancy between the Fe-ligand configurations found in the crystal structures of EcFDP as compared with the now determined solution structures of this enzyme. We identified photoreduction of the as-isolated (oxidised) sample upon prolonged NRVS data collection. Our data suggest the formation of a partially reduced species (the mixed-valence state) with two bridging hydroxo ligands (Fig. 5). Future studies in terms of NRVS-monitored X-ray photoreduction may provide additional spectroscopic insights on non-haem diiron metalloenzymes. Furthermore, our approach provided access to the redox-dependent vibrational signature of the FDP active site. Vibrational bands arising from the $\mathrm{NOH}^{-}$motions, predominantly either parallel or perpendicular to the $\mathrm{Fe} \cdots \mathrm{Fe}$ vector, were identified. Alternative diiron cores with ligands either different to hydroxo, or with the vacant bridging site, are clearly disfavoured as significant components in our EcFDP-D samples. ${ }^{57} \mathrm{Fe}-\mathrm{NRVS}$ spectroscopy, applied here in conjunction with DFT modelling, proves itself as a useful method for addressing metalloenzyme's iron coordination in its fine detail and demonstrated the pioneering resolution of protein $\mathrm{Fe}-\mathrm{OH}$ vibrational bands. We conclude that a di- $\mu$-hydroxo diferric species (in the as-isolated enzyme) is reduced to a mono- $\mu$-hydroxo diferrous state, the functional form ready to react with the NO substrate. An extension of this approach to catalytic intermediates in flavodiiron enzymes will provide valuable information about their structure, thereby opening novel perspectives in gas-converting chemistry.

\section{Author Contributions} M.K. ${ }^{c}$ acquired the Mössbauer spectra; C.L. ${ }^{b}$ acquired the resonance Raman spectra; L.L. and J.A.B. collected the NRVS data with assistance by Y.Y. and K.T.; V.P. performed the DFT calculations; F.F., V.P., M.K. ${ }^{c}$, C.L. ${ }^{b}$, J.A.B., M.K. ${ }^{b}$, M.T., C.L. ${ }^{c}$, and L.L. contributed to the data analysis and participated in the discussions. F.F., V.P., and L.L. wrote the manuscript with input from all authors. (Contributions from ${ }^{\mathrm{b}}$ Technische Universität Berlin and ${ }^{\mathrm{C} H u m b o l d t-U n i v e r s i t a ̈ t}$ zu Berlin.)

\section{Conflicts of interest}

There are no conflicts to declare.

\section{Acknowledgements}

This work was funded through Fundação para a Ciência e a Tecnologia, Portugal, Project PTDC_BIA-BQM_27959_2017 (to M.T.) and by MOSTMICRO-ITQB with refs UIDB/04612/2020 and UIDP/04612/2020. This project has also received funding from the European Union's 
Horizon 2020 research and innovation programme under grant agreement № 810856. L.L, C.L., M.K. and V.P. received funding by the Deutsche Forschungsgemeinschaft (DFG, German Research Foundation) under Germany's Excellence Strategy - EXC 2008 - 390540038 UniSysCat. J.A.B. acknowledges the Max Planck Society and DFG Priority Programme "IronSulfur for Life: Cooperative Function of Iron-Sulfur Centers in Assembly, Biosynthesis, Catalysis and Disease" (SPP 1927) Project BI 2198/1-1 for funding. We thank Oliver Lenz for generous support by using his lab equipment and Peter Hildebrandt, Stephen P. Cramer, Hongxin Wang and Leland B. Gee for helpful discussions. NRVS experiments at BL19LXU of SPring8 were approved under proposal no. 2020A1450, 2016B1316.

\section{Notes and references}

1. A. M. Gardner, R. A. Helmick and P. R. Gardner, J. Biol. Chem., 2002, 277, 8172-8177.

2. R. Silaghi-Dumitrescu, E. D. Coulter, A. Das, L. G. Ljungdahl, G. N. Jameson, B. H. Huynh and D. M. Kurtz, Jr., Biochemistry, 2003, 42, 2806-2815.

3. C. M. Gomes, A. Giuffre, E. Forte, J. B. Vicente, L. M. Saraiva, M. Brunori and M. Teixeira, J. Biol. Chem., 2002, 277, 25273-25276.

4. F. Folgosa, M. C. Martins and M. Teixeira, FEMS Microbiol. Lett., 2018, 365.

5. M. C. Martins, C. V. Romão, F. Folgosa, P. T. Borges, C. Frazão and M. Teixeira, Free Radical Biol. Med., 2019, 140, 36-60.

6. C. V. Romao, J. B. Vicente, P. T. Borges, B. L. Victor, P. Lamosa, E. Silva, L. Pereira, T. M. Bandeiras, C. M. Soares, M. A. Carrondo, D. Turner, M. Teixeira and C. Frazao, J. Mol. Biol., 2016, 428, 46864707.

7. J. B. Vicente and M. Teixeira, J. Biol. Chem., 2005, 280, 34599-34608.

8. R. Silaghi-Dumitrescu, D. M. Kurtz, Jr., L. G. Ljungdahl and W. N. Lanzilotta, Biochemistry, 2005, 44, 6492-6501.

9. A. Di Matteo, F. M. Scandurra, F. Testa, E. Forte, P. Sarti, M. Brunori and A. Giuffre, J. Biol. Chem., 2008, 283, 4061-4068.

10.A. J. Jasniewski and L. Que, Jr., Chem. Rev., 2018, 118, 2554-2592.

11.C. Frazao, G. Silva, C. M. Gomes, P. Matias, R. Coelho, L. Sieker, S. Macedo, M. Y. Liu, S. Oliveira, M. Teixeira, A. V. Xavier, C. Rodrigues-Pousada, M. A. Carrondo and J. Le Gall, Nat. Struct. Biol., 2000, 7, 1041-1045.

12.A. C. Rosenzweig, P. Nordlund, P. M. Takahara, C. A. Frederick and S. J. Lippard, Chem. Biol., 1995, 2, 409-418.

13.D. T. Logan, X. D. Su, A. Aberg, K. Regnstrom, J. Hajdu, H. Eklund and P. Nordlund, Structure, 1996, 4, 1053-1064.

14.A. C. Weitz, N. Giri, R. E. Frederick, D. M. Kurtz, Jr., E. L. Bominaar and M. P. Hendrich, ACS Catal., 2018, 8, 11704-11715.

15.A. C. Weitz, N. Giri, J. D. Caranto, D. M. Kurtz, Jr., E. L. Bominaar and M. P. Hendrich, J. Am. Chem. Soc., 2017, 139, 12009-12019.

16.J. D. Caranto, A. Weitz, M. P. Hendrich and D. M. Kurtz, Jr., J. Am. Chem. Soc., 2014, 136, 79817992.

17.B. G. Fox, M. P. Hendrich, K. K. Surerus, K. K. Andersson, W. A. Froland, J. D. Lipscomb and E. Munck, J. Am. Chem. Soc., 1993, 115, 3688-3701.

18.J. B. Gordon, J. P. McGale, J. R. Prendergast, Z. Shirani-Sarmazeh, M. A. Siegler, G. N. L. Jameson and D. P. Goldberg, J. Am. Chem. Soc., 2018, 140, 14807-14822.

19.J. B. Lynch, C. Juarez-Garcia, E. Munck and L. Que, Jr., J. Biol. Chem., 1989, 264, 8091-8096.

20.T. Hayashi, J. D. Caranto, H. Matsumura, D. M. Kurtz, Jr. and P. Moenne-Loccoz, J. Am. Chem. Soc., $2012,134,6878-6884$. 
21.L. Lauterbach, L. B. Gee, V. Pelmenschikov, F. E. Jenney, S. Kamali, Y. Yoda, M. W. Adams and S. P. Cramer, Dalton Trans., 2016, 45, 7215-7219.

22.L. Lauterbach, H. X. Wang, M. Horch, L. B. Gee, Y. Yoda, Y. Tanaka, I. Zebger, O. Lenz and S. P. Cramer, Chem. Sci., 2015, 6, 1055-1060.

23.K. Park, T. Tsugawa, H. Furutachi, Y. Kwak, L. V. Liu, S. D. Wong, Y. Yoda, Y. Kobayashi, M. Saito, M. Kurokuzu, M. Seto, M. Suzuki and E. I. Solomon, Angew. Chem. Int. Ed., 2013, 52, 1294-1298.

24.N. Karthikeyan, J. J. Prince, S. Ramalingam and S. Periandy, Spectrochim. Acta A Mol. Biomol. Spectrosc., 2015, 139, 229-242.

25.J. Sandersloehr, W. D. Wheeler, A. K. Shiemke, B. A. Averill and T. M. Loehr, J. Am. Chem. Soc., 1989, 111, 8084-8093.

26.W. H. Armstrong, A. Spool, G. C. Papaefthymiou, R. B. Frankel and S. J. Lippard, J. Am. Chem. Soc., 1984, 106, 3653-3667.

27.A. C. Weitz, E. A. Hill, V. F. Oswald, E. L. Bominaar, A. S. Borovik, M. P. Hendrich and Y. S. Guo, Angew. Chem. Int. Ed., 2018, 57, 16010-16014.

28. L. Noodleman and D. A. Case, in Adv. Inorg. Chem., ed. R. Cammack, Academic Press, 1992, vol. 38 , pp. 423-470. 


\section{Hydroxo-bridged active site of a flavodiiron NO reductase revealed by spectroscopy and computations}

Filipe Folgosa, ${ }^{\mathrm{a}, \S}$ Vladimir Pelmenschikov, ${ }^{\mathrm{b},{ }^{*}, \S}$ Matthias Keck, ${ }^{\mathrm{c}}$ Christian Lorent, ${ }^{\mathrm{b}}$ Yoshitaka Yoda, ${ }^{\mathrm{d}}$ James A. Birrell, ${ }^{\text {e }}$ Martin Kaupp, ${ }^{\text {b }}$ Miguel Teixeira, ${ }^{a}$ Kenji Tamasaku, ${ }^{f}$ Christian Limberg, ${ }^{c}$ Lars Lauterbach ${ }^{b}{ }^{*}$

\footnotetext{
a Instituto de Tecnologia Química e Biológica António Xavier, ITQB NOVA, Av. da República, 2780-157 Oeiras, Portugal

b Institut für Chemie, Technische Universität Berlin, 10623 Berlin, Germany. E-mail: lars.lauterbach@tu-berlin.de; pelmentschikov@tu-berlin.de

' Department of Chemistry, Humboldt-Universität zu Berlin, Brook-Taylor-Strasse 2, 12489 Berlin, Germany

d JASRI, SPring-8, Sayo-gun, Hyogo 679-5198, Japan

e Max Planck Institute for Chemical Energy Conversion, Stiftstrasse 34-36, 45470 Mülheim an der Ruhr, Germany

${ }^{f}$ RIKEN SPring-8 Center, Sayo-gun, Hyogo 679-5148, Japan

* Corresponding authors.

$\S$ These authors contributed equally.
}

\section{Materials and Methods}

\section{Sample Preparation}

The enzyme construct, FDP-D (residues 1 to 400 of the norV gene product, lacking the rubredoxin domain), was expressed as previously described. ${ }^{1}$ To obtain ${ }^{57} \mathrm{Fe}$ enriched samples, the growth media was supplemented with $0.1 \mathrm{mM}^{57} \mathrm{FeCl}$ both at the beginning of the growth and at the time of induction. The cells were disrupted by 3 cycles in a French press at 16000 psi (Thermo) in the presence of DNAse (Applichem) and the crude extract was clarified by low-speed centrifugation at 25,000 g for $25 \mathrm{~min}$ and at $138,000 \mathrm{~g}$ for $1 \mathrm{~h}$ and $30 \mathrm{~min}$ and at $4{ }^{\circ} \mathrm{C}$ to remove cell debris and the membrane fraction, respectively. The supernatant was dialysed overnight at $4{ }^{\circ} \mathrm{C}$ against $20 \mathrm{mM}$ Tris $-\mathrm{HCl}$, pH 7.5 containing 18\% glycerol (buffer $\mathrm{A}$ ). The soluble extract was then loaded onto a Q-Sepharose Fast-Flow column ( $50 \mathrm{~mL}$, GE Healthcare) previously equilibrated with buffer A. FDP-D was eluted with a linear gradient from buffer A to $20 \mathrm{mM}$ Tris $-\mathrm{HCl}$, pH 7.5 containing $18 \%$ glycerol and $500 \mathrm{mM} \mathrm{NaCl}$. The eluted fractions were analysed by $15 \%$ SDS-PAGE and UV-visible spectroscopy. Fractions containing pure protein were pooled and concentrated.

FDP-D sample was quantified and the iron and flavin content was evaluated as previously described. ${ }^{2}$ The $^{2}$ determined Fe/flavin/protein ratio was $2( \pm 0.2) / 0.8( \pm 0.2) / 1$.

Reduced FDP-D samples used for NRVS, resonance Raman, and Mössbauer spectroscopy measurements were obtained anaerobically, inside a glovebox, by addition of a buffered sodium dithionite solution. Both as prepared and reduced samples were $2 \mathrm{mM}$ in protein concentration.

\section{Mössbauer Spectroscopy}

Zero-field Mössbauer spectra were recorded on a SEECO MS6 spectrometer that comprises the following instruments: a JANIS CCS-850 cryostat, including a CTI-CRYOGENICS closed cycle $10 \mathrm{~K}$ refrigerator, and a CTICRYOGENICS 8200 helium compressor. The cold head and sample mount are equipped with calibrated DT-670CU-1.4L silicon diode temperature probes and heaters. The temperature was controlled by a LAKESHORE 335 temperature controller. Spectra were recorded using a LND-45431 Kr gas proportional counter with beryllium window connected to the SEECO W204 $\gamma$-ray spectrometer that includes a high voltage supply, a 10 bit and $5 \mu$ s 
ADC and two single channel analysers. Motor control and recording of spectra was taken care of by the W304

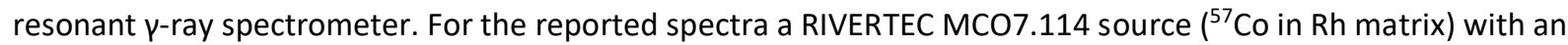
activity of about $1 \mathrm{GBq}$ was used. All spectra were recorded as frozen solutions at $13 \mathrm{~K}$ and data were accumulated for about 24 hours. Mössbauer data were processed and fitted using the WMOSS4 program (www.wmoss.org). Isomeric shifts are referenced to $\alpha$-iron at room temperature.

\section{Nuclear Resonance Vibrational Spectroscopy}

468

Nuclear resonance vibrational spectroscopy (NRVS) measurements were performed at SPring-8 BL19LXU with a 0.8 meV energy resolution at $14.4125 \mathrm{keV}$ as described previously. ${ }^{3} \mathrm{~A} 2 \times 2$ elements avalanche photodiode detector array was used to detect delayed nuclear fluorescence and $\mathrm{K}$ fluorescence by ${ }^{57} \mathrm{Fe}$ atoms. All measurements were performed at a $10 \mathrm{~K}$ reading of the cryostat sensor. The real sample temperature, as obtained from the spectral analysis, was 30-80 K. To enhance the $\mathrm{S} / \mathrm{N}$ ratio in the $\mathrm{Fe}-(\mathrm{OH}) \mathrm{x}-\mathrm{Fe}$ range of the spectra, sectional measurements of these regions were performed. While for the usual scans the time for every point was $5 \mathrm{~s}$, in the case of sectional scans the acquisition time for every data point in the region of interest, i.e. from 300 to $400 \mathrm{~cm}^{-1}$ was $8 \mathrm{~s}$, from 600 to $800 \mathrm{~cm}^{-1}$ was $20 \mathrm{~s}$, and for the remaining regions was $2 \mathrm{~s}$. The raw data were analysed with the PHOENIX software to obtain the iron partial vibrational density of states $\left({ }^{57} \mathrm{Fe}-\mathrm{PVDOS}\right) .{ }^{4,}$ 5

\section{Resonance Raman Spectroscopy}

A LabRam HR-800 Jobin Yvon confocal Raman spectrometer coupled to a liquid- $\mathrm{N}_{2}$-cooled charge-coupled device (CCD) was applied to accumulate resonance Raman spectra of pure FMN ( $2 \mathrm{mM}$ and $50 \mathrm{mM}$ potassium iodide at $\mathrm{pH} 8$ in Tris- $\mathrm{HCl}$ buffer) and FDP samples (as described in the sample preparation section). The $458 \mathrm{~nm}$ or $514 \mathrm{~nm}$ emission lines of an $\mathrm{Ar}^{+}$ion laser beam at a power of 1-2 $\mathrm{mW}$ was focussed on a 2-4 $\mu \mathrm{m}$ spot on the surface of the sample drop to induce Raman scattering. The temperature was set to $80 \mathrm{~K}$ using a liquid- $\mathrm{N}_{2}$-cooled cryostage (Linkam Scientific instruments). Toluene was used as an external standard for frequency calibration of each spectrum. Experimental data were analysed and processed using the Bruker OPUS software version 6.5 or higher.

\section{Density Functional Theory Calculations}

E. coli FDP oxidised active site topology employed in the present density functional theory (DFT) modelling was initially based on the crystal structure of Moorella (M.) thermoacetica FDP in its reduced and subsequently NOreacted state, which corresponds to an oxidised sate $(\mathrm{PDB} 1 \mathrm{YCH})^{6}$. This structure shows a bridging mono-oxo coordination in the active site. This selection of the $X$-ray reference based on a protein different from $E$. coli FDP is justified by $(i)$ the absence of a co-crystallised species resolved in the active site of $M$. thermoacetica FDP, and (ii) otherwise very similar active site arrangements in the two enzymes as shown in Fig. S8. Upon adding protons, the extracted $M$. thermoacetica FDP active site coordinates were conveniently used as a starting structure for the representative FDP-D $D_{\text {RED }}$ state optimisation. Possible effects from either the phosphate anion coordination or the vacant bridging site, as resolved correspondingly in the active sites of as-isolated (oxidised) (PDB 4D02) or dithionite reduced (PDB 5LLD) E. coli FDP, ${ }^{7}$ were investigated in this work separately. The model system involved only the protein side chains binding the Fe sites, terminating at $C_{\alpha}$ carbons, and saturating them with protons to methyl groups as shown in Fig. S10. At this modeling level, no conflicts are present between the aligned amino acid sequences of $E$. coli and $M$. thermoacetica FDPs. The amino acids entering the model are H79(81), E81(83), D83(85), H84(86), H147(148), D166(167), and H227(228), where the protein sequence numbers are respectively for E. coli FDP (M. thermoacetica FDP). All the seven $\mathrm{C}_{\alpha}$ terminal carbon nuclei appearing in the above-described model were locked to their original positions in the $X$-ray crystallographic structures during structural optimisations and treated as frozen during normal mode analyses. Additionally, an alternative scheme including 
fixation of the entire $-\mathrm{C}_{\alpha} \mathrm{H}_{3}$ methyl terminals has been investigated, as detailed below in Supplementary Results and Discussion, subsection (viii).

The DFT calculations were done mostly using GAUSSIAN 09 Revision D.01, ${ }^{8}$ based on a high-quality initial guess from single point calculations using JAGUAR 9.4. ${ }^{9}$ The qualified initial guess approach was specifically employed to ensure broken-symmetry (BS) ${ }^{10}$ solutions, with electronic structures implying open-shell singlet states, unless otherwise mentioned. All the calculations employed the PBEO ${ }^{11}$ hybrid functional in its spin-unrestricted formalism, and the LACV3P** basis set as implemented in JAGUAR 9.4. For the first- and second-row elements, LACV3P** implies $6-311 G^{* *}$ triple- $\zeta$ basis sets including polarization functions. For the Fe atoms, LACV3P** consists of a triple- $\zeta$ basis set for the outermost core and valence orbitals, and the quasi-relativistic Los Alamos effective core potential (ECP) for the innermost electrons. The molecular systems environment was considered using a self-consistent reaction field (SCRF) polarizable continuum model and integral equation formalism (IEFPCM), ${ }^{12}$ with the static dielectric constant set to $\varepsilon=4.0$ as often used for proteins, and the remaining IEF-PCM parameters at their default values for water. The calculations further included the two-body D3 dispersion corrections by Grimme et al. ${ }^{13,14}$ The ${ }^{57} \mathrm{Fe}-\mathrm{PVDOS}$ and diatomic internuclear kinetic energy distribution (KED) intensities were extracted from GAUSSIAN 09 normal mode outputs using an in-house program Q-SPECTOR, successfully applied previously (e.g. in ref. 15) to simulate the spectra. To empirically account for the observed NRVS lineshape, the computed ${ }^{57} \mathrm{Fe}-\mathrm{PVDOS}$ and KED intensities were broadened by Lorentzian convolution with a full width at half maximum $(F W H M)=14 \mathrm{~cm}^{-1}$. An empirical scaling of the calculated frequencies was not applied.

\section{Supplementary Results and Discussion}

\section{Alternative DFT Models}

(i) Redox-dependent alternatives. Isomeric to the main FDP models with either mono- $\left(\mu \mathrm{OH}^{-}\right)$or di- $\left(\mu \mathrm{OH}^{-}\right)_{2}$ hydroxo bridging coordinations, a set of alternative DFT systems targeted redox-dependent effects at the three oxidation levels: Fe(II)Fe(II) reduced, Fe(II)Fe(III) mixed-valence (partially reduced), and Fe(III)Fe(III) oxidised. While no major transformations were produced upon the reduction level shifts in both structures (Fig. S11), the predicted ${ }^{57} \mathrm{Fe}$-PVDOS spectra (Fig. S20) generally display notable variations as described below.

Our primary cross-check addressed the two structures with their oxidation levels interchanged. At the Fe(II)Fe(II) level, a dihydroxo differous system $\mathrm{Fe}(\mathrm{II})-\left(\mu \mathrm{OH}^{-}\right)_{2}-\mathrm{Fe}(\mathrm{II})$ produced strong conflicts to the observed FDP-D RED spectrum (Fig. S20a) throughout the entire $0-600 \mathrm{~cm}^{-1}$ range, e.g. an absence of the $\sim 580 \mathrm{~cm}^{-1}$ feature (attributed to the $\mathrm{Fe}(\mathrm{II})-\mathrm{\mu OH}^{-}$stretch in the monohydroxo system). At the Fe(III)Fe(III) level, a monohydroxo diferric system $\mathrm{Fe}(\mathrm{III})-\left(\mu \mathrm{OH}^{-}\right)-\mathrm{Fe}(\mathrm{III})$ is in lesser conflict with the FDP-Dox NRVS data (Fig. S20c). With its (i) too sharp bands in the $\sim 300-600 \mathrm{~cm}^{-1}$ and (ii) lack of intensity in the $\sim 200-230 \mathrm{~cm}^{-1}$ regions, $\mathrm{Fe}(\mathrm{III})-\left(\mu \mathrm{OH}^{-}\right)-\mathrm{Fe}(\mathrm{III})$ is still inferior to the representative FDP-Dox model. Notably, the $\mathrm{Fe}(\mathrm{III})-\left(\mu \mathrm{OH}^{-}\right)-\mathrm{Fe}(\mathrm{III})$ model produces prominent intensities at $543 \mathrm{~cm}^{-1}$ (Fe(III)-O(Glu81) stretch) and $585 \mathrm{~cm}^{-1}$ (Fe(III)- $\mathrm{HOH}^{-}$stretch), not observed around the low-intensity high-end bands of the FDP-Dox sample.

The mixed-valence Fe(III)Fe(II) states discourse a potential radiative $1 e^{-}$reduction of the FDP-Dox sample under the NRVS experimental conditions with prolonged $(>4 \mathrm{~h}$ ) radiation exposure (see also Fig. S7). Among these $S=$ $1 / 2$ paramagnetic states, two alternatives (either ' $\mathrm{Fe}(\mathrm{II}) \mathrm{Fe}(\mathrm{III})$ ' or ' $\mathrm{Fe}(\mathrm{III}) \mathrm{Fe}(\mathrm{II})$ ') were computationally considered for each isomer, favouring by $\sim 2-6 \mathrm{kcal} / \mathrm{mol}$ the solutions with the ferrous Fe(II) site coordinated by the Asp83 carboxylate. With their structures otherwise similar to those of the homovalent states, the mixed-valence solutions introduce enhanced asymmetry to the metal-hydroxo coordination, where the $\mathrm{Fe}(\mathrm{II})-\mu \mathrm{OH}^{-}$bonds become $\sim 0.2 \AA$ longer than the $\mathrm{Fe}(\mathrm{III})-\mu \mathrm{OH}^{-}$bonds. Here, the monohydroxo models $\mathrm{Fe}(\mathrm{II})-\left(\mu \mathrm{OH}{ }^{-}\right)-\mathrm{Fe}(\mathrm{III})[S=1 / 2]$ and $\mathrm{Fe}(\mathrm{III})-\left(\mu \mathrm{OH}^{-}\right)-\mathrm{Fe}(\mathrm{II})[\mathrm{S}=1 / 2]$ produce high-frequency $\mathrm{Fe}(\mathrm{III})-\mu \mathrm{OH}^{-}$stretches and associated ${ }^{57} \mathrm{Fe}-\mathrm{PVDOS}$ bands at correspondingly 642 and $632 \mathrm{~cm}^{-1}$, in conflict with the baseline intensity level in the $630-640 \mathrm{~cm}^{-1}$ area from the experiment (Fig. S2Ob). The dihydroxo models $\mathrm{Fe}(\mathrm{II})-\left(\mu \mathrm{OH}^{-}\right)_{2}-\mathrm{Fe}(\mathrm{III})[\mathrm{S}=1 / 2]$ and $\mathrm{Fe}(\mathrm{III})-\left(\mu \mathrm{OH}^{-}\right)_{2}-$ 
$\mathrm{Fe}(\mathrm{II})[S=1 / 2]$ perform acceptably well in the higher energy area $>300 \mathrm{~cm}^{-1}$, yet these models do not contribute sufficient intensity close to the $\sim 270 \mathrm{~cm}^{-1}$ global maximum of the representative FDP-Dox spectrum (attributed to the $\mathrm{Fe}-\mathrm{N}$ (His)/O(Asp,Glu) modes). To a lesser extent than in the reduced $\mathrm{Fe}(\mathrm{II})-\left(\mu_{\mathrm{OH}}^{-}\right)_{2}-\mathrm{Fe}(\mathrm{II})$ model ${ }^{57} \mathrm{Fe}-$ PVDOS, the mixed-valence dihydroxo systems instead produce red-shifted global spectral maxima at vibrational energies below $220 \mathrm{~cm}^{-1}$. Similar effects indicating partial photoreduction of the FDP-Dox sample are seen upon longer ( $>4 \mathrm{~h}$ ) NRVS collection intervals, in particular in the NRVS data collected after $16 \mathrm{~h}$ of the beam exposure (Fig. S7). Notably, following the Mössbauer spectroscopy results in Table S2, spectral simulation of the mixedvalence state employed in Figs. S7 and S2Ob included equal (50\%) contributions from the two DFT models with either Fe site reduced, denoted as Fe(III)- $\left(\mu \mathrm{OH}^{-}\right)_{2}-\mathrm{Fe}(\mathrm{II})[S=1 / 2]^{*}$.

(ii) Bridging hydroxyl interaction with Asp83 carboxylate. Upon a shift of the hydroxo ligand to its alternative $2^{\text {nd }}$ bridging position as seen in the oxidised state $\mathrm{Fe}(\mathrm{III})-\left(\mu \mathrm{OH}^{-}\right)_{2}-\mathrm{Fe}(\mathrm{III})$ model, an isomeric reduced state model $\mathrm{Fe}(\mathrm{II})-\left(\mu \mathrm{OH}^{-}\right)^{*}-\mathrm{Fe}(\mathrm{II})$ has been stabilised (Fig. S12). With its relative energy of $+10 \mathrm{kcal} / \mathrm{mol}$, the $\mathrm{Fe}(\mathrm{II})-(\mu \mathrm{OH})^{*}$ - Fe(II) isomer lacks a favourable hydrogen bonding interaction between the hydroxo ligand and Asp83 carboxylate $\left(\mathrm{O}_{\mathrm{D} 1}\right)$, in contrast with the best-fit Fe(II)-( $\left.\mu \mathrm{OH}^{-}\right)-\mathrm{Fe}(\mathrm{II})$ model $(\mu \mathrm{O}(\mathrm{H}) \cdots \mathrm{O}(\mathrm{Asp} 83)=2.76 \AA$ ). Notably, as suggested by Fig. S8, short oxygen-to-oxygen $\mu \mathrm{O} \cdots \mathrm{O}(\mathrm{Asp})$ distances within $3 \AA$ involving the homologous aspartate are available from the $\mathrm{X}$-ray structures of Ec FDP $\left(\mu \mathrm{O}(\mathrm{H}) \cdots \mathrm{O}(\mathrm{Asp} 83)=2.63 \AA\right.$, PDB $\left.4 \mathrm{D02}{ }^{7}\right)$ and $M$. thermoacetica FDP $\left(\mu \mathrm{O}(\mathrm{H}) \cdots \mathrm{O}(\mathrm{Asp} 85)\right.$ ranges between 2.61 to $2.81 \AA$, PDB $\left.1 \mathrm{YCH}^{6}\right)$. The $\mathrm{Fe}(\mathrm{II})-\left(\mu \mathrm{OH}^{-}\right)^{*}-\mathrm{Fe}(\mathrm{II})$ structure is reminiscent of a computational model of the Thermotoga maritima (Tm) FDP reduced state by Weitz et $\mathrm{al}^{16}{ }^{16}$ which similarly avoids hydrogen bonding of a bridging mono-hydroxo ligand with the homologous aspartate (Asp89 in Tm FDP), albeit introducing an in silico rotation of the latter side chain. The optimised $\mu \mathrm{O}(\mathrm{H}) \cdots \mathrm{O}($ Asp83/89) $=3.8 / 3.4 \AA$ distances were obtained in these two independent models of Ec/TmFDP. With its markedly high relative energy, the $\mathrm{Fe}(\mathrm{II})-\left(\mu \mathrm{OH}^{-}\right)^{*}-\mathrm{Fe}(\mathrm{II})$ model leads to ${ }^{57} \mathrm{Fe}-\mathrm{PVDOS}$ largely inconsistent with the observed NRVS bands of FDP-D RED (Fig. S21a). Specifically, due to a lack of the bridging hydroxo ligand polarisation (otherwise induced by interaction with Asp83), this model produces $\mathrm{Fe}-\mu \mathrm{OH}^{-}$bands red-shifted to $\sim 480$ and $\sim 360 \mathrm{~cm}^{-1}$ vs their characteristic positions observed respectively at $\sim 580$ and $\sim 420 \mathrm{~cm}^{-1}$.

(iii) Electronic state alternatives. A complementary line of the DFT models, otherwise isomeric and isoelectronic to the best-fit ones, addressed an influence of the electronic state on the structures and predicted ${ }^{57} \mathrm{Fe}-\mathrm{PVDOS}$ as shown in Figs. S12 and S21. All the DFT results described elsewhere in this work relied on broken-symmetry $(B S)^{10}$ solutions, implying antiferromagnetic coupling (antiparallel spin alignment) of the two Fe sites. Employing ferromagnetic coupling instead, systems Fe(II)- $\left(\mu \mathrm{OH}^{-}\right)-\mathrm{Fe}(\mathrm{II})[S=4]$ (total spin $S=2+2=4$ ) and $\mathrm{Fe}(\mathrm{III})-\left(\mu \mathrm{OH}^{-}\right)_{2}-$ $\mathrm{Fe}(\mathrm{III})[S=5]$ (total spin $S=5 / 2+5 / 2=5$ ) are high-spin (HS) equivalents of the representative reduced and oxidised FDP models. Fig. S21 displays very similar ${ }^{57}$ Fe-PVDOS profiles for the structurally-optimised BS and HS equivalents, with at most only minor $\sim 10 \mathrm{~cm}^{-1}$ deviations between the $\mathrm{Fe}-\mu \mathrm{OH}^{-}$band energies. Along with small calculated BS-to-HS electronic energy gaps within $2 \mathrm{kcal} / \mathrm{mol}$, this result is indicative of a weak exchange coupling between the two Fe sites in FDP. The weak coupling predicted is additionally manifested in essentially unperturbed optimised structures of the HS solutions (Fig. S12). Additionally, an alternative BS solution Fe(II) ${ }^{[S=1]}$ $\left(\mu \mathrm{OH}^{-}\right)-\mathrm{Fe}(\mathrm{II})^{[S=1]}(S=1-1=0)$ for the reduced FDP model could be stabilised, where the Fe sites are intermediatespin $S=1$. This imaginary state, with its energy of approx. $+50 \mathrm{kcal} / \mathrm{mol}$ and $\mathrm{Fe}-\mathrm{N}(\mathrm{His}) / \mathrm{O}(\mathrm{Asp}, \mathrm{Glu})$ bonds $\sim 0.1 \AA$ shorter relatively to the representative $\mathrm{Fe}(\mathrm{II})-\left(\mu \mathrm{OH}^{-}\right)-\mathrm{Fe}(\mathrm{II})$ model, fails to reproduce the experimental spectrum even remotely well.

(iv) Vacant bridging site and protonation alternatives. A set of alternative structural models of the FDP active site has been further explored computationally, based on either the bridging hydroxo ligands elimination or their protonation level changes, as compared to the best-fit $\mathrm{Fe}(\mathrm{II})-\left(\mu \mathrm{OH}^{-}\right)-\mathrm{Fe}(\mathrm{II})$ reduced and $\mathrm{Fe}(\mathrm{III})-\left(\mu \mathrm{OH}^{-}\right)_{2}-\mathrm{Fe}(\mathrm{III})$ 
oxidised models. The structures of these models and their ${ }^{57} \mathrm{Fe}-\mathrm{PVDOS}$ spectra are shown respectively in Figs. S13 and S22.

Systems named $\mathrm{Fe}(\mathrm{II})-(\mathrm{)}) \mathrm{Fe}(\mathrm{II})$ and $\mathrm{Fe}(\mathrm{III})-(\mathrm{)}) \mathrm{Fe}(\mathrm{III})$ with the bridging ligand sites vacant produce increased Fe...Fe separation distances, and spectral signatures clearly different from the experimental NRVS data. Notably, the $\mathrm{Fe}(\mathrm{II})-(\mathrm{)}) \mathrm{Fe}(\mathrm{II})$ configuration, although consistent with the structure of the reduced E. coli FDP PDB 5LLD ${ }^{7}$ (Fig. S8), can be ruled out as a major species of the FDP-DRED NRVS sample (see additional notes on a Fe(II)-( )$\mathrm{Fe}(\mathrm{II})\left(\mathrm{O}_{2}\right)[\mathrm{S}=1]$ model below).

Bridging oxo (oxygen dianion) systems $\mathrm{Fe}(\mathrm{II})-\left(\mu \mathrm{O}^{2-}\right)-\mathrm{Fe}(\mathrm{II})$ and $\mathrm{Fe}(\mathrm{III})-\left(\mu \mathrm{OH}^{-}\right)\left(\mu \mathrm{O}^{2-}\right)-\mathrm{Fe}(\mathrm{III})$ correspond to singly deprotonated systems, and produce intense $\mathrm{Fe}-\mu \mathrm{O}^{2-}$ bands in the $\sim 500-710 \mathrm{~cm}^{-1}$ region, absent at these jointly high intensities and vibrational energies from the NRVS data. An attempt to stabilise a water ligand bridge in the reduced state corresponds to a singly protonated model and results in proton transfer from $\mathrm{H}_{2} \mathrm{O}$ towards the Asp83 carboxylate, where the latter loses its metal coordination (Fe $\cdots O$ O (Asp83) $=2.44 \AA$ ), in a system called Fe(II)$\left(\mu \mathrm{OH}^{-}\right)-\mathrm{Fe}(\mathrm{II})\left(\mathrm{D}_{3} 3 \mathrm{H}^{+}\right)$. This model produces its $\mathrm{Fe}-\mu \mathrm{OH}^{-}$band $\sim 50 \mathrm{~cm}^{-1}$ red-shifted compared to the high-end feature of the FDP-D RED spectrum at $581 \mathrm{~cm}^{-1}$.

(v) Variable dioxygen species. Yet another set of the DFT models featured dioxygen species at the FDP active site as shown in Fig. S14, with their corresponding ${ }^{57}$ Fe-PVDOS spectra in Fig. S23. Structural optimisation of a doubly deprotonated (vs the best-fit oxidised state model) di-oxo $\mathrm{Fe}(\mathrm{III})-\left(\mu \mathrm{O}^{2-}\right)_{2}-\mathrm{Fe}(\mathrm{III})$ system leads instead to an internal redox process and an $\mathrm{O}-\mathrm{O}$ bond formation in a doubly-bridging peroxo diferrous model called $\mathrm{Fe}(\mathrm{II})-$ $\left(\mu_{2}{ }^{-}\right)-\mathrm{Fe}(\mathrm{II})$, with its sharp $\mathrm{Fe}-\mathrm{\mu O}_{2}$ band at $\sim 400 \mathrm{~cm}^{-1}$. Further, an attempt to stabilise the molecular oxygen in a bridging position between the two reduced metal sites, $\mathrm{Fe}(\mathrm{II})-\left(\mu \mathrm{O}_{2}\right)-\mathrm{Fe}(\mathrm{II})[S=1]$, leads instead to a semi-bridging superoxo state $\mathrm{Fe}(\mathrm{III})-\left({\mu \mathrm{O}_{2}}^{*-}\right) \cdots \mathrm{Fe}(\mathrm{II})[S=1]$. The latter model is however $4 \mathrm{kcal} / \mathrm{mol}$ less favourable (electronic energy; $7.5 \mathrm{kcal} / \mathrm{mol}$ less favourable when the free energies are considered) as compared to its isomer, a Fe(II)( ) $-\mathrm{Fe}(\mathrm{II})\left(\mathrm{O}_{2}\right)[\mathrm{S}=1]$ model where the molecular oxygen is discharged from the bridge and placed initially following the $\mathrm{O}_{2}$ coordinates resolved in the structure of the reduced E. coli (PDB 5LLD7) (Figs. 1 (B) and S8). A local minimum for the weakly bound $\mathrm{O}_{2}$ molecule was therefore obtained with the shortest optimised $\mathrm{Fe} \cdots \mathrm{O}$ separation distances to the two iron sites of 3.5/3.7 $\AA$, somewhat longer than 2.6/3.4 $\AA$ as found in PDB 5LLD. The ${ }^{57} \mathrm{Fe}-\mathrm{PVDOS}$ signature of the $\mathrm{Fe}(\mathrm{II})-\left(\mathrm{)}-\mathrm{Fe}(\mathrm{II})\left(\mathrm{O}_{2}\right)[\mathrm{S}=1]\right.$ model (Fig. S23) is apparently similar to that of the $\mathrm{Fe}(\mathrm{II})-(\mathrm{)}-\mathrm{Fe}$ (II) model (Fig. S22a). In summary, while the above-considered dioxygen species spectra are not

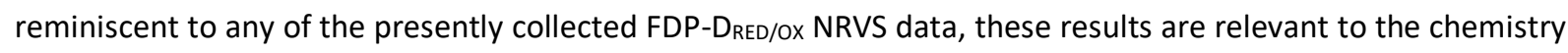
by FDPs, which often display both $\mathrm{O}_{2}$ and NO reductase activities.

(vi) Phosphate anion coordination. Potential occupancy of the FDP active site by a phosphate anion, resolved in the as-isolated (oxidised) E. coli FDP (PDB 4D02) ${ }^{7}$ structure additionally to the mono hydroxo bridge (Fig. S8), was investigated in alternative DFT models shown in Fig. S15 with their computed ${ }^{57}$ Fe-PVDOS spectra in Fig. S24. The highly negative and bulky $\mathrm{PO}_{4}{ }^{3-}$ species are likely to introduce extra interactions with the active site environment (as compared to e.g. hydroxo ligands) not explicitly available in the present DFT setup. To partially account for such interactions, models with the protonated $\mathrm{PO}_{4} \mathrm{H}^{2-}$ species were considered as well. The latter protonated form of the phosphate anion as well better corresponds to the physiologic $\mathrm{pH}$ levels. The two oxidised state models Fe(III)- $\left(\mu \mathrm{OH}^{-}\right)-\mathrm{Fe}(\mathrm{III})\left(\mathrm{PO}_{4} \mathrm{H}^{2-}\right)$ and $\mathrm{Fe}(\mathrm{III})-\left(\mu \mathrm{OH}^{-}\right)-\mathrm{Fe}(\mathrm{III})\left(\mathrm{PO}_{4}{ }^{3-}\right)$ overlap very well with the experimental Xray structure (Fig. S15 bottom); the $\mathrm{Fe}-\mathrm{O}\left(\mathrm{PO}_{4} \mathrm{H}^{2-}\right) / \mathrm{Fe}-\mathrm{O}\left(\mathrm{PO}_{4}{ }^{3-}\right)=1.90-1.93 / 1.83-1.85 \AA$ distances slightly favour the protonated $\mathrm{PO}_{4} \mathrm{H}^{2-}$ modeling, when compared to the corresponding values of 1.9 and $2.3 \AA$ as found in $\mathrm{PDB}$ 4D02. At the same time, phosphate coordination to the reduced FDP state in models $\left.\mathrm{Fe}(\mathrm{II})-(\mu \mathrm{OH})^{-}\right)-\mathrm{Fe}(\mathrm{II})\left(\mathrm{PO}_{4} \mathrm{H}^{2-}\right.$ ) and $\mathrm{Fe}(\mathrm{II})-\left(\mathrm{HOH}^{-}\right)-\mathrm{Fe}(\mathrm{II})\left(\mathrm{PO}_{4}{ }^{3-}\right)$ (Fig. S15 top) is concluded to induce critical active site perturbations, such as $\mathrm{Fe}-\mathrm{O}(\mathrm{Asp}) / \mathrm{N}(\mathrm{His})$ protein ligands loss. Among the phosphate-containing oxidised state models, $\mathrm{Fe}(\mathrm{III})-\left(\mu \mathrm{OH}^{-}\right)-$ $\mathrm{Fe}(\mathrm{III})\left(\mathrm{PO}_{4} \mathrm{H}^{2-}\right)$ produces a more realistic ${ }^{57} \mathrm{Fe}-\mathrm{PVDOS}$ spectra. However, similarly to another mono-hydroxo model $\mathrm{Fe}(\mathrm{III})-\left(\mu \mathrm{OH}^{-}\right)-\mathrm{Fe}(\mathrm{III})$ described above, it shows intensity drop-down in the $\sim 200-230 \mathrm{~cm}^{-1}$ region and also around 
$\sim 400 \mathrm{~cm}^{-1}$, now less consistent with the FDP-Dox spectrum (Fig. S24b). The phosphate-dependent normal modes yielding noticeable ${ }^{57} \mathrm{Fe}-\mathrm{PVDOS}$ intensities in this model are O-P-O bends, coupled to either the $\mathrm{Fe}(\mathrm{III})-\mathrm{\mu OH}^{-}$ stretches at 511 and $484 \mathrm{~cm}^{-1}$, or to the $\mathrm{Fe}-\mathrm{O}\left(\mathrm{PO}_{4} \mathrm{H}^{2-}\right)$ symmetric stretch at $432 \mathrm{~cm}^{-1}$.

(vii) Bridging hydroxyl interaction with a solvent water molecule. Following an earlier iron-oxido/hydroxido ${ }^{57} \mathrm{Fe}-\mathrm{NRVS}$ and DFT study, ${ }^{17}$ an importance of hydrogen bonding interactions to the iron-bound hydroxo ligand has been presently examined by inclusion of a solvent water molecule as found in the FDP active site pocket of, e.g., the reduced state of $M$. thermoacetica FDP (Fig. S8). The corresponding DFT models Fe(II)- $\left(\mu \mathrm{OH}^{-}\right)-$ $\mathrm{Fe}(\mathrm{II})\left(\mathrm{H}_{2} \mathrm{O}\right)$ and $\mathrm{Fe}(\mathrm{III})-\left(\mu \mathrm{OH}^{-}\right)_{2}-\mathrm{Fe}(\mathrm{III})\left(\mathrm{H}_{2} \mathrm{O}\right)$ are shown in Fig. $\mathrm{S} 16$, with their predicted ${ }^{57} \mathrm{Fe}-\mathrm{PVDOS}$ spectra in Fig. S25. The $\mu \mathrm{O}(\mathrm{H}) \cdots \mathrm{O}\left(\mathrm{H}_{2} \mathrm{O}\right)=2.8-2.9 \AA$ (oxygen-oxygen nuclei) distance remains essentially unaltered between the $\mathrm{PDB} 1 \mathrm{YCH}^{6} \mathrm{X}$-ray reference and the optimised structures, supportive of the protonation scenario from the present modeling. The weakly bound $\mathrm{H}_{2} \mathrm{O}$ molecule however forms additional (Asp166/Glu81) $\mathrm{\cdots} \cdot \mathrm{H}\left(\mathrm{H}_{2} \mathrm{O}\right.$ ) hydrogen bonds to the metal-bound carboxylates upon structure optimisations, which are possibly artefacts in the absence of other protein side chains forming the FDP active site pocket. Several characteristic $\mathrm{Fe}-\mu \mathrm{OH}^{-}$bands $>400 \mathrm{~cm}^{-1}$ become unfavourably red-shifted by $20-30 \mathrm{~cm}^{-1}$ in the $\mathrm{Fe}(\mathrm{II})-\left(\mu \mathrm{OH}^{-}\right)-\mathrm{Fe}(\mathrm{II})\left(\mathrm{H}_{2} \mathrm{O}\right)$ and $\mathrm{Fe}(\mathrm{III})-\left(\mu \mathrm{OH}^{-}\right)_{2}-$ $\mathrm{Fe}(\mathrm{III})\left(\mathrm{H}_{2} \mathrm{O}\right)$ models. The implicit solvent SCRF / IEF-PCP scheme otherwise employed here, in contrast to the explicit $\mathrm{H}_{2} \mathrm{O}$ inclusion, is therefore empirically concluded to serve as an optimal approach.

(viii) Rigid protein backbone scheme. In view of notable displacements of the Fe-coordinating residues obtained for some of the models described above, a rigid (" $[R]$ ") protein backbone framework scheme has been alternatively explored in models $\mathrm{Fe}(\mathrm{II})-\left(\mu \mathrm{OH}^{-}\right)-\mathrm{Fe}(\mathrm{II})[\mathrm{R}]$ and $\mathrm{Fe}(\mathrm{III})-\left(\mu \mathrm{OH}^{-}\right)_{2}-\mathrm{Fe}(\mathrm{III})[R]$ shown in Fig. S17, with their predicted ${ }^{57} \mathrm{Fe}-\mathrm{PVDOS}$ spectra in Fig. S26. In contrast to the $\mathrm{C}_{\alpha}$-only fixation scheme permitting rotations of the side chains, such rotations are severely restricted when the entire $-\mathrm{C}_{\alpha} \mathrm{H}_{3}$ methyl terminal fixations are imposed. Alternative side chain to backbone fixation schemes have been previously examined in DFT modeling of ${ }^{57} \mathrm{Fe}-$ NRVS spectra of e.g. the methane monooxygenase binuclear iron site ${ }^{18}$ and protein [4Fe-4S] clusters. ${ }^{15}$ Interestingly, the rigid backbone scheme results in an over-extended (Asp166)O $\cdots$ Fe $=2.8 \AA$ distance in the reduced state structure, implying the bidentate Asp166 coordination lost to one of the Fe sites (Fig. S17). In contrast, all three $\mathrm{X}$-ray structures collected in Fig. $\mathrm{S} 8$ and the reduced/oxidised representative models from the $\mathrm{C}_{\alpha}$-only fixation scheme show the (Asp166)O-Fe $=2.1-2.2 \AA$ distance within its bonding range. The (Asp166)OFe coordination loss in the $\mathrm{Fe}(\mathrm{II})-\left(\mu \mathrm{OH}^{-}\right)-\mathrm{Fe}(\mathrm{II})[R]$ model can be rationalised by positioning of the His 148 residue in the $M$. thermoacetica FDP PDB $1 \mathrm{YCH}^{6} \mathrm{X}$-ray reference, which coordinates to the same Fe site; in the rigid backbone DFT model, the His 148 imidazole displacement is restricted and the favourable Fe coordination to both the His148 imidazole and Asp166 carboxylate cannot be achieved. The His148 position notably different to that of PDB $1 \mathrm{YCH}^{6}$ is seen in both the E. coli FDP structures (Figs. S8) and the representative DFT models (Fig. S9). While the reduced state $\mathrm{Fe}(\mathrm{II})-\left(\mu \mathrm{OH}^{-}\right)-\mathrm{Fe}(\mathrm{II})[R]$ model produces its characteristic high-frequency band $\sim 50 \mathrm{~cm}^{-1}$ blue-shifted (Fig. S26a) as compared to that from the representative model and the FDP-DRED NRVS data (570$\left.580 \mathrm{~cm}^{-1}\right)$, the oxidised state rigid backbone model Fe(III)-( $\left.\mathrm{OOH}^{-}\right)_{2}-\mathrm{Fe}(\mathrm{III})[R]$ does not lead to the (Asp166)O-Fe coordination loss and performs on ${ }^{57} \mathrm{Fe}-\mathrm{PVDOS}$ well in line with the experimental results (Fig. S26b); above 300 $\mathrm{cm}^{-1}$, the performance of $\mathrm{Fe}(\mathrm{III})-\left(\mu \mathrm{OH}^{-}\right)_{2}-\mathrm{Fe}(\mathrm{III})[R]$ is somewhat superior to the otherwise representative $\mathrm{Fe}(\mathrm{III})-$ $\left(\mu \mathrm{OH}^{-}\right)_{2}-\mathrm{Fe}$ (III) model. In summary, the common 'soft backbone' $\mathrm{C}_{\alpha}$-only fixation scheme was found optimal for a multi-state modeling of the FDP active site.

\section{Mössbauer Spectroscopy of a Photoreduced State}

Mössbauer spectra recorded after the NRVS measurements (Fig. S5) revealed two new additional iron species with a total of $12 \%$ contribution (Table S2) with parameters corresponding to high-spin $\mathrm{Fe}^{2+}$, which indicates partial photoreduction by the $14.4 \mathrm{keV} \mathrm{X}$-rays. Assuming reduction of only one out of two Fe centres per active site, $12 \% \mathrm{Fe}^{2+}$ couples to $12 \% \mathrm{Fe}^{3+}$ in a mixed-valence state. This provides $24 \%$ contribution of the signal assigned 
to the photoreduced state. Following analysis in subsection (i) above and in the main text, photoreduction of the FDP-Dox sample to a fully reduced diferrous species is a less likely alternative.

Table S1 Overview of Mössbauer parameters and bridging/terminal ligands at the active site of non-haem diiron enzymes. $\delta=$ isomer shift, $\Delta \mathrm{E}_{\mathrm{Q}}=$ quadrupole splitting. The oxidised Fe(III)Fe(III) (upper section) and reduced $\mathrm{Fe}(\mathrm{II}) \mathrm{Fe}(\mathrm{II})$ (lower section) enzyme states are augmented with notations 'ox' and 'red', respectively.

\begin{tabular}{|c|c|c|c|c|}
\hline Enzyme & Fe Ligand(s) & $\delta(\mathrm{mm} / \mathrm{s})$ & $\Delta \mathrm{E}_{\mathrm{Q}}(\mathrm{mm} / \mathrm{s})$ & Ref. \\
\hline \multicolumn{5}{|l|}{$\mathrm{Fe}(\mathrm{III}) \mathrm{Fe}(\mathrm{III}):$} \\
\hline FDP-Dox E.coli & $\operatorname{bis}\left(\mu-\mathrm{OH}^{-}\right)^{\text {a }}$ & $0.50,0.49$ & $0.73,1.03$ & this study \\
\hline FDP-ox T. maritima & $\operatorname{bis}\left(\mu-\mathrm{OH}^{-}\right)^{a}$ & $0.48,0.43$ & $1.04,0.94$ & 16 \\
\hline deflavo-FDP-ox T. maritima & $\operatorname{bis}\left(\mu-\mathrm{OH}^{-}\right)^{\mathrm{a}}$ & 0.44 & 0.92 & 16 \\
\hline oxy-haemerythrin & $\mathrm{OOH}^{-}, \mu-\mathrm{O}^{2-\mathrm{a}, \mathrm{b}, \mathrm{c}}$ & $0.46,0.47$ & $1.87,0.94$ & $19-22$ \\
\hline sMMO-ox & $\operatorname{bis}\left(\mu-\mathrm{OH}^{-}\right)^{b}$ & 0.50 & 1.07 & 23,24 \\
\hline ribonucleotide reductase-ox & $\mu-\mathrm{O}^{2-}, 2 \mathrm{H}_{2} \mathrm{O}^{\mathrm{b}}$ & $0.55,0.45$ & $-1.62,-2.44$ & 25,26 \\
\hline toluene-4-monooxygenase & $\begin{array}{l}\mu-\mathrm{OH}^{-}, \mu \text {-thioglycolate } \\
\mathrm{H}_{2} \mathrm{O}^{\mathrm{b}}\end{array}$ & $0.51,0.56$ & $0.93,1.55$ & 27,28 \\
\hline \multicolumn{5}{|l|}{$\mathrm{Fe}(\mathrm{II}) \mathrm{Fe}(\mathrm{II}):$} \\
\hline FDP-D RED E.coli & $\mu-\mathrm{OH}^{-\mathbf{a}}$ & $1.18,1.20,1.31$ & $2.16,2.51,3.23$ & this study \\
\hline $\mathrm{Fe}\left(\mathrm{H}_{2} \mathrm{O}\right)_{6}$ & & 1.39 & 3.38 & 29 \\
\hline FDP $_{\text {red }}$ T. maritima & $\mu-\mathrm{OH}^{-\mathrm{a}}$ & 1.15 & +2.39 & 16 \\
\hline deflavo-FDP red T. maritima & $\mu-\mathrm{OH}^{-\mathbf{a}}$ & 1.15 & +2.5 & 16 \\
\hline deoxy-haemerythrin & $\mu-\mathrm{OH}^{-b}$ & 1.15 & 2.80 & $19-22$ \\
\hline $\mathrm{sMMO}_{\text {red }}$ & $\mu-\mathrm{OH}^{-}, \mu-\mathrm{COO}^{-\mathrm{d}, \mathrm{b}}$ & 1.30 & $3.14,2.4$ & $23,24,30$ \\
\hline $\begin{array}{l}\text { ribonucleotide reductase- } \\
\text { red }\end{array}$ & $\mu-\mathrm{COO}^{-e, b}$ & 1.26 & 3.13 & 25,31 \\
\hline toluene-4-monooxygenase & n.a.* & 1.31 & $3.21,2.68$ & 28 \\
\hline
\end{tabular}

* Structure is not available.

701 a Spectroscopic evidence.

$702{ }^{\text {b }}$ Crystal structure.

$703{ }^{c}$ Computational evidence.

704 d Glu243 bidentate, additional to Glu144.

705 e Glu238 bidentate, additional to Glu115 (amino acid numbering from E. coli R2 RNR). 


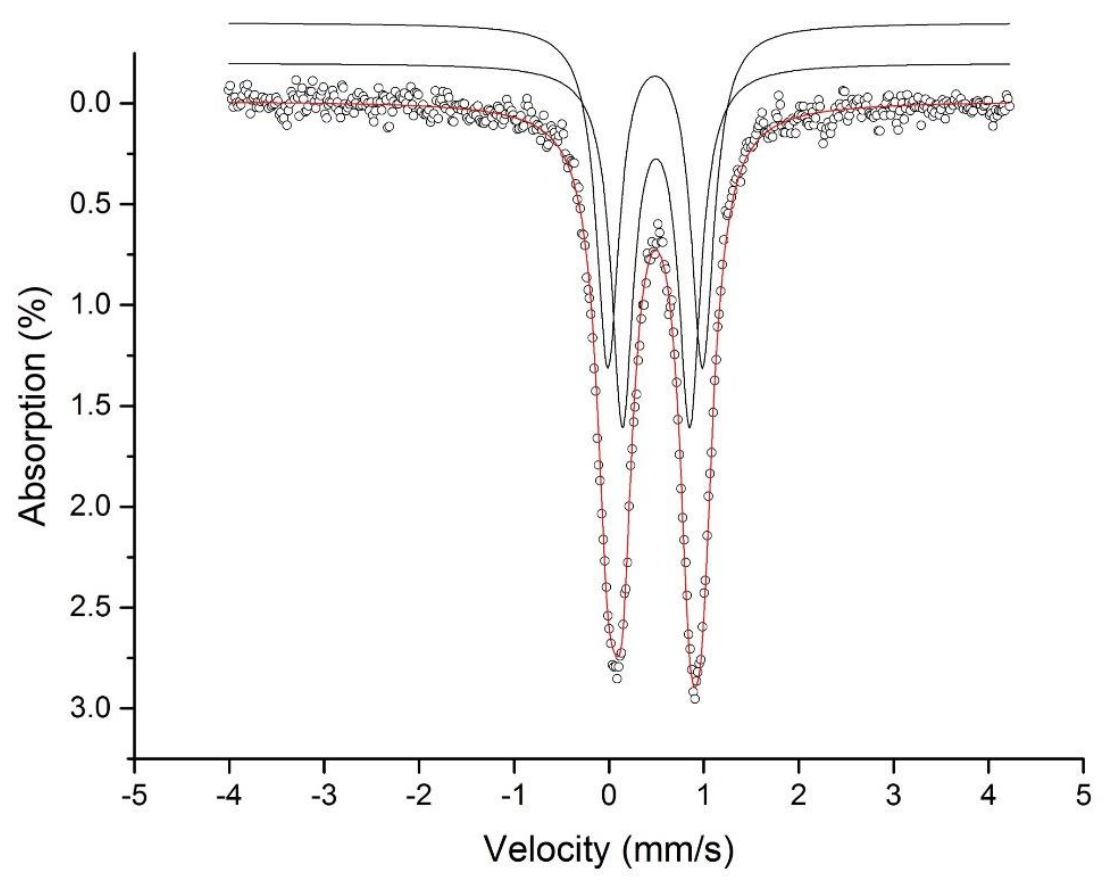

Fig. S1 Mössbauer spectrum for FDP-Dox. Solid lines on top of experimental spectra represent the different fitted species (Tables 1 and S2). The empty circles are the experimental data, the red line is the global fit, and the black lines indicate the component subspectra. Extended Mössbauer data collection of FDP-Dox (3 days) show constant peak positions (not shown), indicating no radiation damage by the applied ${ }^{57} \mathrm{Co}$ source. 


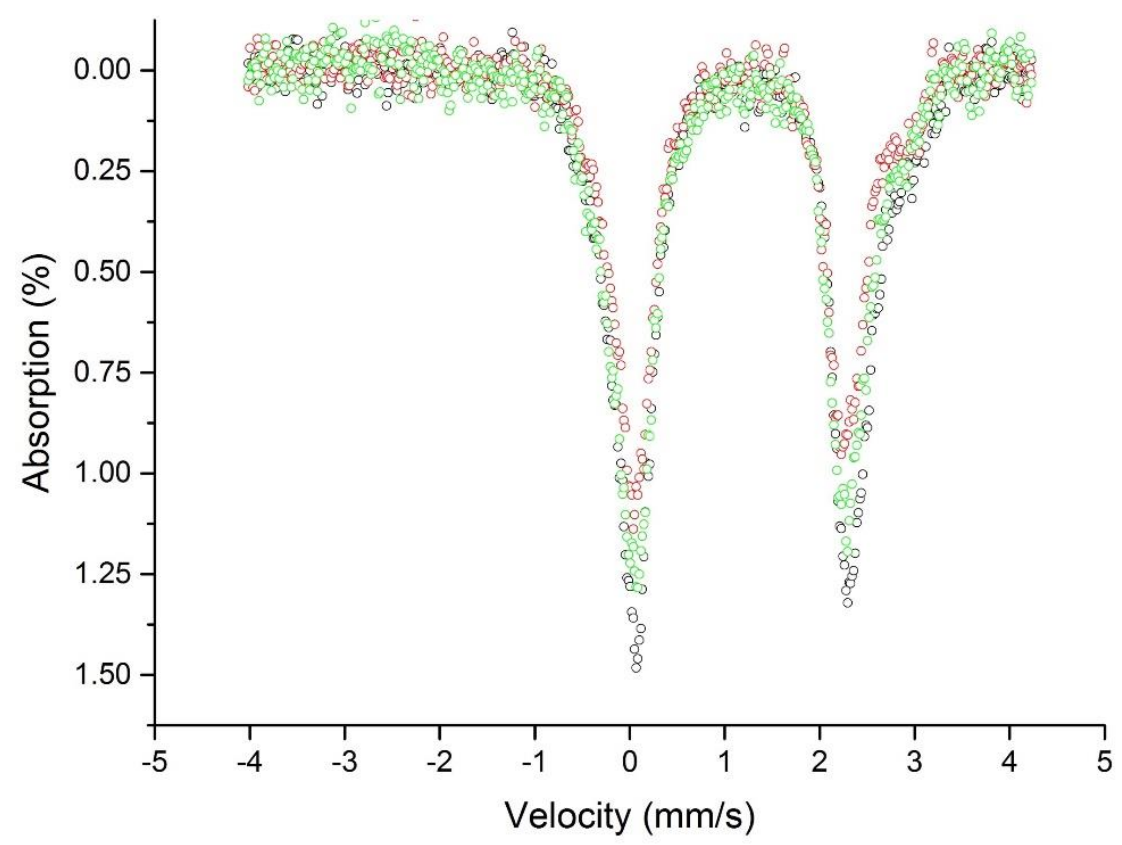

Fig. S2 Mössbauer spectra of the FDP-DrED sample at $13 \mathrm{~K}$ (black circles), at $120 \mathrm{~K}$ (red circles), both in the absence of an applied magnetic field, and at $13 \mathrm{~K}$ with a magnetic field of $37 \mathrm{mT}$ applied parallel to the $\mathrm{\gamma}$-ray direction (green circles).

Fig. S3 Mössbauer subspectra of FDP-DreD (experimental: empty circles, global fit: solid red line). Solid black lines on top of experimental spectra represent the component subspectra (Tables 1 and S2).

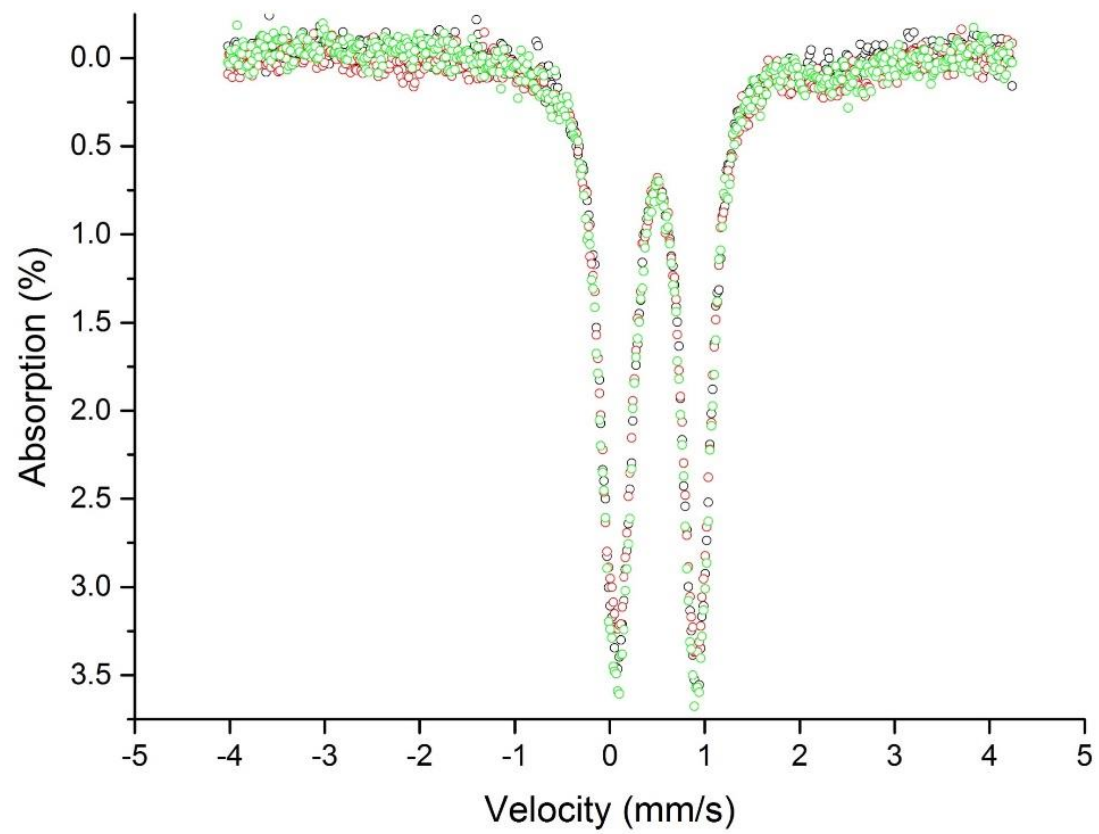

Fig. S4 Zero-field Mössbauer spectra of the FDP-Dox NRVS sample after $4 \mathrm{~h}$ (black dots), $6 \mathrm{~h}$ (red dots) and $10 \mathrm{~h}$ (green dots) of NRVS irradiation. 


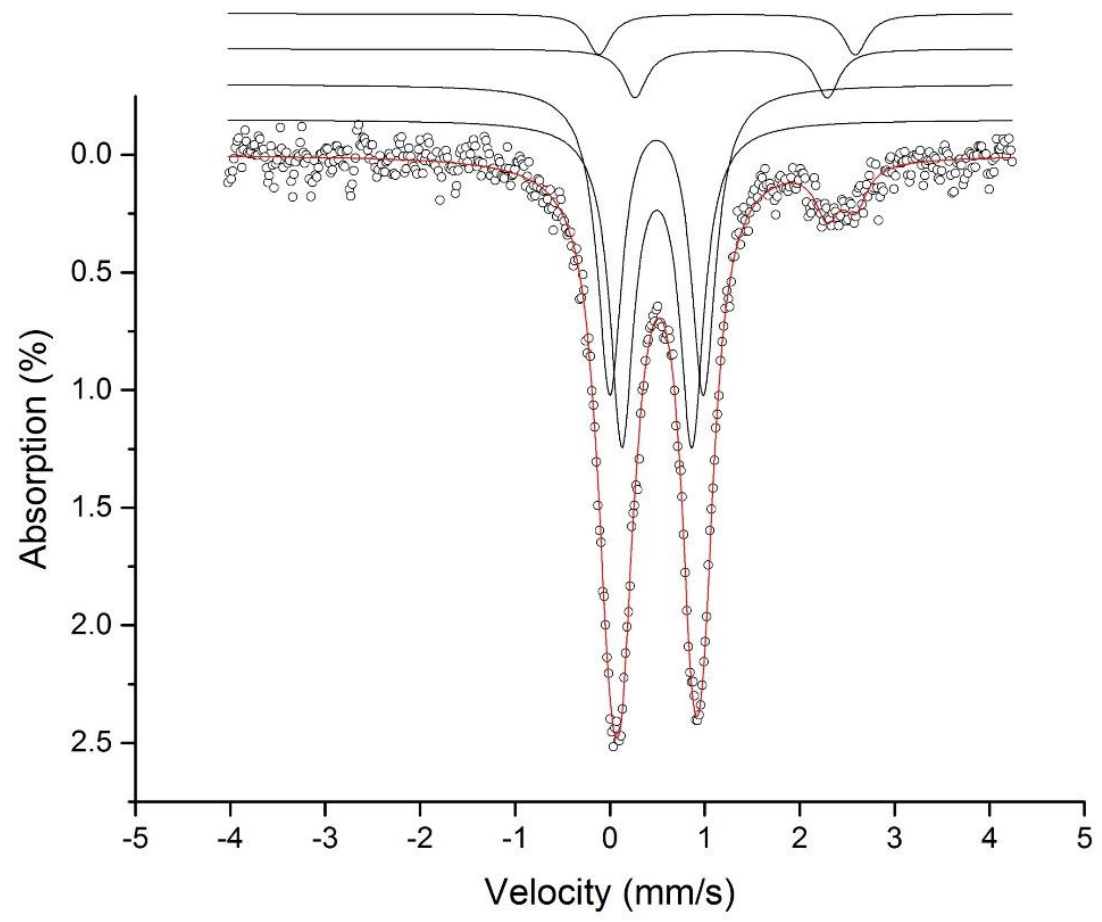

Fig. S5 Zero-field Mössbauer spectrum (experimental: black dots, simulation: red line) of FDP-Dox sample after $20 \mathrm{~h}$ of NRVS measurement. Solid lines on top of experimental spectrum represent different simulated species listed in Table S2.

Table S2 Mössbauer parameters of FDP-Dox sample after 20 and $10 \mathrm{~h}$ of NRVS irradiation in comparison to FDPDox and FDP-DRED before NRVS. $\delta=$ isomer shift, $\Delta E_{Q}=$ quadrupole splitting, $\Gamma=$ line width at half maximum, $I=$ intensity contribution, h.s. = high spin.

\begin{tabular}{llllllll}
\hline Sample & Species & & & $\delta(\mathrm{mm} / \mathrm{s})$ & $\Delta \mathrm{EQ}_{(\mathrm{mm} / \mathrm{s})}$ & $\Gamma(\mathrm{mm} / \mathrm{s})$ & $\mathrm{I}(\%)$ \\
\hline $\begin{array}{l}\text { FDP-Dox } \\
\text { After 2Oh }\end{array}$ & $\# 1$ & $\mathrm{Fe}^{3+}$ & h.s. & 0.50 & 0.74 & 0.30 & 44 \\
NRVS & $\# 2$ & $\mathrm{Fe}^{3+}$ & h.s. & 0.49 & 0.99 & 0.32 & 44 \\
& $\# 3$ & $\mathrm{Fe}^{2+}$ & h.s. & 1.28 & 2.03 & 0.30 & 6.5 \\
& $\# 4$ & $\mathrm{Fe}^{2+}$ & h.s. & 1.24 & 2.70 & 0.30 & 5.5 \\
\hline FDP-Dox & $\# 1$ & $\mathrm{Fe}^{3+}$ & h.s. & 0.50 & 0.72 & 0.27 & 47 \\
After 10h & $\# 2$ & $\mathrm{Fe}^{3+}$ & h.s. & 0.49 & 0.98 & 0.28 & 47 \\
NRVS & $\# 3$ & $\mathrm{Fe}^{2+}$ & h.s. & 1.25 & 2.00 & 0.3 & 3.5 \\
& $\# 3$ & $\mathrm{Fe}^{2+}$ & h.s. & 1.22 & 2.79 & 0.3 & 2.5 \\
\hline FDP-Dox & $\# 1$ & $\mathrm{Fe}^{3+}$ & h.s. & 0.50 & 0.71 & 0.28 & 50 \\
Before NRVS & $\# 2$ & $\mathrm{Fe}^{3+}$ & h.s. & 0.49 & 1.00 & 0.29 & 50 \\
\hline FDP-DRED & $\# 1$ & $\mathrm{Fe}^{2+}$ & h.s. & 1.18 & 2.14 & 0.29 & 43.5 \\
Before NRVS & $\# 2$ & $\mathrm{Fe}^{2+}$ & h.s. & 1.20 & 2.46 & 0.38 & 43.5 \\
& $\# 3$ & $\mathrm{Fe}^{2+}$ & h.s. & 1.32 & 3.23 & 0.44 & 13 \\
\hline
\end{tabular}



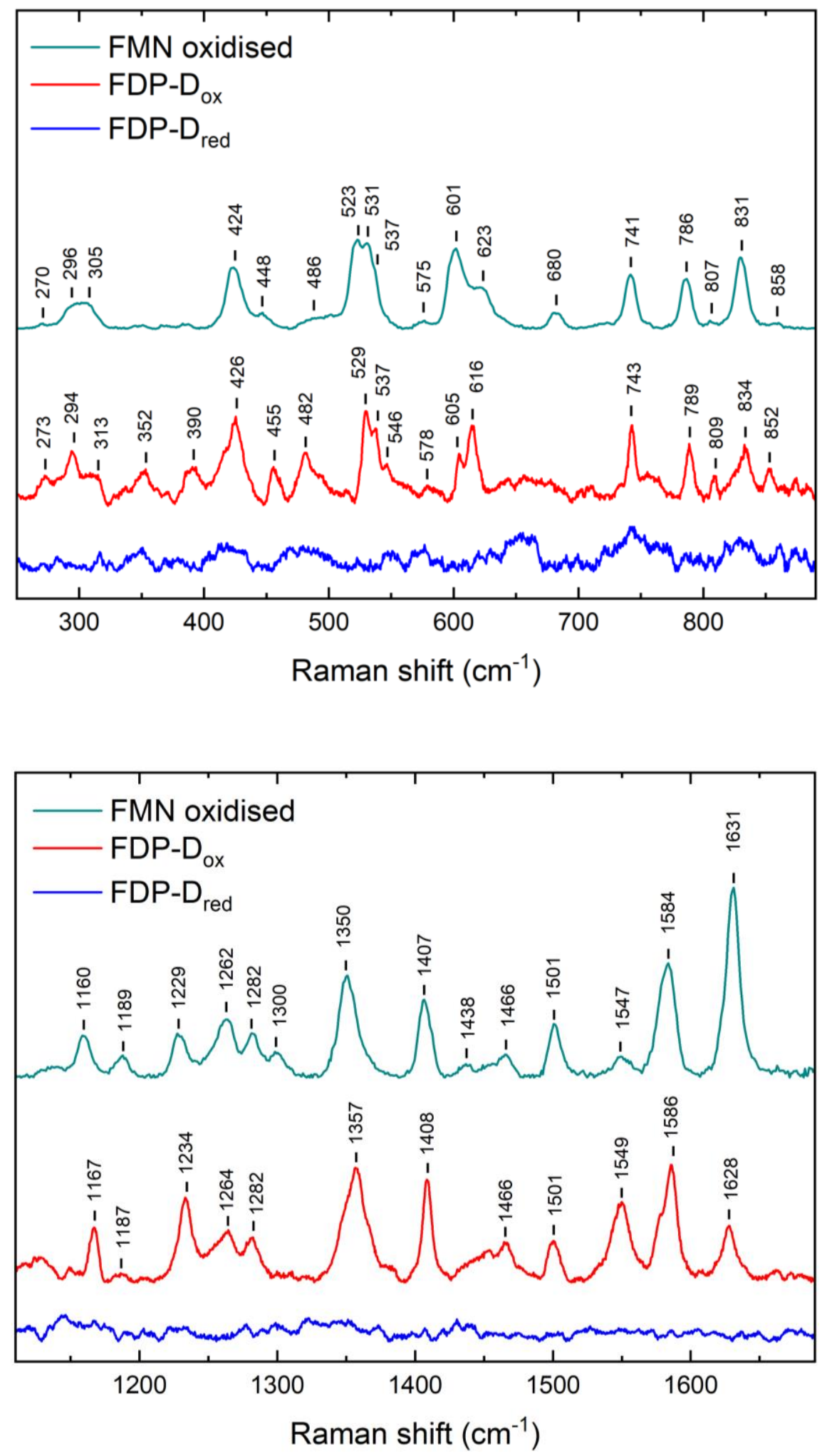

Fig. 66 Resonance Raman (RR) spectra of oxidised FMN (dark cyan), oxidised (red) and reduced (blue) FDP-D in the low- (top panel) and high-frequency (bottom panel) ranges. Spectra were recorded at $80 \mathrm{~K}$ using $458 \mathrm{~nm}$ (for pure FMN) and $514 \mathrm{~nm}$ laser excitation for FDP-D characterisation. While the RR spectra of oxidised and reduced FDP-D are normalised to the non-resonant marker band of phenylalanine at $1004 \mathrm{~cm}^{-1}$, the spectrum of pure FMN is normalised with respect to the most intense signals at $529 / 523 \mathrm{~cm}^{-1}$ (top panel) and $1357 / 1350 \mathrm{~cm}^{-1}$ (bottom panel) in oxidised FDP-D. Variations of the relative signal intensities may correspond to the different 


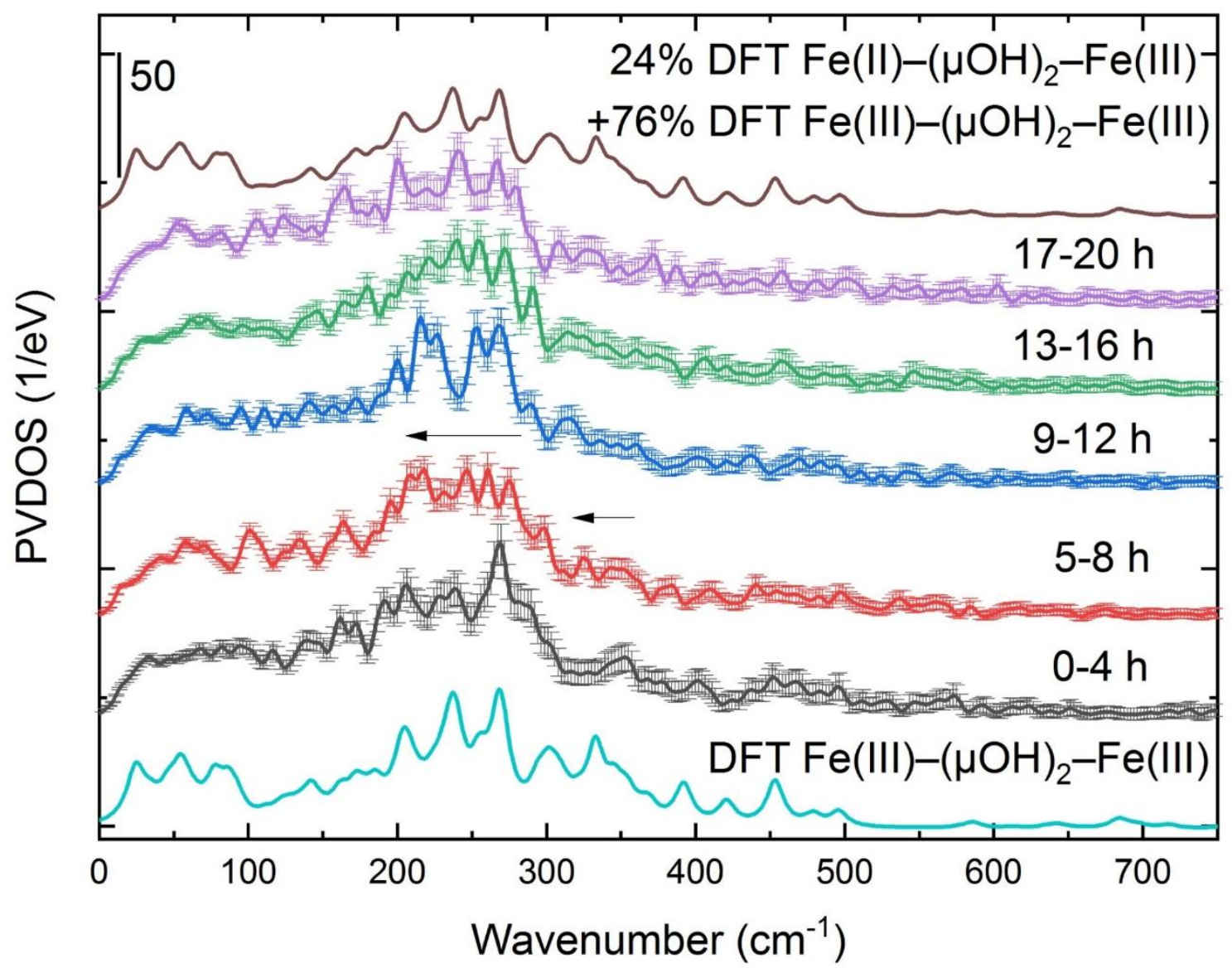

energies used for laser excitation. Small shifts of the band positions are most likely related to the environmental differences between free and enzyme-bound FMN.

Fig. S7 NRVS spectra of FDP-Dox obtained after various intervals of data collection. ${ }^{57}$ Fe-PVDOS were calculated from spectra obtained during consecutive $4 \mathrm{~h}$ intervals of the data collection and are presented with standard deviations. As every individual scan was obtained in $1 \mathrm{~h}$, each of the spectra shown collects data from 4 scans. DFT-simulated spectra from the representative FDP-Dox model Fe(III)- $\left(\mu \mathrm{OH}^{-}\right)_{2}-\mathrm{Fe}$ (III) (bottom) and $24 \%$ contribution of the mixed-valence model Fe(III)- $\left(\mu \mathrm{OH}^{-}\right)_{2}-\mathrm{Fe}(\mathrm{II})[S=1 / 2]^{*}$ (top) are shown next to the spectra of FDP-Dox $(0-4 \mathrm{~h})$ and partial photoreduced $(17-20 \mathrm{~h})$ species, respectively (see Fig. S5 and Table S2 for more details). A DFT-simulated spectrum for the pure (100\%) mixed-valence state Fe(III)- $\left(\mu \mathrm{OH}^{-}\right)_{2}-\mathrm{Fe}(\mathrm{II})[\mathrm{S}=1 / 2]^{*}$ (as explained in the Supplementary Results and Discussion subsection (i)) is found in Fig. 20b. Arrows indicate changes of spectra upon additional 4 hours of the X-ray photoreduction process. The first 4 scans of this sample (0-4 h) and additionally the first 4 scans of three other samples were used for calculating the averaged ${ }^{57} \mathrm{Fe}-$ 


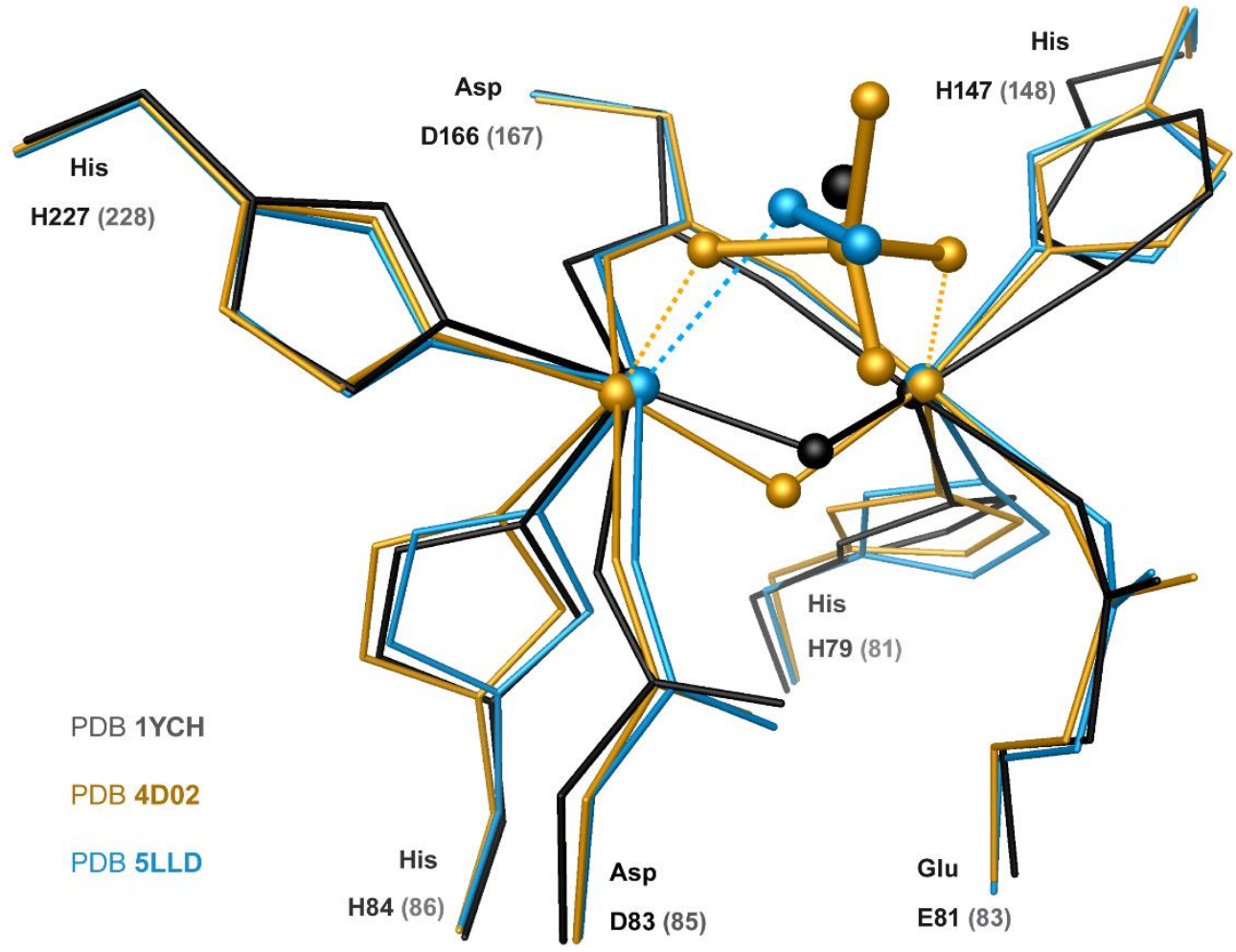

Fig. S8 Crystallographic structures of the FDP active site from the E. coli enzyme as-isolated (beige, PDB 4D02 ${ }^{7}$ ) and dithionite-reduced (blue, PDB $5 L_{L D}{ }^{7}$ ) forms, superimposed onto the structure of the $M$. thermoacetica enzyme reduced and NO-reacted form (which correspond to a diferric species, black, PDB $1 \mathrm{YCH}^{6}$ ) using positions of the seven matching terminal $C_{\alpha}$ carbon nuclei from the Fe-binding residues. The corresponding RMSD values for the matching $C_{\alpha}$ positions after the superposition are 0.194 (4D02 vs 1 YCH) and 0.219 (5LLD vs $\left.1 Y C H\right) \AA$. The ball-and-stick representation applies to the two Fe sites and non-protein molecular species resolved in their vicinity (mono-, di-oxygenous species, and phosphate). The amino acid numbering shown corresponds to the 


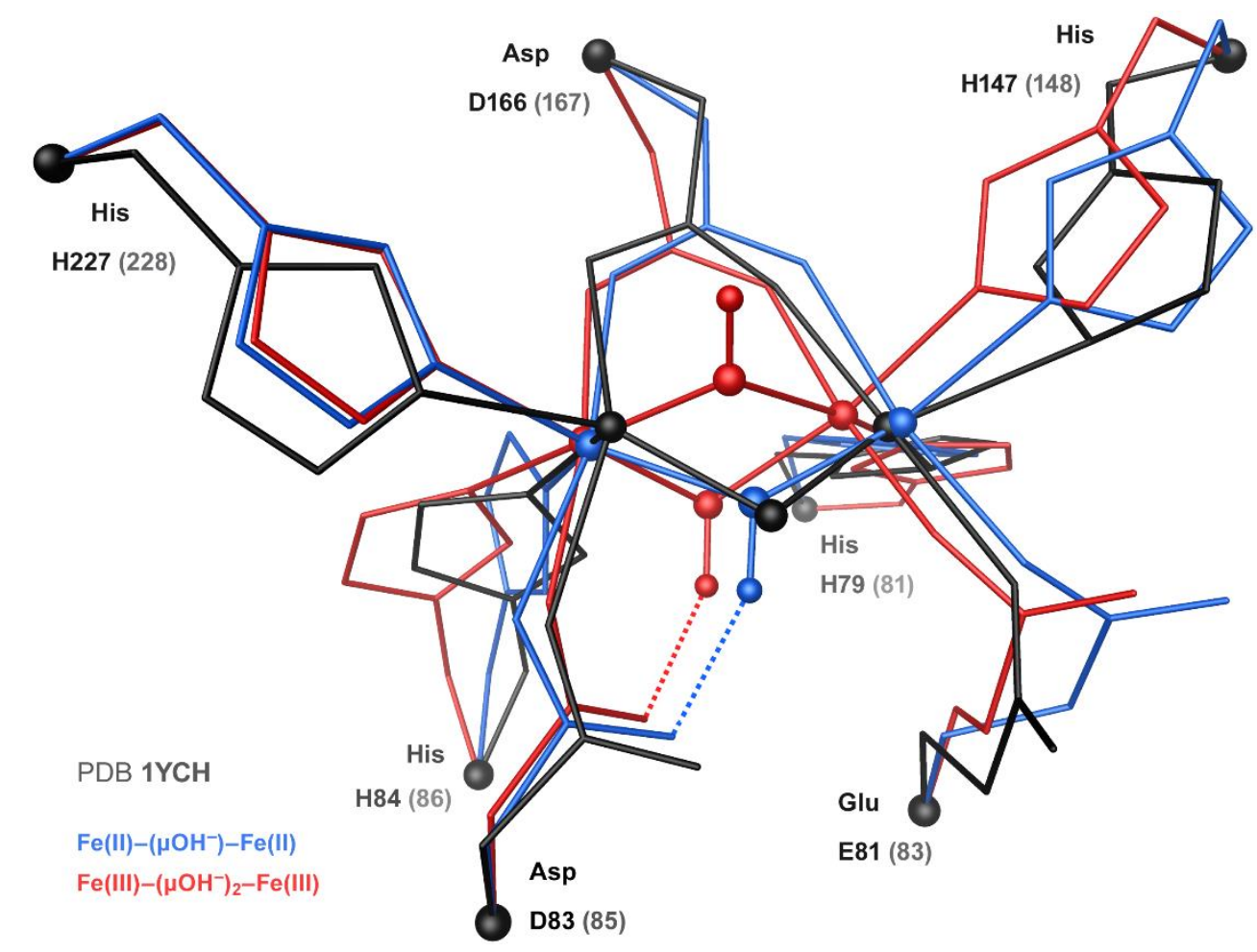

Fig. S9 Representative DFT-optimised models of the FDP reduced Fe(II)-( $\left.\mu \mathrm{OH}^{-}\right)-\mathrm{Fe}(\mathrm{II})$ (blue) and oxidised Fe(III)$\left(\mu \mathrm{OH}^{-}\right)_{2}-\mathrm{Fe}(\mathrm{III})$ (red) states, overlaid with crystallographic structure of the $M$. thermoacetica FDP (PDB 1YCH (black). For clarity, protonation is shown only for the bridging $\mathrm{HOH}^{-}$ligands, which are depicted in the ball-andstick representation. The ball-and-stick representation applies also to the two Fe sites and seven $\mathrm{C}_{\alpha}$ (black) terminal carbon nuclei. The latter were fixed to their original X-ray crystallographic positions. The amino acid numbering shown corresponds to the sequences of FDP from E. coli (M. thermoacetica). 

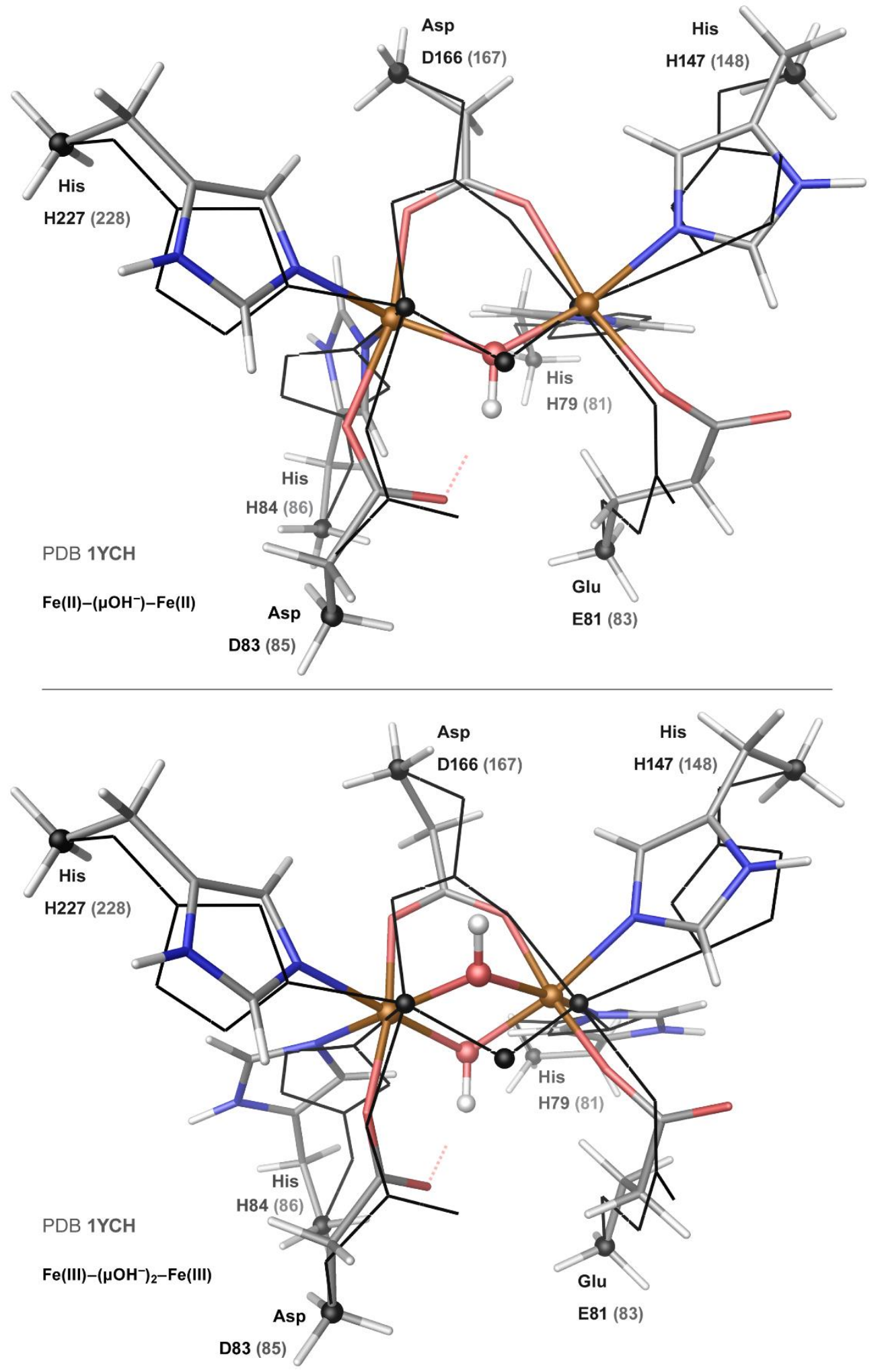

Fig. S10 Representative DFT-optimised models of the FDP active site in the reduced $\mathrm{Fe}(\mathrm{II})-\left(\mu \mathrm{OH}^{-}\right)-\mathrm{Fe}(\mathrm{II})$ (top) and oxidised as-isolated $\mathrm{Fe}(\mathrm{III})-\left(\mathrm{HOH}^{-}\right)_{2}-\mathrm{Fe}$ (III) (bottom) states (element colors, tube representation), overlaid with the X-ray crystal structure of the $M$. thermoacetica FDP (PDB $1 Y C H,{ }^{6}$ black, wire representation). The bridging $\mu \mathrm{OH}^{-}$ligands and the two Fe sites are depicted in ball-and-stick representation. This representation applies also to the seven $C_{\alpha}$ terminal carbon nuclei (black), which were fixed to their original X-ray crystallographic positions. The amino acid numbering shown corresponds to the sequences of FDP from E. coli (M. thermoacetica). 

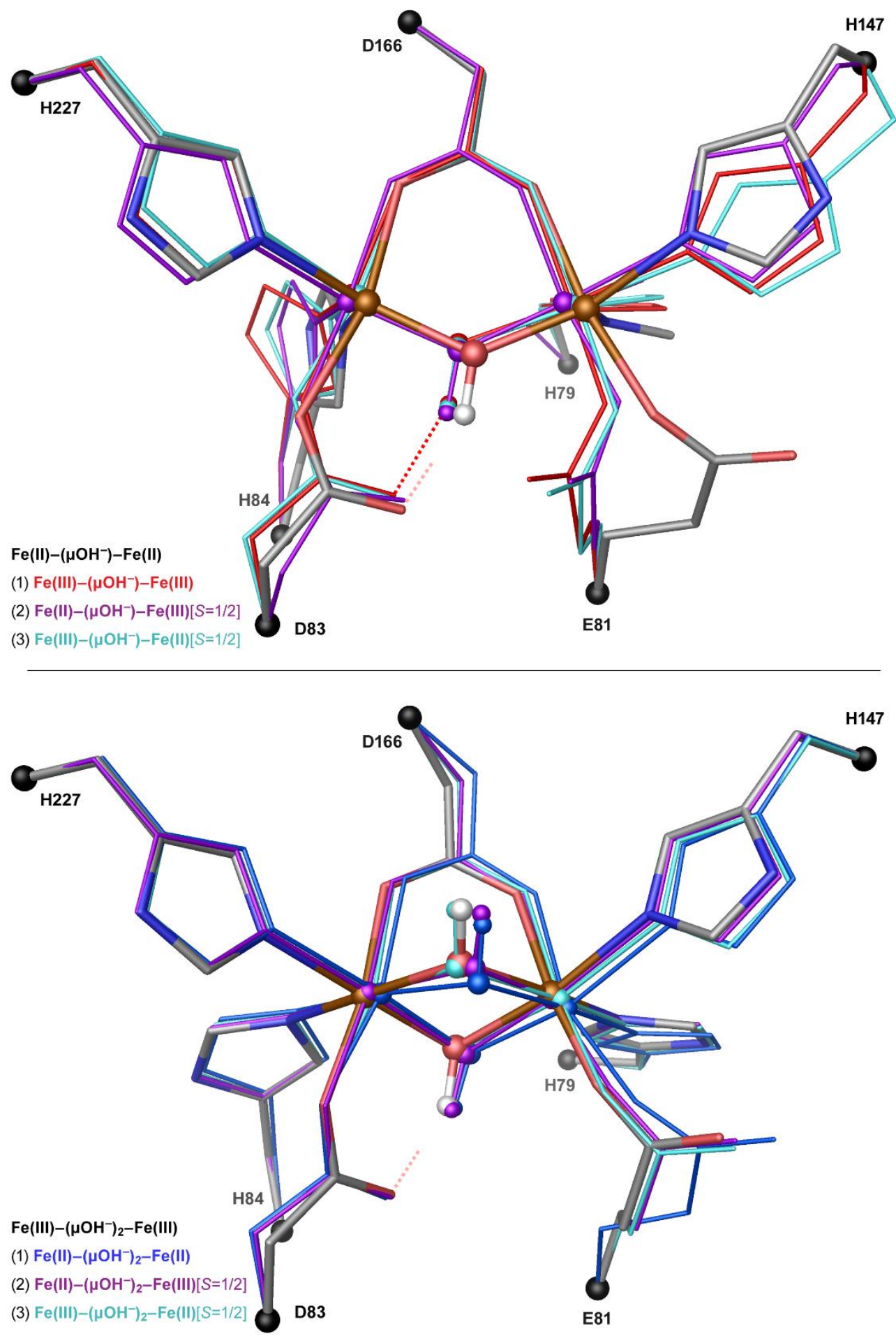

Fig. S11 Representative Fe(II)-( $\left.\mu \mathrm{OH}^{-}\right)-\mathrm{Fe}(\mathrm{II})$ (top) and Fe(III)-( $\left.\mu \mathrm{OH}^{-}\right)_{2}-\mathrm{Fe}$ (III) (bottom) DFT models of the FDP active site (element colors, tube representation), overlaid together with isomeric (but not isoelectronic) structures at alternative metal oxidation levels (thin tubes). Top: (1) $\mathrm{Fe}(\mathrm{III})-\left(\mu \mathrm{OH}^{-}\right)-\mathrm{Fe}(\mathrm{III})$ (red), (2) $\mathrm{Fe}(\mathrm{III})-\left(\mu \mathrm{OH}^{-}\right.$ )-Fe(III)[S=1/2] (violet), (3) Fe(III)-( $\left.\mu \mathrm{OH}^{-}\right)-\mathrm{Fe}(\mathrm{II})[S=1 / 2]$ (cyan). Bottom: (1) Fe(II)-( $\left.\mu \mathrm{OH}^{-}\right)_{2}-\mathrm{Fe}$ (II) (blue), (2) $\mathrm{Fe}(\mathrm{II})-$ $\left(\mu \mathrm{OH}^{-}\right)_{2}-\mathrm{Fe}(\mathrm{III})[S=1 / 2]$ (violet), (3) $\mathrm{Fe}(\mathrm{III})-\left(\mu \mathrm{OH}^{-}\right)_{2}-\mathrm{Fe}(\mathrm{II})[S=1 / 2]$ (cyan). For the mixed-valence $\mathrm{Fe}(\mathrm{II}) \mathrm{Fe}(\mathrm{III})$ and $\mathrm{Fe}(\mathrm{III}) \mathrm{Fe}(\mathrm{II})$ systems, the metal oxidation levels are consistently left-to-right both in the model nomenclatures and structures shown. For clarity, the protonations are shown only for the bridging $\mathrm{\mu OH}^{-}$ligands, which are depicted in ball-and-stick representation. The ball-and-stick representation applies as well to the two Fe sites and seven $C_{\alpha}$ (black) terminal carbon nuclei, the latter locked to their original X-ray crystal structure positions. 


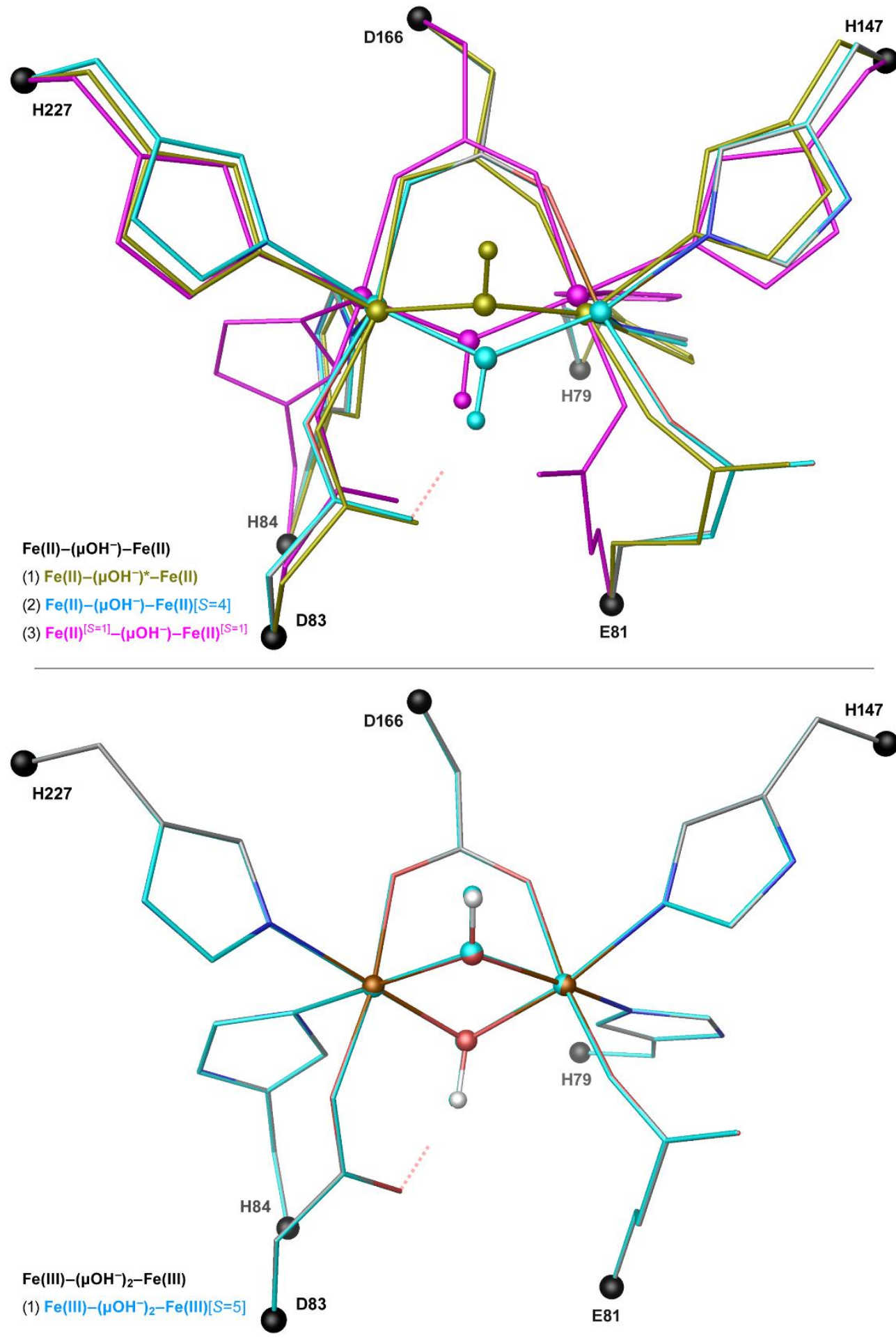

Fig. S12 Representative Fe(II)-( $\left.\mathrm{NOH}^{-}\right)-\mathrm{Fe}$ (II) (top) and Fe(III)-( $\left.\mathrm{OOH}^{-}\right)_{2}-\mathrm{Fe}$ (III) (bottom) DFT models of the FDP active site (element colors, thin tube representation), overlaid together with isomeric (and isoelectronic) structures at the same metal oxidation levels (monochrome, thin tubes). Top: (1) $\mathrm{Fe}(\mathrm{II})-\left(\mathrm{HOH}^{-}\right)^{*}-\mathrm{Fe}(\mathrm{II})$, showing alternative position of the monoxydroxo ligand, (2) $\mathrm{Fe}(\mathrm{II})-\left(\mu \mathrm{OH}^{-}\right)-\mathrm{Fe}(\mathrm{II})[S=4]$, total high-spin $S=4$ (cyan), and (3) $\mathrm{Fe}(\mathrm{II})^{[S=1]}-\left(\mu \mathrm{OH}^{-}\right)-\mathrm{Fe}(\mathrm{II})^{[S=1]}$, intermediate spin $S=1$ for each Fe site (magenta). Bottom: (1) Fe(III)-( $\left.\mu \mathrm{OH}^{-}\right)_{2}-$ $\mathrm{Fe}(\mathrm{III})[S=5]$, total high-spin $S=5$ (cyan). For clarity, the protonations are shown only for the bridging $\mu \mathrm{OH}^{-}$ligands, which are depicted in ball-and-stick representation. The ball-and-stick representation applies as well to the two Fe sites and seven $C_{\alpha}$ (black) terminal carbon nuclei, the latter locked to their original X-ray crystal structure positions. 

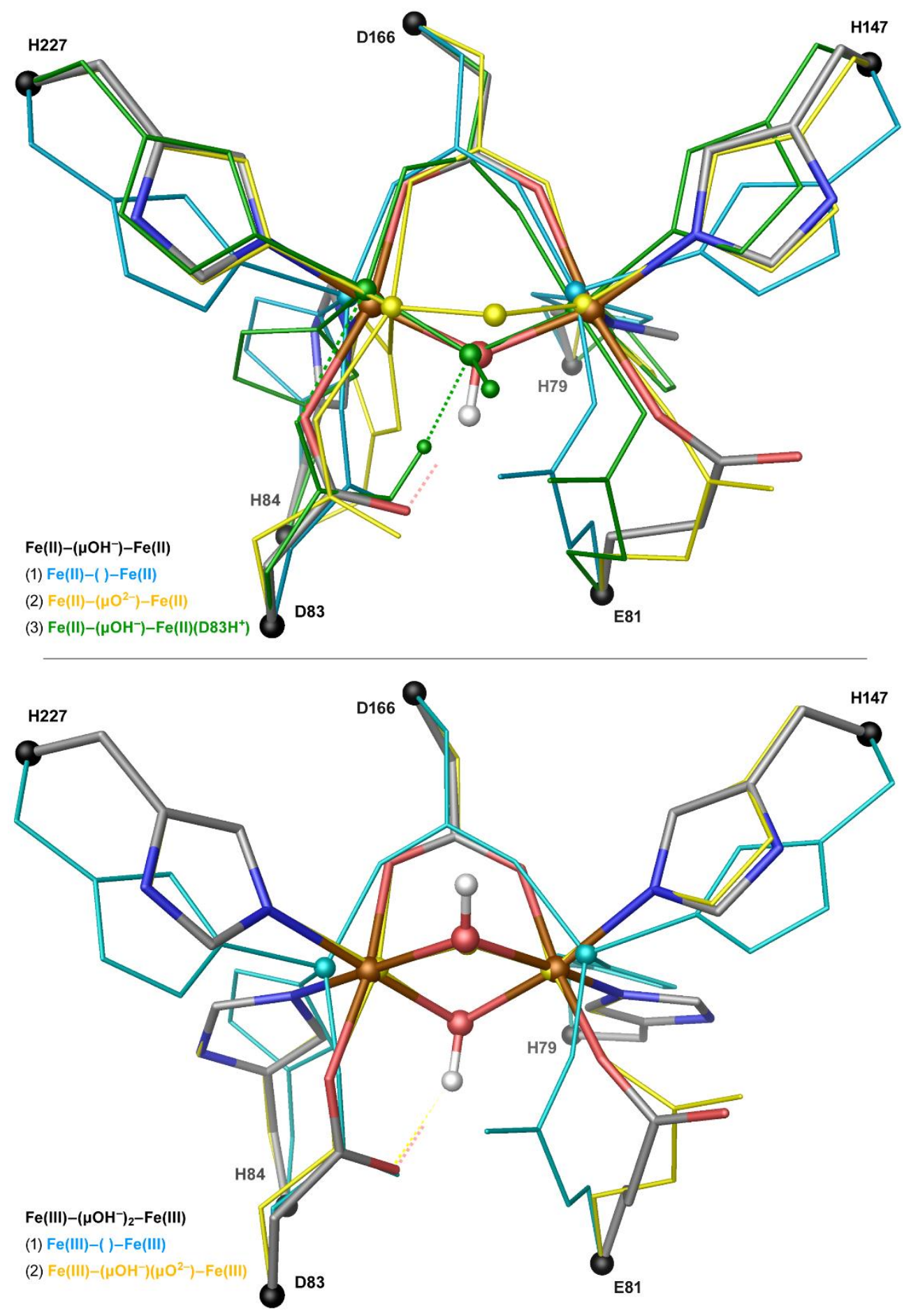

Fig. S13 Representative Fe(II)-( $\left.\mathrm{OOH}^{-}\right)-\mathrm{Fe}$ (II) (top) and Fe(III)-( $\left.\mathrm{OOH}^{-}\right)_{2}-\mathrm{Fe}$ (III) (bottom) DFT models of the FDP active site (element colors, tube representation), overlaid together with models showing either vacant bridging site or alternative protonation status (monochrome, thin tubes) as listed below. Top, $\mathrm{Fe}$ (II) $\mathrm{Fe}$ (II) oxidation level: (1) $\mathrm{Fe}(\mathrm{II})-(\mathrm{)}) \mathrm{Fe}(\mathrm{II})$ (cyan), (2) $\mathrm{Fe}(\mathrm{II})-\left(\mu \mathrm{O}^{2-}\right)-\mathrm{Fe}(\mathrm{II})$ (yellow), and (3) $\mathrm{Fe}(\mathrm{II})-\left(\mu \mathrm{OH}^{-}\right)-\mathrm{Fe}(\mathrm{II})\left(\mathrm{D}_{3} 3 \mathrm{H}^{+}\right)$(green). Bottom, $\mathrm{Fe}(\mathrm{III}) \mathrm{Fe}(\mathrm{III})$ oxidation level: (1) $\mathrm{Fe}(\mathrm{III})-\left(\right.$ )-Fe(III) (cyan) and (2) $\mathrm{Fe}(\mathrm{III})-\left(\mu \mathrm{OH}^{-}\right)\left(\mu \mathrm{O}^{2-}\right)-\mathrm{Fe}(\mathrm{III})$ (yellow). For clarity, the protonations are shown only for the bridging oxygenous ligands and $\mathrm{D} 3 \mathrm{H}^{+}$carboxylate, which are depicted in ball-and-stick representation. The ball-and-stick representation applies as well to the two Fe sites and seven $\mathrm{C}_{\alpha}$ (black) terminal carbon nuclei, the latter locked to their original X-ray crystal structure positions. 


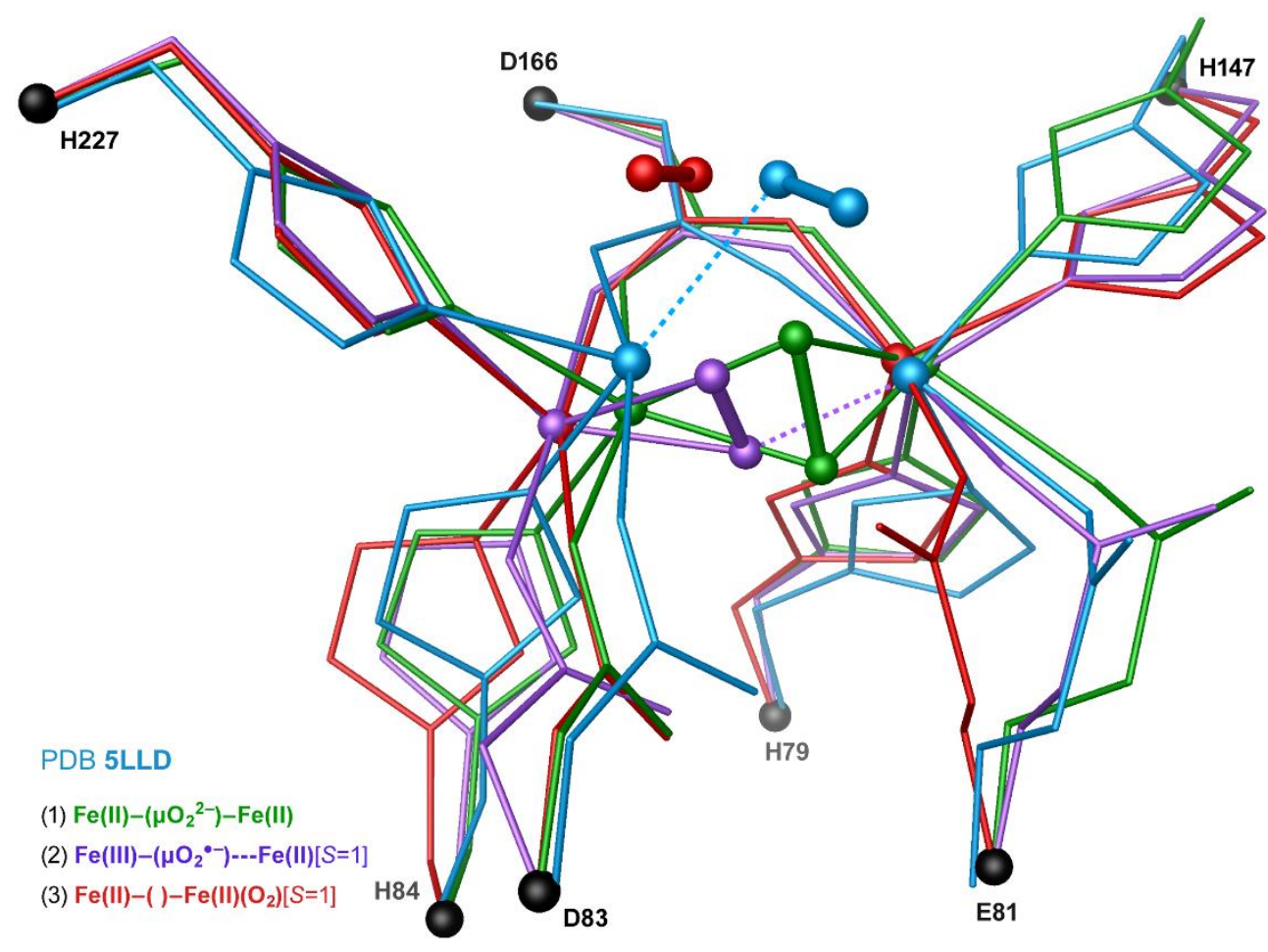

Fig. S14 DFT models of the FDP active site harboring alternative dioxygen species, overlaid with the reduced $E$.

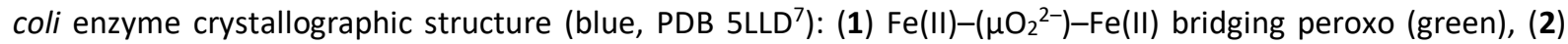
$\mathrm{Fe}(\mathrm{III})-\left(\mu_{\mathrm{O}_{2}}{ }^{-}\right) \cdots \mathrm{Fe}(\mathrm{II})[S=1]$ semi-bridging superoxo, total spin $S=1$ (purple), and (3) $\mathrm{Fe}(\mathrm{II})-(\mathrm{)})-\mathrm{Fe}(\mathrm{II})\left(\mathrm{O}_{2}\right)[S=1]$ weakly bound molecular oxygen, total spin $S=1$ (red). For clarity, the protein residue protonations are not shown. The dioxygen species are depicted in ball-and-stick representation. The ball-and-stick representation applies as well to the two Fe sites and seven $C_{\alpha}$ (black) terminal carbon nuclei, the latter locked to their original X-ray crystal structure positions. 

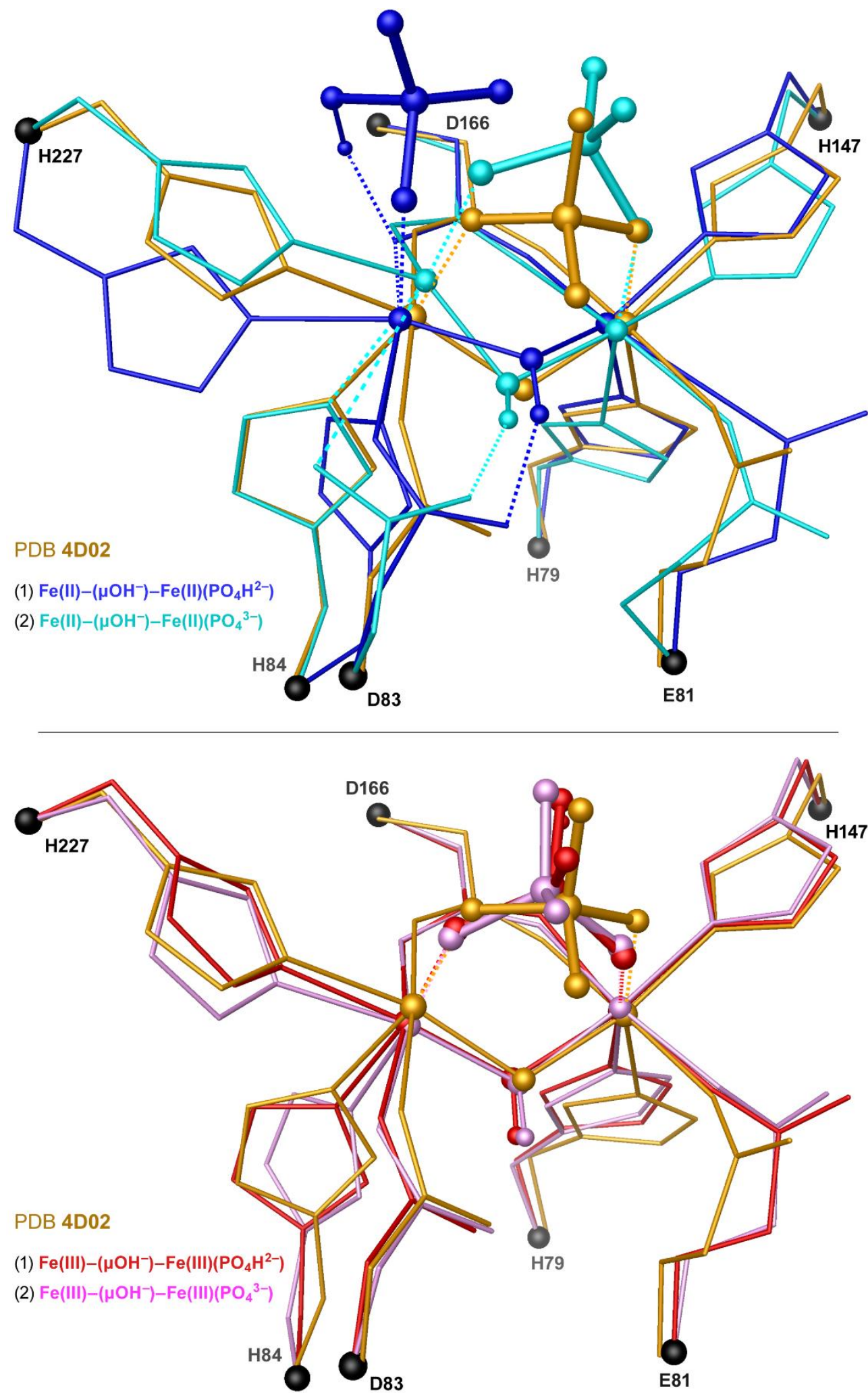

Fig. S15 DFT models of the FDP active site exploring alternatives of the phosphate anion coordination as found in the as-isolated E. coli enzyme crystallographic structure (beige, PDB 4D02 ${ }^{7}$ ). Top, $\mathrm{Fe}(\mathrm{II}) \mathrm{Fe}(\mathrm{II})$ reduced level: (1) $\mathrm{Fe}(\mathrm{II})-\left(\mu_{\mathrm{OH}}\right)-\mathrm{Fe}(\mathrm{II})\left(\mathrm{PO}_{4} \mathrm{H}^{2-}\right)$ (blue), (2) $\mathrm{Fe}(\mathrm{II})-\left(\mu_{\mathrm{OH}}^{-}\right)-\mathrm{Fe}(\mathrm{II})\left(\mathrm{PO}_{4}{ }^{3-}\right)$ (cyan). Bottom, $\mathrm{Fe}(\mathrm{III}) \mathrm{Fe}(\mathrm{III})$ oxidised level: (1) $\mathrm{Fe}(\mathrm{III})-\left(\mu \mathrm{OH}^{-}\right)-\mathrm{Fe}(\mathrm{III})\left(\mathrm{PO}_{4} \mathrm{H}^{2-}\right)(\mathrm{red}),(2) \mathrm{Fe}(\mathrm{III})-\left(\mu_{\mathrm{OH}}^{-}\right)-\mathrm{Fe}(\mathrm{III})\left(\mathrm{PO}_{4}{ }^{3-}\right)$ (pink). For clarity, the protonations are shown only for the bridging $\mathrm{\mu OH}^{-}$ligands and phosphate, which are depicted in ball-and-stick representation. The balland-stick representation applies as well to the two Fe sites and seven $\mathrm{C}_{\alpha}$ (black) terminal carbon nuclei, the latter locked to their original $\mathrm{X}$-ray crystal structure positions. 

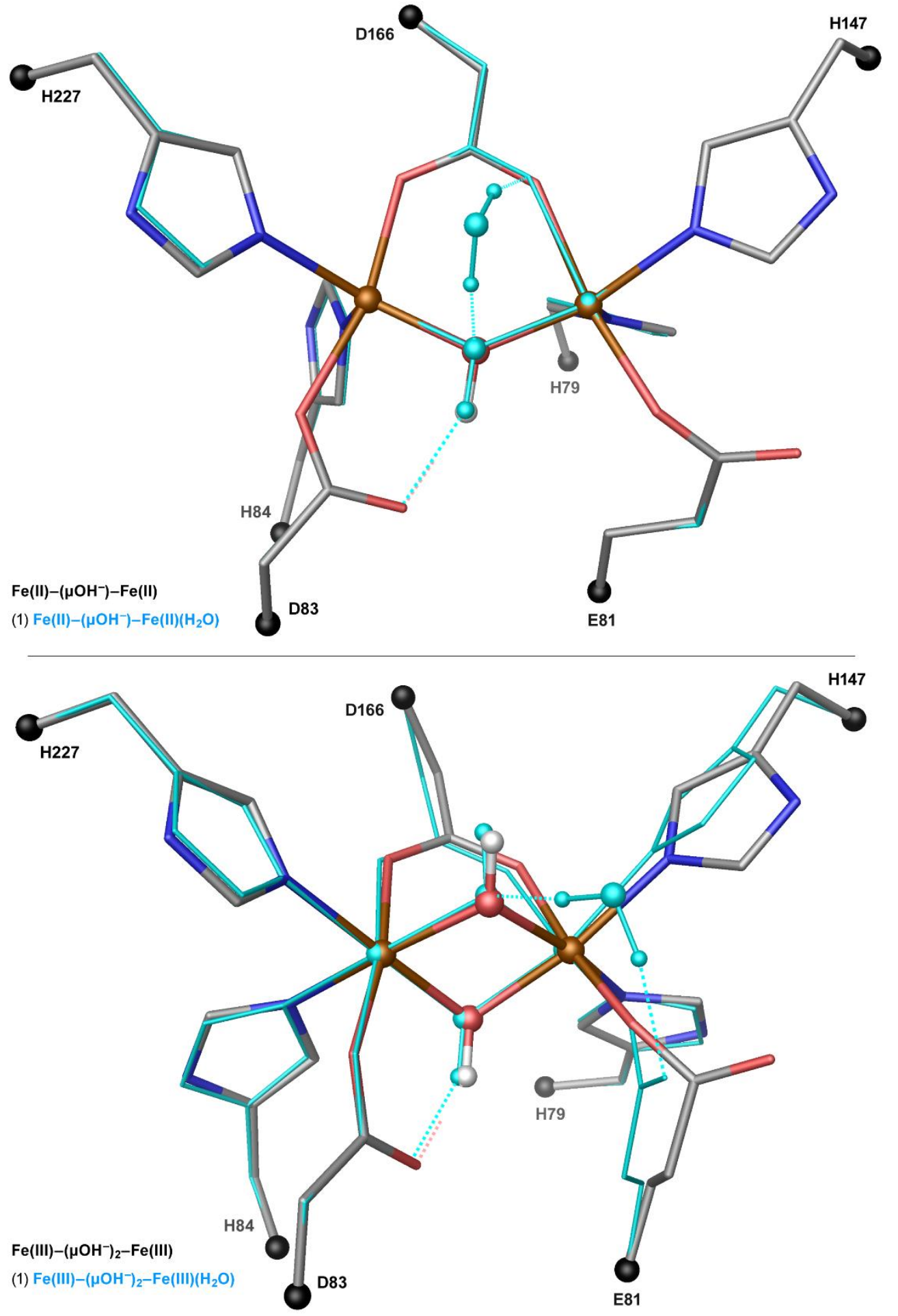

Fig. S16 Representative Fe(II)-( $\left.\mathrm{OOH}^{-}\right)-\mathrm{Fe}$ (II) (top) and Fe(III)-( $\left.\mathrm{OOH}^{-}\right)_{2}-\mathrm{Fe}$ (III) (bottom) DFT models of the FDP active site (element colors, tube representation), overlaid together with their alternatives including a solvent water molecule in hydrogen bonding contact to the bridging hydroxo ligand (cyan, thin tubes), top: (1) Fe(II)$\left(\mu \mathrm{OH}^{-}\right)-\mathrm{Fe}(\mathrm{II})\left(\mathrm{H}_{2} \mathrm{O}\right)$, and bottom: (1) $\mathrm{Fe}(\mathrm{III})-\left(\mu \mathrm{OH}^{-}\right)_{2}-\mathrm{Fe}(\mathrm{III})\left(\mathrm{H}_{2} \mathrm{O}\right)$. For clarity, the protonations are shown only for the bridging $\mu \mathrm{OH}^{-}$ligands and $\mathrm{H}_{2} \mathrm{O}$ molecule, which are depicted in ball-and-stick representation. The ball-andstick representation applies as well to the two Fe sites and seven $C_{\alpha}$ (black) terminal carbon nuclei, the latter locked to their original $\mathrm{X}$-ray crystal structure positions. 

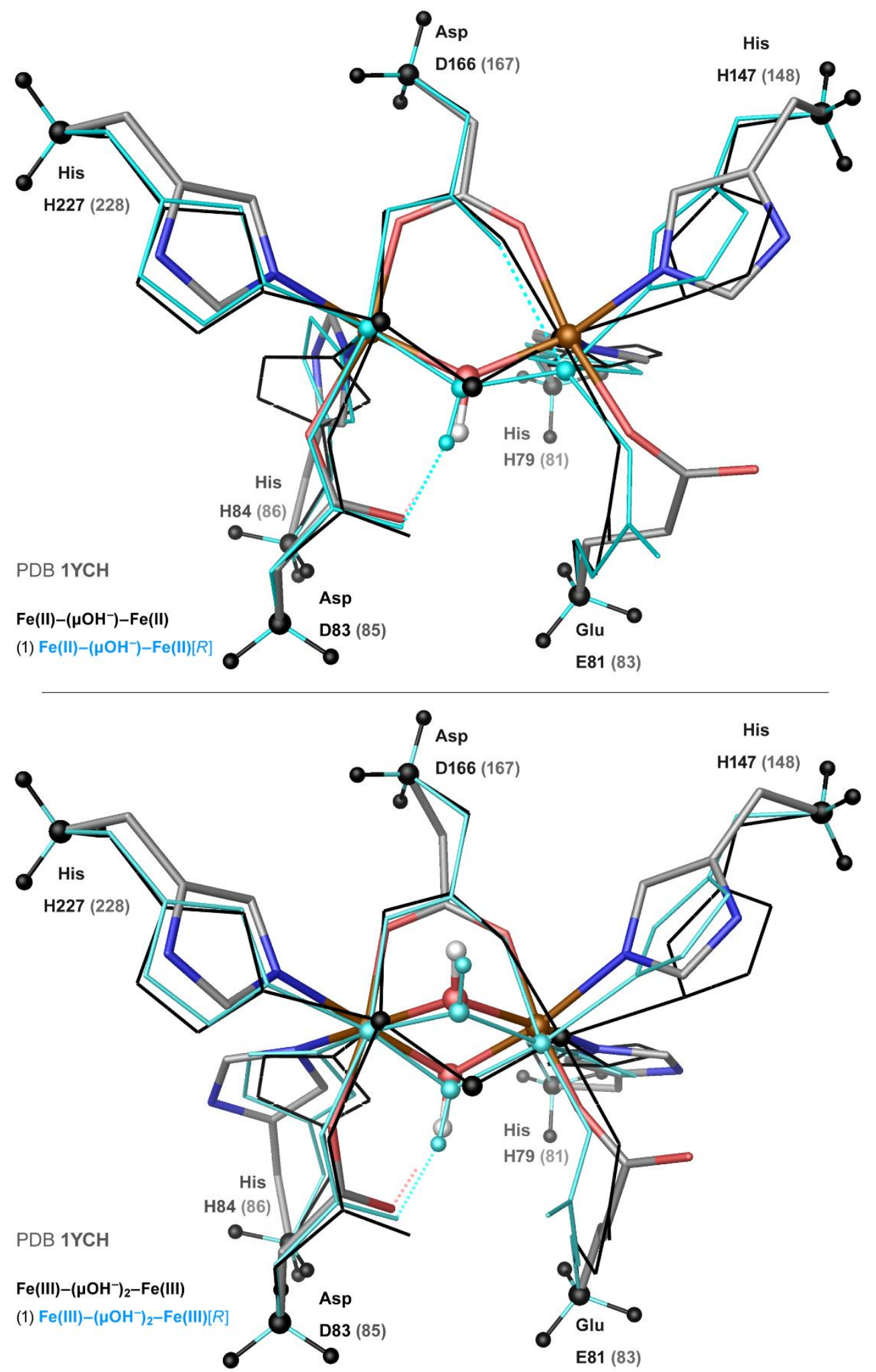

Fig. S17 Representative DFT-optimised models of the FDP active site in the reduced Fe(II)-( $\left.\mathrm{OH}^{-}\right)-\mathrm{Fe}$ (II) (top) and oxidised as-isolated $\mathrm{Fe}(\mathrm{III})-\left(\mathrm{HOH}^{-}\right)_{2}-\mathrm{Fe}$ (III) (bottom) states (element colors, tube representation), overlaid with their alternatives exploring a rigid (" $[R]^{\prime \prime)}$ protein backbone framework with additional fixations of the entire $\mathrm{C}_{\alpha} \mathrm{H}_{3}$ methyl terminal fragments (cyan, thin tubes), top: (1) $\mathrm{Fe}(\mathrm{II})-\left(\mu \mathrm{OH}^{-}\right)-\mathrm{Fe}(\mathrm{II})[R]$, and bottom: (1) $\mathrm{Fe}(\mathrm{III})-\left(\mu \mathrm{OH}^{-}\right.$ )$_{2}-\mathrm{Fe}(\mathrm{III})[R]$. The overlay as well includes the X-ray crystal structure reference (M. thermoacetica FDP, PDB $1 \mathrm{YCH}^{6}{ }^{6}$ black, wire representation). The bridging $\mu^{-} \mathrm{OH}^{-}$ligands and the two Fe sites are depicted in ball-and-stick representation. This representation applies also to the fixed terminal fragments nuclei (black). The rest of the protons are omitted for clarity. The amino acid numbering shown corresponds to the sequences of FDP from $E$. coli (M. thermoacetica). 

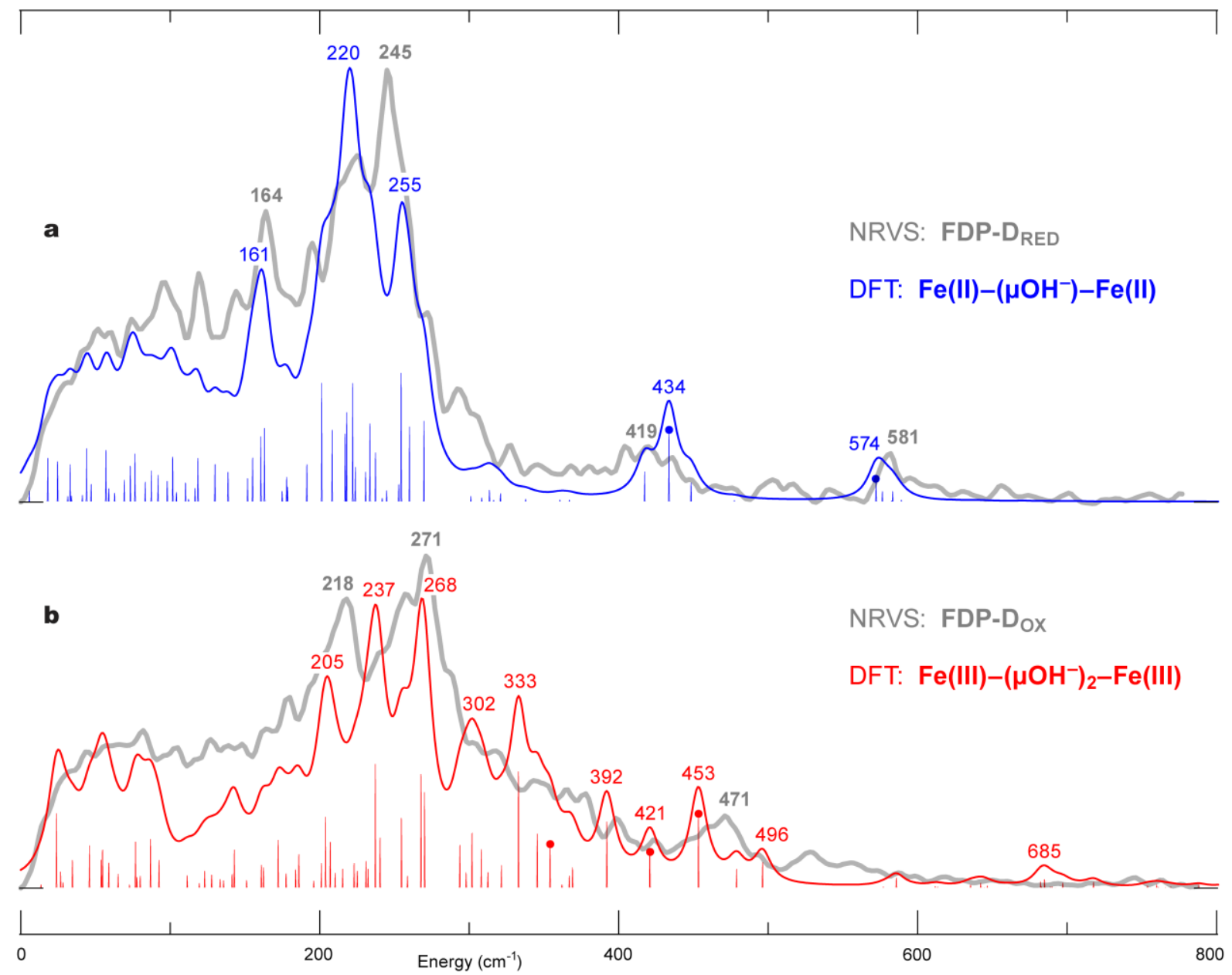

Fig. S18 ${ }^{57} \mathrm{Fe}-$ PVDOS spectra of FDP-D in its (a) reduced and (b) oxidised states from NRVS experiments (grey lines) and DFT calculations (blue/red lines) using the best-fit models shown in Figs. S9 or S10. Stick-style DFT data is additionally provided, showing individual normal mode positions and their ${ }^{57}$ Fe-PVDOS intensities. Selected normal modes with significant $\mathrm{Fe}-\mu \mathrm{OH}$ vibrational character are marked with dots and depicted in the main text Fig. 4. 

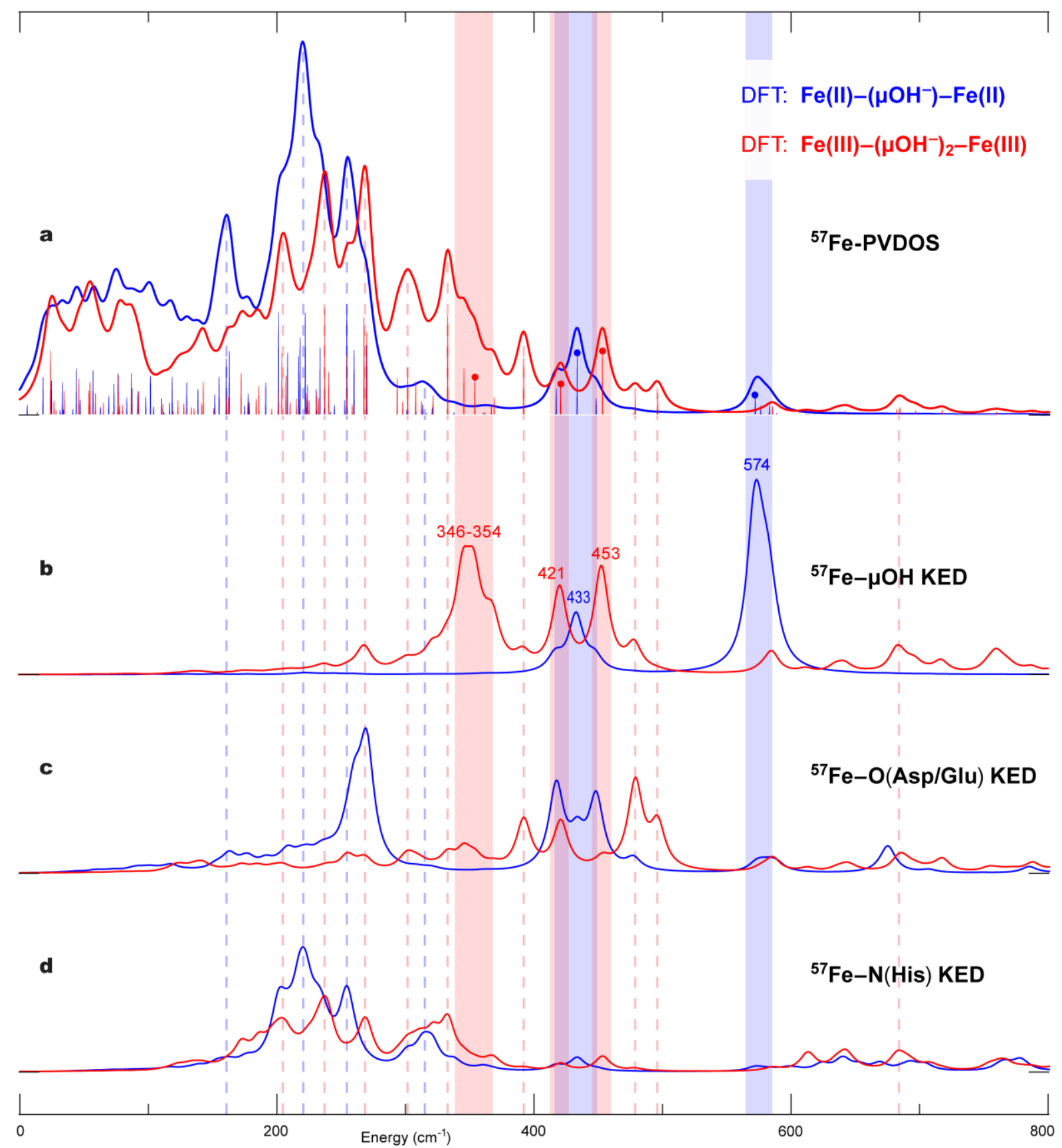

Fig. S19 Vibrational analysis of the DFT-based (a) ${ }^{57} \mathrm{Fe}-\mathrm{PVDOS}$ spectra in the FDP-DRED reduced (blue, $\mathrm{Fe}(\mathrm{II})-\left(\mu \mathrm{OH}^{-}\right.$ )-Fe(II) model) and FDP-Dox oxidised (red, $\mathrm{Fe}(\mathrm{III})-\left(\mu_{\mathrm{OH}}^{-}\right)_{2}-\mathrm{Fe}(\mathrm{III})$ model) states using Fe-ligand interatomic displacement KED profiles for the (b) ${ }^{57} \mathrm{Fe}-\mu \mathrm{O}(\mathrm{H}),(\mathbf{c}){ }^{57} \mathrm{Fe}-\mathrm{O}\left(\mathrm{Asp} / \mathrm{Glu}\right.$ ), and (d) ${ }^{57} \mathrm{Fe}-\mathrm{N}$ (His) pairs. In (a), stick-style DFT data is additionally provided, showing individual normal mode positions and their ${ }^{57} \mathrm{Fe}-\mathrm{PVDOS}$ intensities. Spectral regions with significant $\mathrm{Fe}-\mu \mathrm{OH}$ vibrational character as deduced from (b) are highlighted using vertical bars; selected normal modes of this character are marked with dots (and illustrated in the main text Fig. 4). 

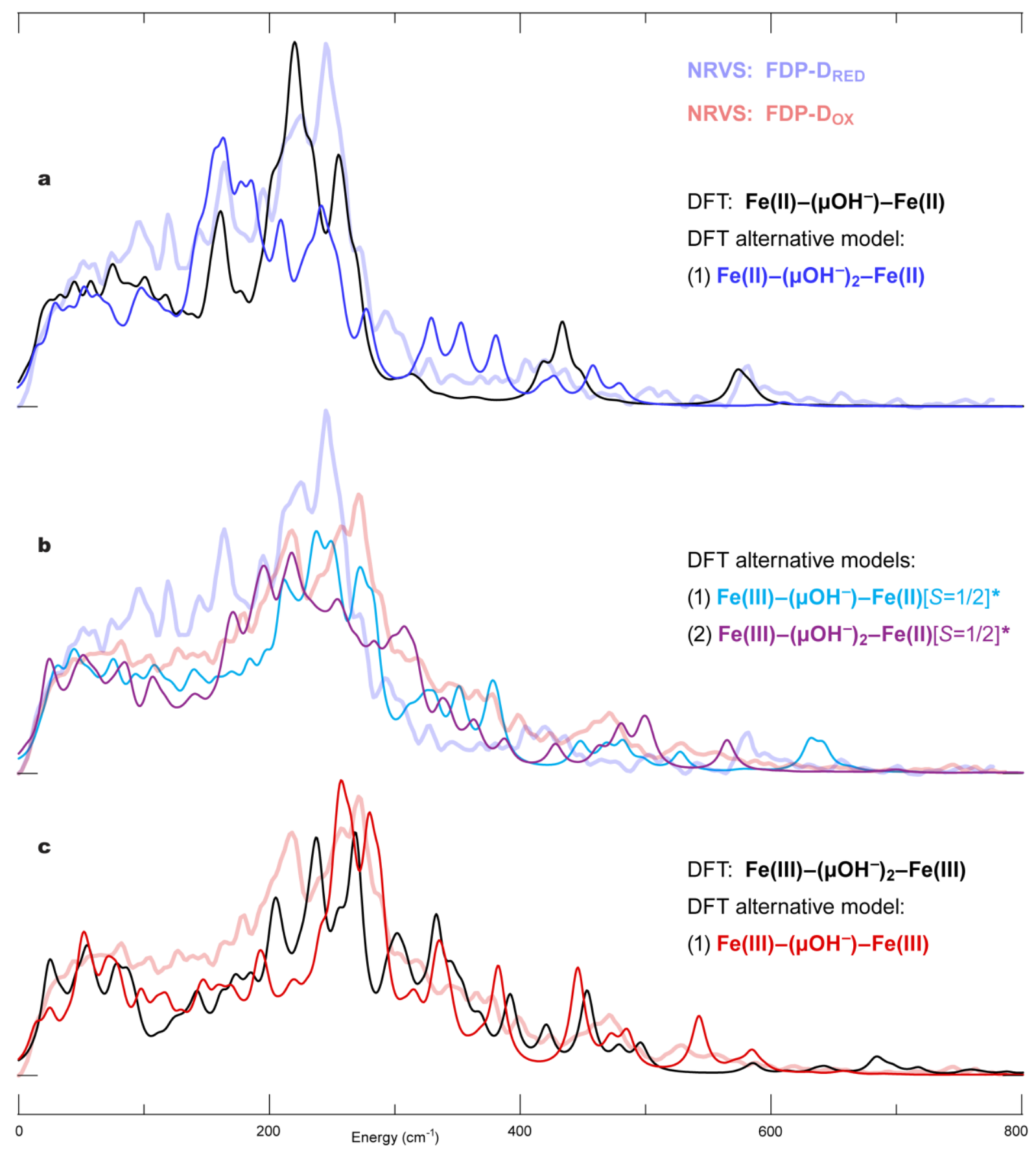

Fig. $\mathbf{S 2 0}{ }^{57} \mathrm{Fe}-\mathrm{PVDOS}$ spectra of FDP in its (a) Fe(II)Fe(II) reduced, (b) Fe(III)Fe(II) mixed-valence, and (c) Fe(III)Fe(III) oxidised states from DFT calculations using two isomer models at different oxidation levels as shown in Fig. S11. The DFT-predicted spectra are shown for both the representative (black lines) and alternative (lines in colour) models. For the mixed-valence systems in (b), the spectra are averaged $\left({ }^{*}\right)$ between the two $\mathrm{Fe}(\mathrm{III}) \mathrm{Fe}(\mathrm{II})$ and $\mathrm{Fe}(\mathrm{II}) \mathrm{Fe}$ (III) states (see text and Fig. S11). The ${ }^{57} \mathrm{Fe}-\mathrm{PVDOS}$ spectra from the NRVS experiment (pale blue for FDP$D_{\text {RED }}$ / red for FDP-Dox) are overlaid with those from DFT for a comparison. 

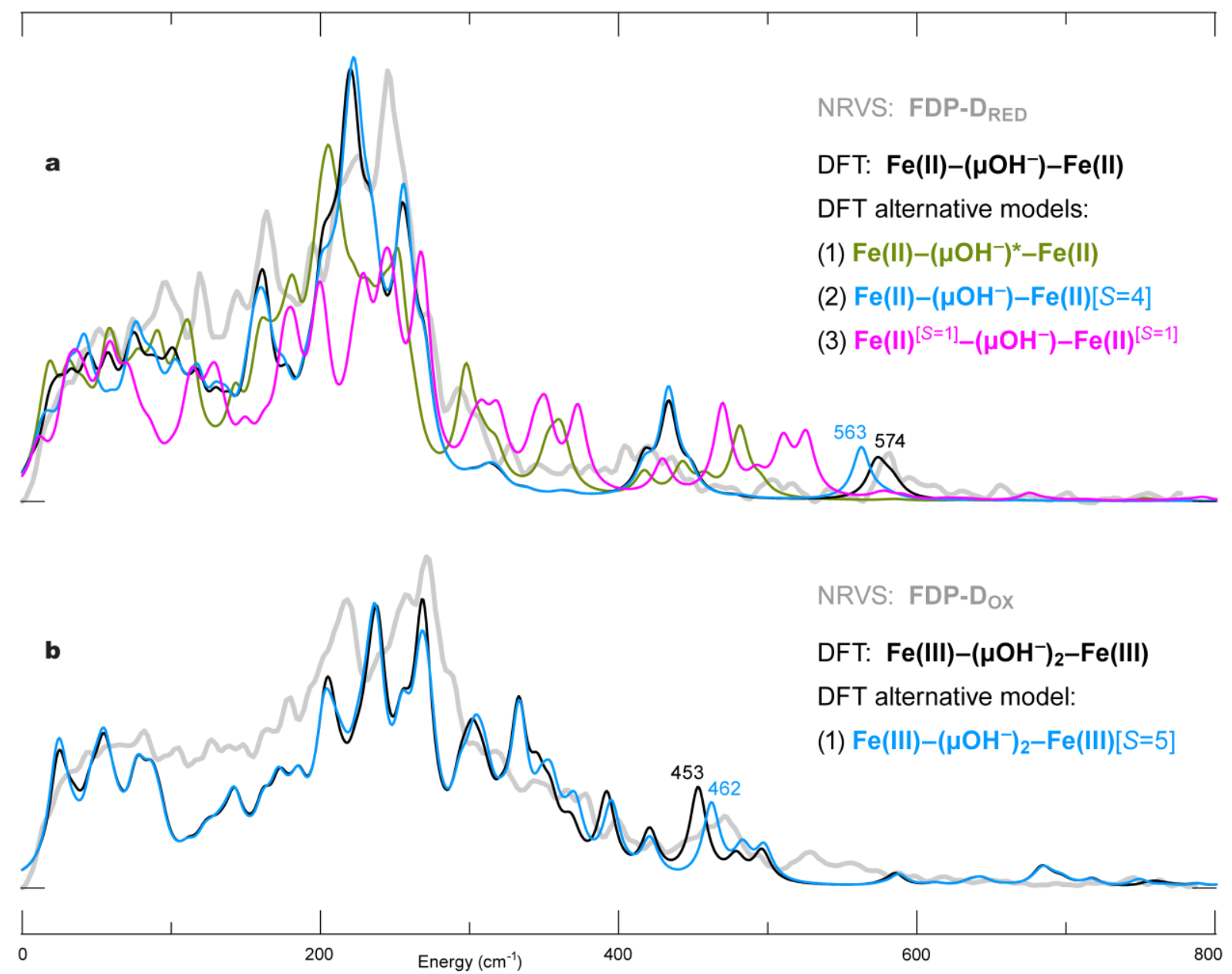

Fig. $\mathbf{S 2 1}{ }^{57} \mathrm{Fe}-\mathrm{PVDOS}$ spectra of FDP-D in its (a) reduced and (b) oxidised states from NRVS experiment (grey lines) and DFT calculations using representative models (black lines) and their isomers (lines in colour), shown in Fig. S12. The models labelled with ' $S=\ldots$...' numbers correspond to alternative electronic structures with either individual Fe site ( $\left.(S=\ldots . .]^{\prime}\right)$ or total $\left({ }^{\prime}[S=\ldots . .\right.$.$] ') spin values different to the ground state.$ 

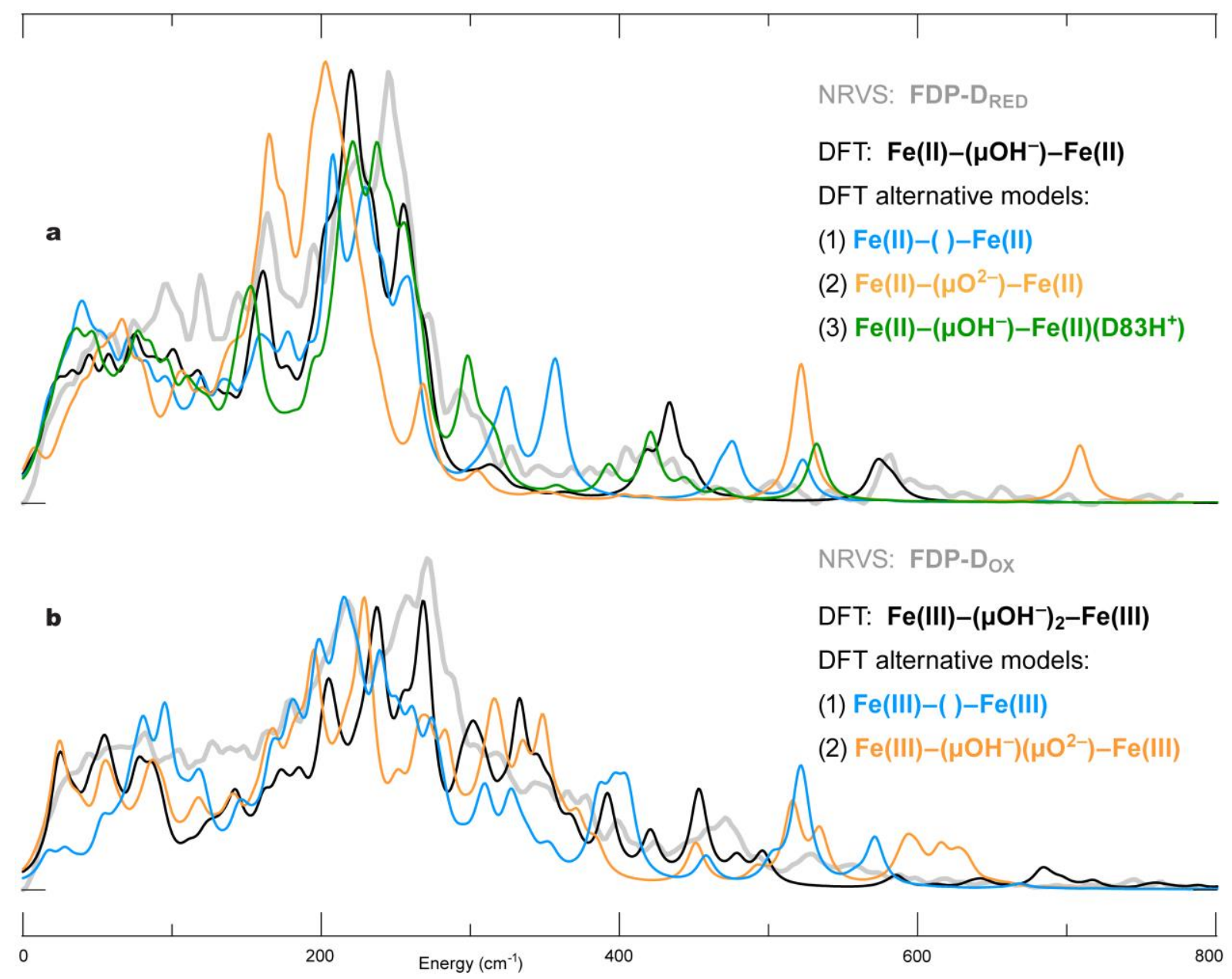

Fig. $\mathbf{S 2 2}{ }^{57} \mathrm{Fe}-\mathrm{PVDOS}$ spectra of FDP-D in its (a) reduced and (b) oxidised states from NRVS experiment (grey lines) and DFT calculations using models shown in Fig. S13. The DFT-predicted spectra are shown for both the representative (black lines) and alternative (lines in colour) models. 


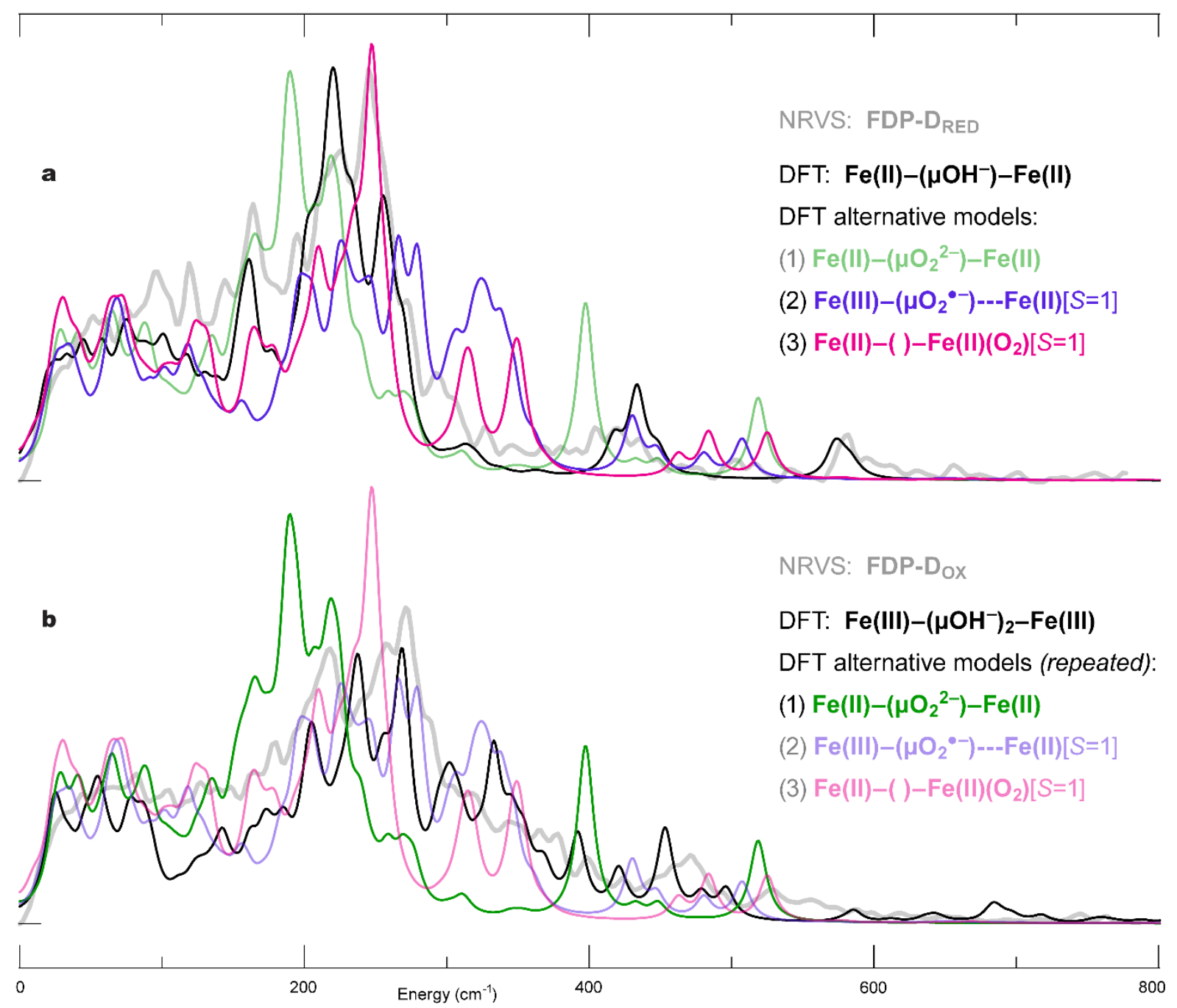

Fig. $\mathbf{S 2 3}{ }^{57} \mathrm{Fe}-\mathrm{PVDOS}$ spectra of FDP-D in its (a) reduced and (b) oxidised states from NRVS experiment (grey lines) and DFT calculations using representative models (black lines), and models that produced alternative dioxygen species (lines in colour) as shown in Fig. S14. The dioxygen species spectra repeat twice in (a) and (b), with lines in pale for those models that initially implied a different Fe-s oxidation level as explained in Supplementary Results and Discussion, subsection (v). 


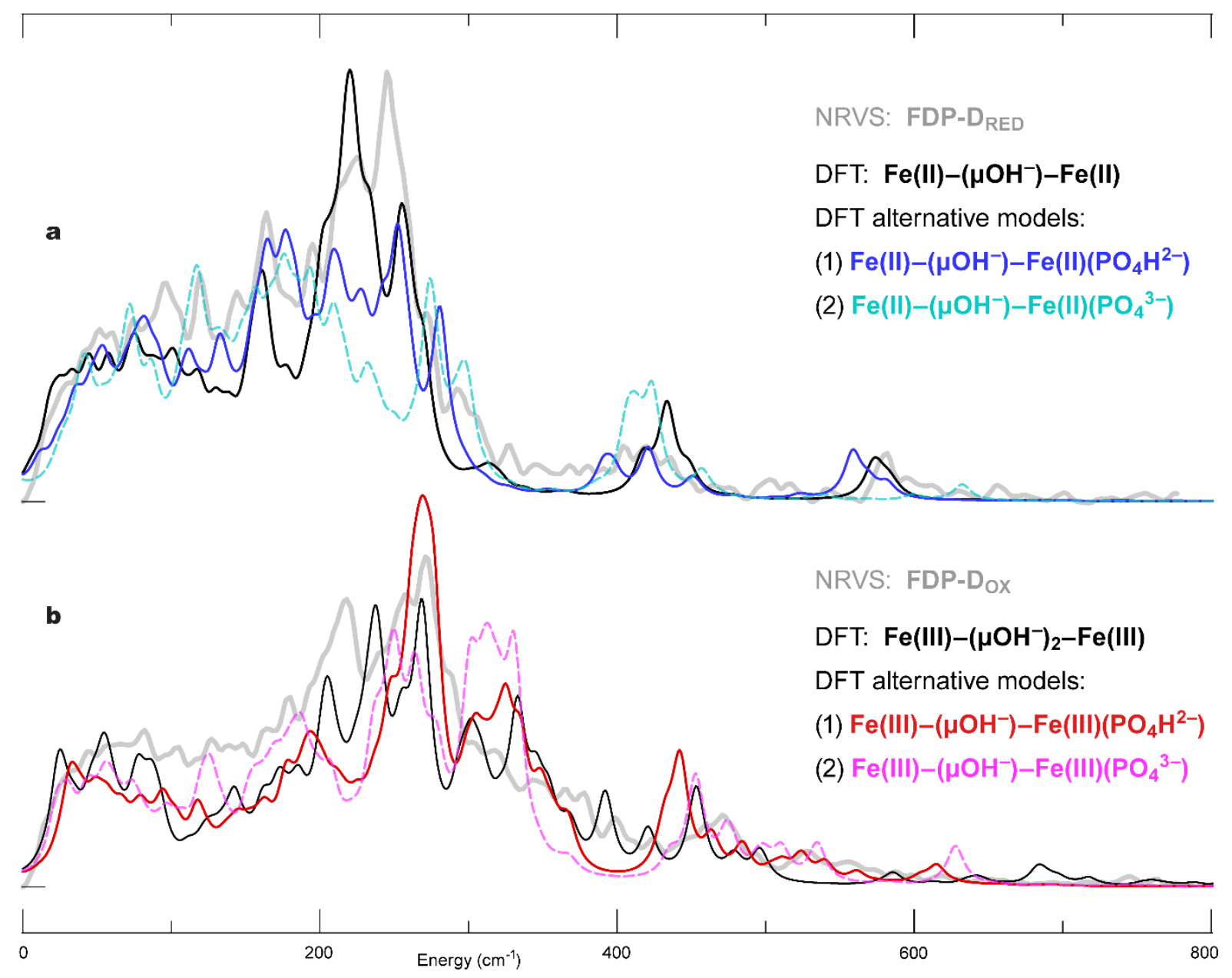

Fig. $\mathbf{S 2 4}{ }^{57} \mathrm{Fe}-\mathrm{PVDOS}$ spectra of FDP-D in its (a) reduced and (b) oxidised states from NRVS experiment (grey lines) and DFT calculations using models including the phosphate anion (lines in colour) as shown in Fig. S15. The DFTpredicted spectra are additionally shown for the representative models (black lines). 

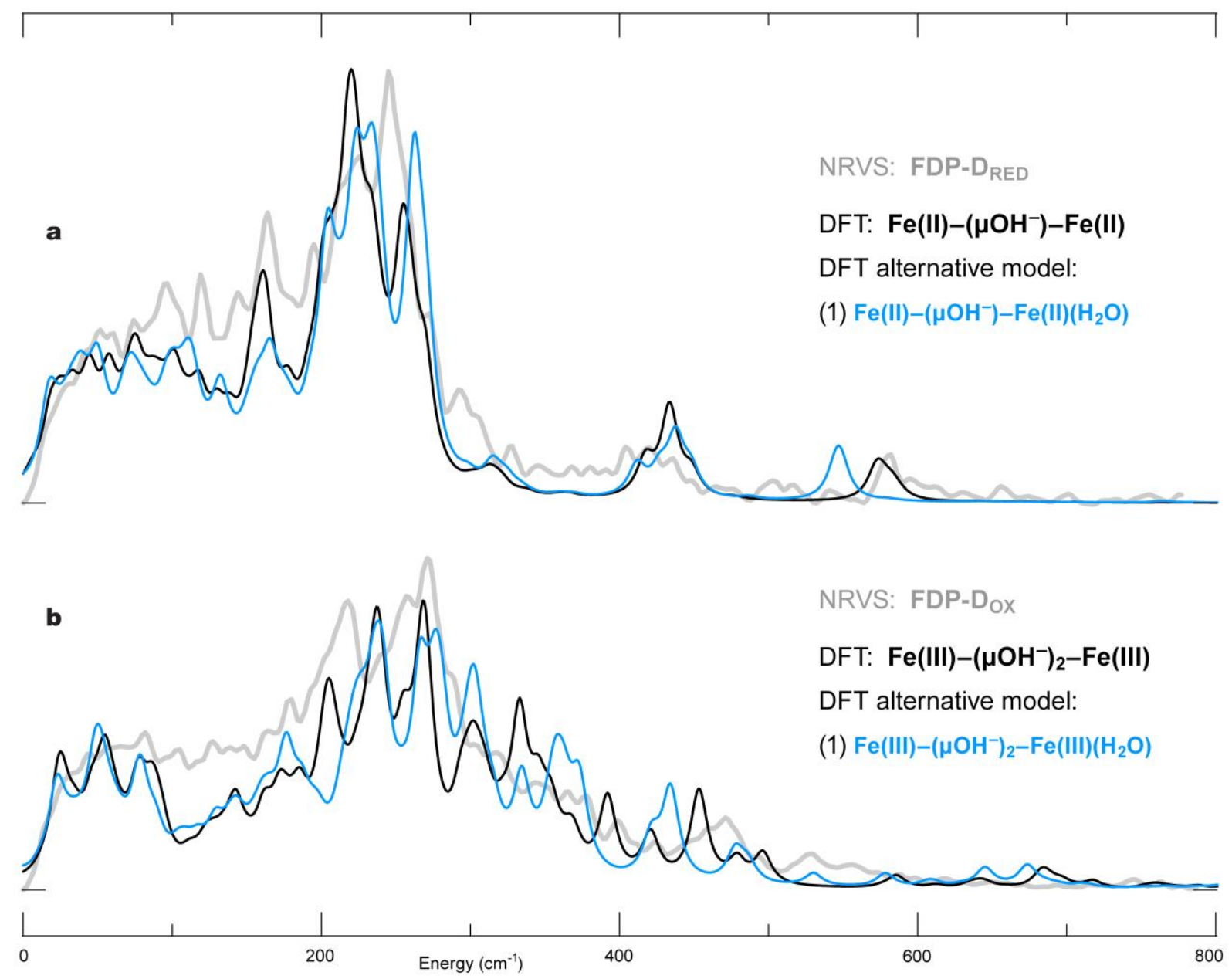

958

Fig. $\mathbf{S 2 5}{ }^{57} \mathrm{Fe}-\mathrm{PVDOS}$ spectra of FDP-D in its (a) reduced and (b) oxidised states from NRVS experiment (grey lines) and DFT calculations using models including a solvent water molecule inclusion (lines in cyan) as shown in Fig. S16. The DFT-predicted spectra are additionally shown for the representative models (black lines). 

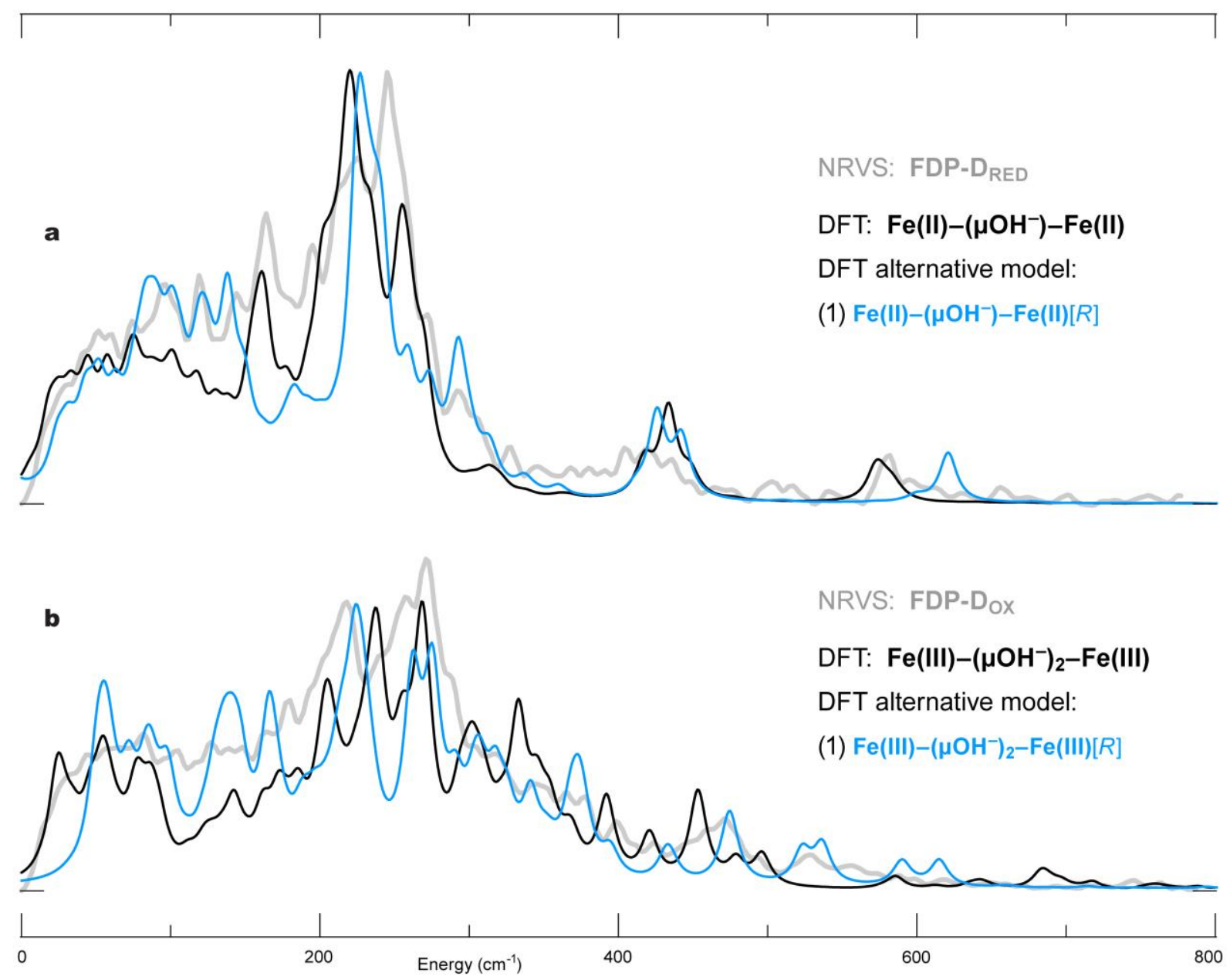

Fig. $\mathbf{S 2 6}{ }^{57} \mathrm{Fe}-\mathrm{PVDOS}$ spectra of FDP-D in its (a) reduced and (b) oxidised states from NRVS experiment (grey lines) and DFT calculations using models exploring a rigid ("[R]") protein backbone framework with additional fixations of the entire $-\mathrm{C}_{\alpha} \mathrm{H}_{3}$ methyl terminal fragments (lines in cyan) as shown in Fig. S17. The DFT-predicted spectra are additionally shown for the representative models (black lines). 


\section{References}

981 1. J. B. Vicente and M. Teixeira, J. Biol. Chem., 2005, 280, 34599-34608.

982 2. F. Folgosa, M. C. Martins and M. Teixeira, Sci. Rep., 2018, 8, 10164.

983 3. L. Lauterbach, H. X. Wang, M. Horch, L. B. Gee, Y. Yoda, Y. Tanaka, I. Zebger, O. Lenz and S. P. Cramer, Chem. Sci., $984 \quad 2015,6,1055-1060$.

985 4. L. B. Gee, H. X. Wang and S. P. Cramer, Methods Enzymol., 2018, 599, 409-425.

$986 \quad 5 . \quad$ W. Sturhahn, Hyperfine Interact., 2000, 125, 149-172.

R. Silaghi-Dumitrescu, D. M. Kurtz, Jr., L. G. Ljungdahl and W. N. Lanzilotta, Biochemistry, 2005, 44, 6492-6501.

C. V. Romao, J. B. Vicente, P. T. Borges, B. L. Victor, P. Lamosa, E. Silva, L. Pereira, T. M. Bandeiras, C. M. Soares, M. A. Carrondo, D. Turner, M. Teixeira and C. Frazao, J. Mol. Biol., 2016, 428, 4686-4707. M. J. Frisch, G. W. Trucks, H. B. Schlegel, G. E. Scuseria, M. A. Robb, J. R. Cheeseman, G. Scalmani, V. Barone, B. Mennucci, G. A. Petersson, H. Nakatsuji, M. Caricato, X. Li, H. P. Hratchian, A. F. Izmaylov, J. Bloino, G. Zheng, J. L. Sonnenberg, M. Hada, M. Ehara, K. Toyota, R. Fukuda, J. Hasegawa, M. Ishida, T. Nakajima, Y. Honda, O. Kitao, H. Nakai, T. Vreven, J. A. Montgomery, Jr., J. E. Peralta, F. Ogliaro, M. Bearpark, J. J. Heyd, E. Brothers, K. N. Kudin, V. N. Staroverov, R. Kobayashi, J. Normand, K. Raghavachari, A. Rendell, J. C. Burant, S. S. Iyengar, J. Tomasi, M. Cossi, N. Rega, J. M. Millam, M. Klene, J. E. Knox, J. B. Cross, V. Bakken, C. Adamo, J. Jaramillo, R. Gomperts, R. E. Stratmann, O. Yazyev, A. J. Austin, R. Cammi, C. Pomelli, J. W. Ochterski, R. L. Martin, K. Morokuma, V. G. Zakrzewski, G. A. Voth, P. Salvador, J. J. Dannenberg, S. Dapprich, A. D. Daniels, Ö. Farkas, J. B. Foresman, J. V. Ortiz, J. Cioslowski and D. J. Fox, Gaussian 09, Revision D.01, Gaussian Inc., Wallingford CT, 2009.

Jaguar, version 9.4, Schrodinger, Inc., New York, NY, 2016.

L. Noodleman and D. A. Case, Adv. Inorg. Chem., 1992, 38, 423-470.

C. Adamo and V. Barone, J. Chem. Phys., 1999, 110, 6158-6170.

J. Tomasi, B. Mennucci and R. Cammi, Chem. Rev., 2005, 105, 2999-3093.

S. Grimme, J. Antony, S. Ehrlich and H. Krieg, J. Chem. Phys., 2010, 132, 154104.

L. Goerigk and S. Grimme, Phys. Chem. Chem. Phys., 2011, 13, 6670-6688.

D. Mitra, V. Pelmenschikov, Y. Guo, D. A. Case, H. Wang, W. Dong, M. L. Tan, T. Ichiye, F. E. Jenney, M. W. Adams, Y. Yoda, J. Zhao and S. P. Cramer, Biochemistry, 2011, 50, 5220-5235.

A. C. Weitz, E. A. Hill, V. F. Oswa
Ed., 2018, 57, 16010-16014.

18. K. Park and E. I. Solomon, Can. J. Chem., 2014, 92, 975-978.

19. D. M. Kurtz, D. F. Shriver and I. M. Klotz, Coord. Chem. Rev., 1977, 24, 145-178.

20. M. Wirstam, S. J. Lippard and R. A. Friesner, J. Am. Chem. Soc., 2003, 125, 3980-3987.

21. Soc., 1993, 115, 3688-3701.

29. W. G. Han, T. Liu, T. Lovell and L. Noodleman, J. Comput. Chem., 2006, 27, 1292-1306.

30. J. C. Jones, R. Banerjee, K. Shi, H. Aihara and J. D. Lipscomb, Biochemistry, 2020, 59, 2946-2961.

31. D. T. Logan, X. D. Su, A. Aberg, K. Regnstrom, J. Hajdu, H. Eklund and P. Nordlund, Structure, 1996, 4, 1053-1064. 